UNIVERSIDADE DE SÃO PAULO

ESCOLA DE ENFERMAGEM

MARCIA REGINA CUNHA

VULNERABILIDADES DAS MULHERES À INFECÇÃO DE SÍTIO CIRÚRGICO PÓS-PARTO CESÁREO: ESTUDO EXPLORATÓRIO E PROPOSTA DE UM ROTEIRO PARA AUXÍLIO À CONSULTA DE ENFERMEIRO NA ATENÇÃO BÁSICA

SÃO PAULO

2015 



\section{VULNERABILIDADES DAS MULHERES À INFECÇÃO DE SÍTIO CIRÚRGICO PÓS-PARTO CESÁREO: ESTUDO EXPLORATÓRIO E PROPOSTA DE UM ROTEIRO PARA AUXÍLIO À CONSULTA DE ENFERMEIRO NA ATENÇÃO BÁSICA}

Dissertação apresentada ao Programa de Pós-Graduação Mestrado Profissional em Atenção Primária à Saúde no Sistema Único de Saúde da Escola de Enfermagem da Universidade de São Paulo, para obtenção do título de Mestre em Ciências.

Área de concentração: Cuidado em Atenção Primária em Saúde

Orientadora: Profa. Dra. Lúcia Yasuko Izumi Nichiata

\section{VERSÃO CORRIGIDA}

A versão original encontra-se disponível na Biblioteca da Escola de Enfermagem da Universidade de São Paulo e na Biblioteca Digital de Teses e Dissertações da Universidade de São Paulo.

\section{SÃO PAULO}


AUTORIZO A REPRODUÇÃO E DIVULGAÇÃO TOTAL OU PARCIAL DESTE TRABALHO, POR QUALQUER MEIO CONVENCIONAL OU ELETRÔNICO, PARA FINS DE ESTUDO E PESQUISA, DESDE QUE CITADA A FONTE.

Assinatura:

Data:

\section{Catalogação na Publicação (CIP)}

Biblioteca "Wanda de Aguiar Horta"

\section{Escola de Enfermagem da Universidade de São Paulo}

\section{Cunha, Marcia Regina}

Vulnerabilidades das mulheres à infecção de sítio cirúrgico pós-parto cesáreo: estudo exploratório e proposta de um roteiro para auxílio à consulta de enfermeiro na atenção básica / Marcia Regina Cunha. São Paulo, 2015.

$157 p$.

Dissertação (Mestrado) - Escola de Enfermagem da Universidade de São Paulo.

Orientadora: Prof. ${ }^{\text {a }}$ Dr. ․ㅡ Lúcia Yasuko Izumi Nichiata

Área de concentração: Cuidado em Atenção Primária em Saúde

1. Atenção primária à saúde. 2. Cesárea. 3. Puerpério 4. Infecções bacterianas. 5. Enfermagem. I. Título. 
Nome: Marcia Regina Cunha

Título: Vulnerabilidades das mulheres à infecção de sítio cirúrgico pós-parto cesáreo: estudo exploratório e proposta de um roteiro para auxílio à consulta de enfermeiro na Atenção Básica

Dissertação apresentada ao Programa de pós-graduação Mestrado Profissional em Atenção Primária à Saúde no Sistema Único de Saúde da Escola de Enfermagem da Universidade de São Paulo, para obtenção do título de Mestre.

Aprovado em

\section{BANCA EXAMINADORA}

Prof. Dr. Instituição:

Julgamento: Assinatura:

Prof. Dr. Instituição:

Julgamento: Assinatura:

Prof. Dr. Instituição:

Julgamento: Assinatura: 



\section{DEDICATÓRIA}

Dedico esta vitória a todos que, direta ou indiretamente, vibravam com minhas conquistas, me levantaram nas quedas e lutaram comigo...

Em especial aos meus pais, Diamantino e Ivone, que me permitiram vir a esta terra como filha, me ensinando a lutar pelos nossos sonhos, nunca perder o foco, e que os obstáculos eram somente pequenos desvios de rota, mas que com perseverança tudo seria possível.

Aos meus filhos, Lucas, Mariana e Matheus, por tanta paciência, por entenderem minha ausência, sem nada cobrar ou pedir, pelo contrário sempre junto a mim, me trazendo força e ânimo, nunca deixando que eu desistisse da jornada.

Ao meu amigo, companheiro e grande incentivador Edvandro, que esteve todos os momentos ao meu lado, vibrando, chorando, me dando colo nas horas de tristeza, Gronca nas horas de desânimo e me amando com um amor incondicional.

Às minhas irmãs e sobrinhos, por sempre acreditarem em mim e aceitarem tanta ausência.

À Mel, minha companheirinha de quatro patas, por tanto amor e fidelidade.

A Deus, pela vida, por ter colocado no meu caminho seres de luz na figura de família e amigos. 



\section{AGRADECIMEENTOS}

Agradeço à minha orientadora Profa. Lúcia Izumi pela oportunidade, confiança, companheirismo, amizade e paciência. Sem você este dia não seria possível.

Às professoras Maria Clara Padoveze e Sueli Ciosak, pelo apoio, pelas contribuições, pelo estímulo e, sobretudo, por acreditarem em mim.

Às minhas colegas do Mestrado Profissional, pela convivência, por partilhar saberes, dúvidas, angústias e conquistas.

Às Unidades Básicas de Saúde, em especial às agentes comunitárias de saúde e gerentes do serviço, por todo o apoio. 

"Nunca deixe que The digam que não vale a pena

Acreditar no sonho que se tem

Ou que seus planos nunca vão dar certo

Ou que você nunca vai ser alguém

Tem gente que machuca os outros

Tem gente que não sabe amar

Mas eu sei que um dia a gente aprende

Se você quiser alguém em quem confiar

Confie em si mesmo

Quem acredita sempre alcança. "

(Renato Russo, Flávio Venturini, 1986) 

Cunha, MR. Vulnerabilidades das mulheres à infecção de sítio cirúrgico pós-parto cesáreo: estudo exploratório e proposta de um roteiro para auxílio à consulta de enfermeiro na Atenção Básica. [dissertação]. São Paulo: Escola de Enfermagem, Universidade de São Paulo; 2015.

\section{RESUMO}

A infecção de sítio cirúrgico pós-cesárea corresponde a 8\% de todas as infecções pósparto. Sua magnitude está relacionada ao alto percentual de partos cesáreos, no mundo todo. O puerpério é um período em que há maior atenção ao recém-nascido, podendo passar despercebidas condições que indicam infecção. Objetivos: Descrever o perfil das mulheres submetidas ao parto cesáreo (condições de vida, saúde reprodutiva e perfil sociodemográfico), correlacionando-o à presença de infecção e propor um roteiro que auxilie o enfermeiro da atenção básica a identificar indícios de infecção de sítio cirúrgico pós-cesárea no puerpério. Método: estudo exploratório, descritivo, transversal, retrospectivo, realizado por meio de revisão de prontuários (prontuários geral e Mãe Paulistana e Ficha A do SIAB) de 89 mulheres que tiveram parto cesáreo, de 01/01 a 31/12/2014. Tomaram-se informações de diagnóstico médico de infecção de sítio cirúrgico e situações em que havia, pelo menos, uma condição sugestiva de sinais e sintomas. A análise foi realizada segundo estatística descritiva (teste de Fischer). Resultados: A ocorrência de sinais e sintomas de infecção de sítio cirúrgico pós- cesárea foi verificada em 11 prontuários. Em 16 prontuários, não foram encontrados sinais e sintomas, e 62 prontuários não continham informações ou elas estavam incompletas. Raça/cor e dor em baixo ventre podem indicar infecção, mulheres pardas e negras foram as mais frequentes do grupo que apresentaram sinais sugestivos de infecção, apresentando diferença estatística significativa ( $p .=0,038$ ). O roteiro para consulta de enfermagem no puerpério pósparto cesáreo complementa dados que auxilia a identificação da ocorrência de sinais e sintomas sugestivos de infecção de sítio cirúrgico e auxilia a identificação de diagnósticos de Enfermagem. Conclusão: $O$ roteiro pode auxiliar o profissional enfermeiro a reconhecer situações de risco e vulnerabilidade para o desenvolvimento de infecção de sítio cirúrgico pós-parto cesáreo ou outro sinal de complicação pósparto, contribuindo com a melhoria da qualidade da assistência e segurança do paciente.

PALAVRAS-CHAVE: Atenção primária, cesárea, infecção puerperal, puerpério, papel do profissional de enfermagem. 

Cunha, MR. Women's vulnerability to surgical infection after cesarean section; an exploratory study and guide proposal to support nurse's consultation at Basic Attention. [thesis]. São Paulo: Escola de Enfermagem, Universidade de São Paulo; 2015.

\section{ABSTRACT}

The surgical infection after cesarean section applies to $8 \%$ of all infections post childbirth. The magnitude of this event is related to cesarean section's high percent in the whole world. The puerperium is the period where there is more attention to the new born and the conditions that points to the infection can be unnoticed. Goals: To describe the profile of women who are submitted to cesarean section (life conditions, reproductive health and socio-demographic profile) correlating it to the presence of the infection and to propose a guide that will help the Basic Attention nurse to identify the surgical infection after cesarean section evidences at the puerperium. Method: exploratory, descriptive, transversal and retrospective study, achieved by medical record review (general records, Mãe Paulistana and Ficha A from SIAB) of eighty-nine women who had cesarean section, from January 01st to December 31st, 2014. Were analyzed medical records that had information about medical diagnosis of infection after cesarean section and conditions that contained at least one high trace of infection after cesarean section's signs and symptoms. The analysis was held through descriptive statistics (Fischer's test). Results: The occurrence of signs and symptoms of surgical infection after cesarean section was observed in eleven medical records. In sixteen records wasn't found any reference to these signs and symptoms and sixtytwo records didn't had the information or they were incomplete. Race/color, lower womb pain can indicate infection, black and dark women were more frequent among the group that presented high signs of infection, performing a significant statistical difference ( $p .=0,038)$. The guide to nurse consulting at puerperium after cesarean section complements the data that helps to identify the signs and symptoms of infection after cesarean section and supports the identification of nursing diagnosis. Conclusion: The guide can help the nurse to recognize situations of risk and vulnerability for the development of infection after cesarean section or any other sign of complication post childbirth complication, contributing to a better quality of patient's assistance and safety.

KEY-WORDS: Primary attention, cesarean section, puerperium infection,puerperium, nursing professional role. 



\section{LISTA DE QUADROS}

Quadro 1-Instrumento para coleta de dados dos prontuários de mulheres submetidas ao parto cesáreo, segundo categoria e variável.

Quadro 2-Roteiro para consulta do enfermeiro no puerpério pós-parto cesáreo. 108 



\section{LISTA DE GRÁFICOS}

Gráfico 1 - Uso de tabaco, álcool e outras drogas por mulheres que apresentaram ou não sinais e sintomas sugestivos de infecção de sítio cirúrgico.

Gráfico 2 - Intervalo entre a gestação e o último parto de mulheres que apresentaram ou não sinais e sintomas sugestivos de infecção de sítio cirúrgico pósparto cesáreo.

Gráfico 3 - Resultados de exames laboratoriais reagentes para sorologia de sífilis, hepatite B e infecção urinária de mulheres que apresentaram ou não sinais e sintomas sugestivos de infecção de sítio cirúrgico pós-parto cesáreo.

Gráfico 4 - Sinais e sintomas sugestivos de infecção de sítio cirúrgico pós-parto cesáreo apresentados por mulheres do grupo com sinais. 



\section{LISTA DE TABELAS}

Tabela 1 - Número e proporção das mulheres que tiveram parto cesáreo, segundo condições de vida, Município de São Paulo, 2014 ...............................70

Tabela 2 - Número, proporção, razão de chances e valor de $p$ de mulheres que apresentaram ou não sinais e sintomas de infecção de sítio cirúrgico pósparto cesáreo, segundo condições de vida, Município de São Paulo, 2014.

Tabela 3 - Número e proporção de mulheres que tiveram parto cesáreo, segundo características sociodemográficas, Município de São Paulo, 2014........73

Tabela 4 - Número, proporção, razões de chance e valor de $p$, de mulheres que apresentaram ou não sinais e sintomas sugestivos de infecção de sítio cirúrgico pós-parto cesáreo, segundo características sociodemográficas, Município de São Paulo, 2014.

Tabela 5 - Número e proporção das mulheres que tiveram parto cesáreo, segundo condições de saúde, Município de São Paulo, 2014.

Tabela 6 - Número, média, desvio-padrão, mediana, quartil e valor de p de mulheres que apresentaram ou não sinais e sintomas sugestivos de infecção de sítio cirúrgico pós-parto cesáreo, segundo altura, peso e idade, Município de São Paulo, 2014 79

Tabela 7 - Número, proporção, razão de chances e valor de $p$, de mulheres que apresentaram ou não sinais e sintomas sugestivos de infecção de sítio cirúrgico pós-parto cesáreo, segundo condições de saúde, Município de São Paulo, 2014. 79

Tabela 8 - Número e proporção de mulheres que tiveram parto cesáreo, segundo dados da gestação e parto, Município de São Paulo, 2014. .82

Tabela 9 - Número, proporção, razão de chances e valor de $p$ de mulheres que apresentaram ou não sinais e sintomas de infecção de sítio cirúrgico pósparto cesáreo, segundo dados da gestação e parto, Município de São Paulo, 2014.

Tabela 10 -Número e proporção de mulheres que tiveram parto cesáreo, segundo indicadores de sinais e sintomas sugestivos de infecção de sítio cirúrgico no puerpério, Município de São Paulo, 2014.

Tabela 11 -Número, proporção e valor de $p$ de mulheres que apresentaram ou não sinais sugestivos de infecção de sítio cirúrgico pós-parto cesáreo, segundo dados de puerpério, Município de São Paulo, 2014. 



\section{LISTA DE SIGLAS}

$A B$

ACS

AMA

Anvisa

APS

CAPS

CCD

$\mathrm{CCIH}$

CDC

CEInfo

CIAP

CIPESC $\AA$

CNCIRAS

COFEn

COREN

CVC

CVE

DST

ESF

Fiocruz

IPCS

IRAS

ISC

NHS

NSP

OMS

ONU

OPS

PE
Atenção Básica

Agente comunitário de saúde

Assistência médico-ambulatorial

Agência Nacional de Vigilância à Saúde

Atenção Primária à Saúde

Centro de Apoio Psicossocial

Coordenadoria de Controle de doenças

Comissão de Controle de Infecção Hospitalar

Deseases Control and Prevention

Coordenação de Epidemiologia e Informação

Classificação Internacional de Atenção Primária

Classificação Internacional das práticas de enfermagem em Saúde Coletiva

Comissão Nacional de Prevenção e Controle de Infecções relacionadas à Assistência à Saúde

Conselho Federal de Enfermagem

Conselho Regional de Enfermagem

Cateter venoso central

Centro de Vigilância Epidemiológica

Doença sexualmente transmissível

Estratégia Saúde da Família

Fundação Oswaldo Cruz

Infecção de corrente sanguínea

Infecções relacionadas à atenção à saúde

Infecção de sítio cirúrgico

National Patient Safety Agency

Núcleo de segurança do paciente

Organização Mundial da Saúde

Organização das Nações Unidas

Organização Pan-americana de saúde

Processo de enfermagem 


$\begin{array}{ll}\text { PHPN } & \text { Programa de Humanização no pré-natal e nascimento } \\ \text { PNAB } & \text { Política Nacional da Atenção Básica } \\ \text { PNPCIRAS } & \text { Programa Nacional de Prevenção e Controle de Infecções } \\ & \text { Relacionadas à Assistência à Saúde } \\ \text { PNUD } & \text { Programa das Nações Unidas para o Desenvolvimento } \\ \text { PROVITAE } & \text { Projeto Estadual de Prevenção de Infecção Cirúrgica } \\ \text { RAS } & \text { Redes de atenção à saúde } \\ \text { RDC } & \text { Resolução da Diretoria Colegiada } \\ \text { REBRAENSP } & \text { Rede Brasileira de Enfermagem e Segurança do Paciente } \\ \text { RM } & \text { Resistência microbiana } \\ \text { SAE } & \text { Sistematização da Assistência de Enfermagem } \\ \text { SES } & \text { Secretaria de Estado da Saúde } \\ \text { SINASC } & \text { Sistema de informação sobre nascidos vivos } \\ \text { SISPrenatal } & \text { Sistema de acompanhamento do Programa de Humanização no } \\ & \text { pré-natal e nascimento } \\ \text { SNVS } & \text { Sistema Nacional de Vigilância Saúde } \\ \text { SUS } & \text { Sistema Único de Saúde } \\ \text { UBS } & \text { Unidade Básica de Saúde } \\ \text { UNICEF } & \text { Fundo das Nações Unidas para a Infância } \\ \text { USP } & \text { Universidade de São Paulo } \\ \text { UTI } & \text { Unidade de Terapia Intensiva } \\ \text { VAP } & \text { Vigilância pós-alta }\end{array}$




\section{SUMÁRIO}

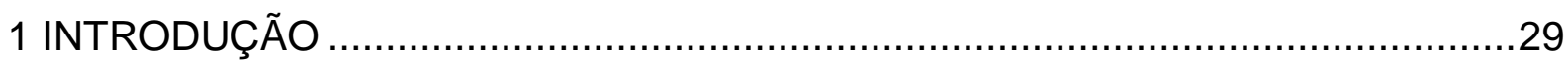

1.1 O PARTO CESÁREO E A INFECÇÃO DE SÍTIO CIRÚRGICO.......................29

1.2 DIRETRIZES POLÍTICAS E TÉCNICAS PARA O CONTROLE DAS

INFECÇÕES DE SÍTIO CIRÚRGICO PÓS-PARTO CESÁREO.

1.3 O SISTEMA ÚNICO DE SAÚDE BRASILEIRO E A ASSISTÊNCIA À MULHER

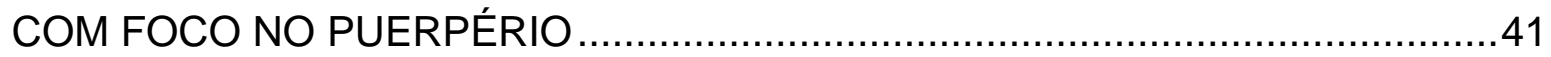

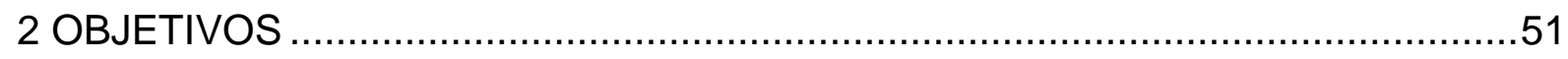

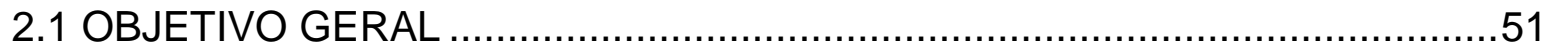

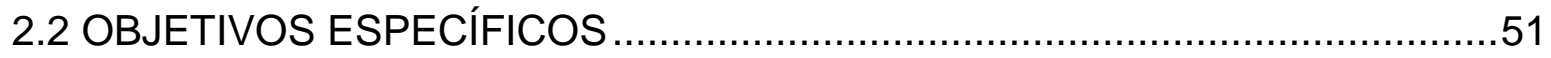

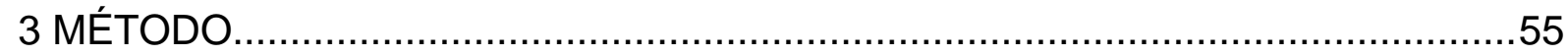

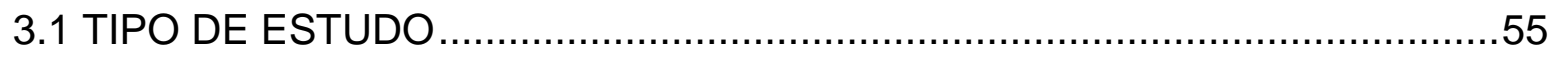

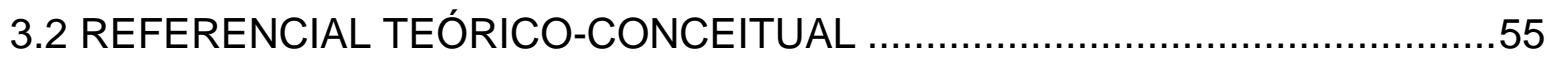

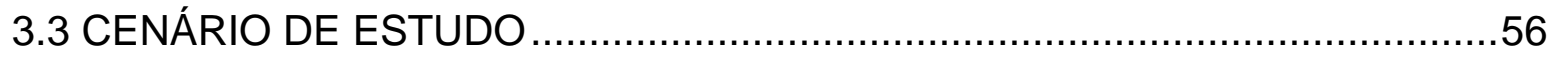

3.4 FONTE DOS DADOS E CRITÉRIOS DE INCLUSÃO E EXCLUSÃO...............57

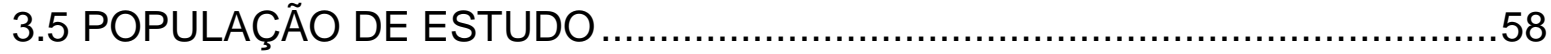

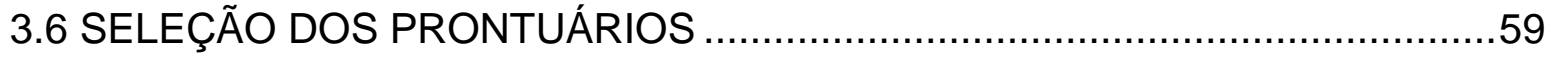

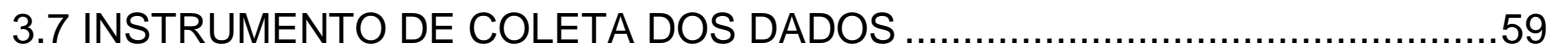

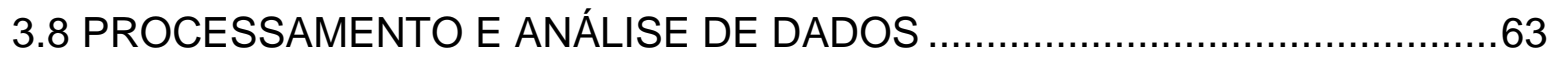

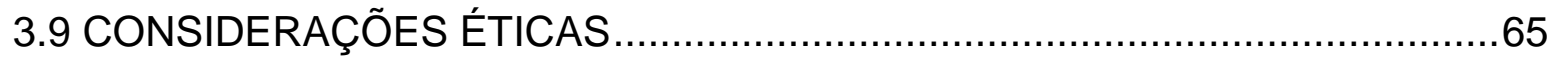

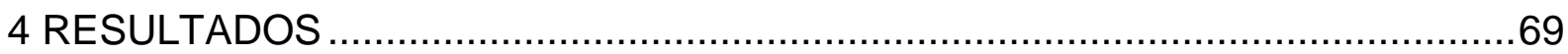

4.1 PERFIL DE CONDIÇÃO DE VIDA E SOCIODEMOGRÁFICO DAS MULHERES QUE TIVERAM PARTO CESÁREO ............................................69

4.2 CONDIÇÕES DE SAÚDE, PARTO E PUERPÉRIO …..................................76

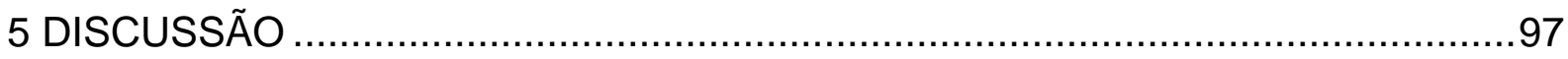

6 CONCLUSÃO E CONSIDERAÇÕES FINAIS ………...................................113

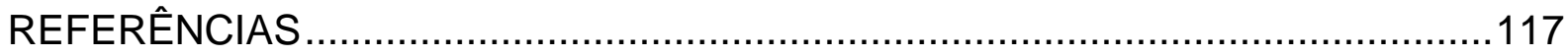

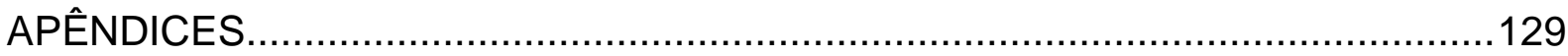

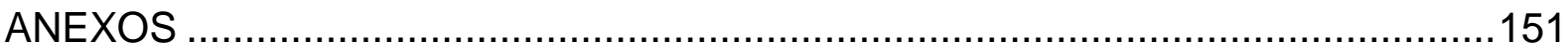



1 INTRODUCÃO 



\section{INTRODUÇÃO}

\subsection{O PARTO CESÁREO E A INFECÇÃO DE SíTIO CIRÚRGICO'1}

Segundo a Organização Mundial da Saúde (OMS), a assistência ao parto deve garantir segurança da mulher e de seu bebê, intervindo apenas de acordo com o necessário. A OMS preconiza que a taxa de parto cesáreo deve ser inferior a 15\% do total dos partos realizados em todo o mundo, no entanto, reconhece-se que este procedimento vem crescendo cada vez mais em altas proporções (Patah, Malik, 2011).

Estudo de revisão da literatura científica, nos anos de 1999 a 2010, sobre o modelo de assistência ao parto e a ocorrência de cesáreas no mundo demonstrou que há elevação das taxas nos últimos 20 anos, em vários países. A Inglaterra, no ano de 1990, tinha uma proporção de 11,3 partos cesáreos para cada 100 mil nascidos vivos, aumentando, no ano de 2004, para 22,7 partos cesáreos. O Canadá que, em 1995, apresentava uma proporção de 17,5 partos cesáreos para cada 100 mil nascidos vivos passou a 26,1 em 2006, e a Alemanha que, em 1999, tinha uma proporção de 19,8 em 2004, passou a 25,9. Os dois países que apresentaram a maior e menor proporção de parto cesáreo por 100 mil nascidos vivos, no ano de 2001, foi a Coreia do Sul com 39,2 contra a Holanda com 13,5, respectivamente (Patah, Malik, 2011).

No Brasil, segundo o Sistema de Informação sobre Nascidos Vivos- SINASC (2014), a proporção de partos cesáreos em 2009 era de 48,9\%, chegando em 2012 a $55,62 \%$. Em 2007, dos três milhões de nascimentos, 1,41 milhão nasceu por esta via, ou seja, $47 \%$ nasceram por parto cesáreo.

No Sistema Único de Saúde (SUS), de todos os partos, cerca de $40 \%$ é cesáreo, já no setor privado este percentual sobe para $80 \%$ do total. Ressalta-se que $48 \%$ das primíparas submeteram-se a uma cesariana e que $46 \%$ de todas foram realizadas com agendamento prévio (Victora et al., 2011).

\footnotetext{
1 Os substantivos "a cesárea/a cesariana" são do gênero feminino. Ex.: O médico realizou uma cesárea naquela paciente. No entanto, cesáreo(a) pode se usar como um adjetivo. E como tal, concordará com o substantivo a que se refere. Ex.: O médico realizou um parto cesáreo hoje. O médico realizou dois partos cesáreos hoje. Seria o mesmo uso que: um parto normal, dois partos normais (Houaiss e Villar, 2009).
} 
Um estudo utilizando os dados do Sistema de Informação sobre Nascidos Vivos do Ministério da Saúde (SINASC), nos anos de 1994 a 2009, nas cinco regiões do país, resultou em um percentual de parto cesáreo variando entre $32 \%$ e $48,4 \%$, com tendência a aumento na incidência deste tipo de parto em quatro regiões, principalmente a Nordeste. Diferentemente, na região Centro-Oeste observou-se redução dos índices, nos anos de 1998 e 1999. No ano de 2009, o percentual de partos cesáreos no Brasil foi de $48,4 \%$ do total de nascidos vivos, ou seja, três vezes maior que aquele recomendado pela Organização Mundial da Saúde que é de 15\% (Hofelmann, 2012).

O parto cesáreo tem riscos aumentados em até 1,5 vezes a mais em relação ao parto vaginal para a maioria dos problemas e complicações, em termos de mortalidade e morbidade grave, tanto para a mulher quanto para o bebê (Romanelli et al., 2012; Petter et al., 2013).

Os riscos do parto cesáreo foram demonstrados, em um estudo com 24 países da África e América Latina, entre os anos de 2004 a 2005, e na Ásia nos anos de 2007 a 2008, que as cesáreas sem indicação clínica estão relacionadas a complicações na puérpera com aumento da mortalidade, internação em Unidade de Terapia Intensiva (UTI), histerectomia nos primeiros sete dias após o parto e perinatais como morte fetal, mortalidade neonatal até a alta hospitalar, internação em UTI maior ou igual a sete dias. Dentre os países onde a pesquisa foi realizada, somente o Japão se encontrava no grupo de países desenvolvidos (Souza et al., 2010).

Em relação aos neonatos, estudo realizado nos Estados Unidos com aproximadamente 5 milhões de nascimentos e 11.897 mortes infantis, entre os anos de 1998 a 2001, com o objetivo de verificar os riscos de mortalidade neonatal associados à cesariana sem indicação em comparação ao parto vaginal, resultou numa mortalidade de bebês 2,9 vezes maior naqueles nascidos por parto cesáreo (MacDorman et al., 2006). Outro estudo, realizado entre os anos de 1999 a 2002, com 8.026.415 nascimentos e 17.412 mortes infantis, identificou uma taxa de mortalidade neonatal no parto cesáreo sem complicações $69 \%$ maior em comparação ao parto vaginal (MacDorman et al., 2008). 
Na América Latina, as cesáreas sem indicação são responsáveis pela ocorrência a cada ano de 100 mortes maternas e 40.000 casos de doença respiratória neonatal (Belizan et al., 1999).

A alta incidência de parto cesáreo tem como consequência o aumento da morbidade e mortalidade materna, neonatal. O presente estudo interessa-se em focalizar as infecções de sítio cirúrgico que constituem uma das complicações pósoperatórias comuns, estando relacionadas ao período de internação, aos altos custos de internação, à morbidade, à mortalidade e à qualidade da assistência prestada. $O$ parto cesáreo prolonga em mais de sete dias a internação e aumenta em 15\% o risco de reinternação (Romanelli, 2012; Petter et al., 2013).

As infecções relacionadas ao parto cesáreo estão entre as Infecções Relacionadas à Atenção à Saúde (IRAS), ganhando destaque nos últimos anos. É considerado pela OMS um problema de saúde pública em todo o mundo, devido ao aumento de custos no cuidado ao usuário e à elevação do tempo de internação, da morbidade, mortalidade, indicando para a necessidade do desenvolvimento de política pública e ações voltadas ao controle e à redução de tais eventos (WHO, 2002; Anvisa, 2013).

Segundo o Centers for Deseases Control and Prevention (CDC) dos Estados Unidos, as infecções de sítio cirúrgico são definidas como superficiais e profundas e infecção de órgão ou espaço e ocorrem em até 30 dias após o procedimento ou em até 1 ano, nos casos de cirurgia com implante (CDC, 2015; Del Monte, 2009).

A infecção de sítio cirúrgico incisional superficial é caracterizada pelo envolvimento da pele e tecido subcutâneo e deve apresentar, pelo menos, um dos sinais e sintomas caracterizados por drenagem de secreção purulenta da incisão, presença de micro-organismo isolado assepticamente de secreção ou tecido, abertura deliberada dos pontos pelo cirurgião, dor, edema, eritema, calor local ou diagnóstico feito pelo médico (CDC, 2015; Del Monte, 2009).

$\mathrm{Na}$ infecção de sítio cirúrgico incisional profunda, há o acometimento dos tecidos moles profundos (músculo ou fáscia), devendo apresentar um dos sinais e sintomas como drenagem de secreção purulenta ou deiscência espontânea ou aberta 
pelo cirurgião de incisão profunda, febre, dor localizada, edema, rubor, abscesso ou outra evidência envolvendo fáscia ou músculo, achado no exame direto, na reoperação, no histopatológico ou radiológico e no diagnóstico médico (CDC, 2015; Del Monte, 2009).

Já na infecção de órgão ou espaço, há o envolvimento de outra região anatômica do sítio cirúrgico que não a incisão e apresenta um dos sinais e sintomas como drenagem purulenta por dreno locado em órgão ou cavidade, micro-organismo isolado de maneira asséptica de secreção ou tecido de órgão ou cavidade, abscesso achado no exame direto, reoperação, histopatológico ou radiológico e diagnóstico médico (CDC, 2015; Del Monte, 2009).

A infecção de sítio cirúrgico é a principal causa de morbidade e mortalidade em pacientes submetidos à cirurgia, correspondendo a $38 \%$ das infecções hospitalares em pacientes cirúrgicos e a $16 \%$ do total de infecções hospitalares no geral; é a segunda causa de infecção hospitalar e a primeira de pacientes cirúrgicos (CVE, 2006; Petter et al., 2013).

Estudos que tratam dos problemas e complicações decorrentes propriamente do parto cesáreo, na grande maioria, referem-se ao período que compreende o preparo pré e pós-cirúrgico, incluído o período de parto imediato e o de puerpério ( $1^{\circ}$ ao $30^{\circ}$ dias pós-parto). As taxas de infecção de sítio cirúrgico pós-parto cesáreo apresentadas em pesquisas são diferentes quando comparadas a uma vigilância passiva, ou enquanto a mulher se encontra em internação hospitalar, e vigilância ativa, após a alta hospitalar, resultando, nesta última, em números mais reais (Del Monte, 2009).

Os fatores que influenciam para a ocorrência de infecção de sítio cirúrgico em pacientes que se submeteram a procedimento cirúrgico em geral são baseados no paciente, como doenças crônicas (Hipertensão Arterial, Diabetes Mellitus), estado nutricional (desnutrição, obesidade, perda rápida de peso), idade avançada, imunossupressão, infecção de sítios distantes.

Relacionam-se também ao período pré-operatório, compreendendo no tempo de internação, tricotomia extensa, período intra-operatório, determinado pelo tempo 
cirúrgico prolongado, técnica cirúrgica e uso de drenos (CVE, 2006; Petter et al., 2013).

No parto cesáreo inclui-se como fatores de risco para a infecção de sítio cirúrgico o trabalho de parto prolongado, excesso de toque vaginal, presença de mecônio no líquido amniótico, parto prematuro, primiparidade, tempo de ruptura de membranas, realização de cesárea de urgência, cesárea de gemelares. Ligado à idade avançada acima dos 35 anos e ao tempo cirúrgico prolongado. No parto cesáreo, o tempo esperado para a realização do procedimento é de 57 minutos (Del Monte, 2009; Petter et al., 2013).

Um estudo de vigilância da incidência de infecções de sítio cirúrgico pós-parto cesáreo e seus fatores de risco, realizado na Noruega, nos anos de 2005, 2006 e 2007, avaliou 3.491 puérperas até 30 dias após o parto, e observaram-se que 290 mulheres (8,3\%) apresentaram infecção puerperal, destas mulheres, 86\% apresentaram os sintomas após a alta hospitalar, evidenciando a importância de um acompanhamento adequado após a saída do hospital, em período estendido (Eriksen et al., 2009).

Nos Estados Unidos, a incidência de infecção de sítio cirúrgico é de 2 a $5 \%$ para as cirurgias classificadas como limpas e até $40 \%$ em algumas cirurgias contaminadas. Entre as infecções puerperais, a infecção de sítio cirúrgico é a principal complicação no pós-parto cesáreo (Petter et al., 2013).

Um estudo brasileiro de vigilância pós-alta de partos cesáreos, com 187 mulheres em até 30 dias após a cirurgia, revelou 44 puérperas que apresentaram infecção de sítio cirúrgico (23,5\%). Destas, 39 (93\%) tiveram início dos sintomas sugestivos de infecção em até 15 dias após o parto, corroborando quanto à importância da vigilância após a alta (Del Monte, 2009). 


\subsection{DIRETRIZES POLÍTICAS E TÉCNICAS PARA O CONTROLE DAS INFECÇÕES DE SÍTIO CIRÚRGICO PÓS-PARTO CESÁREO}

A Organização das Nações Unidas (ONU), após analisar os maiores problemas mundiais em todos os âmbitos, estabeleceu em 2000, os Oito Objetivos do Milênio que devem ser atingidos até o ano de 2015, com destaque ao quinto objetivo que indica a melhoria da saúde das gestantes, trazendo como base a redução em três quartos da taxa de mortalidade materna (PNUD, 2014). Isto deve incluir necessariamente o acompanhamento do puerpério e a identificação precoce de infecção relacionada ao parto cesáreo, melhorando assim a qualidade da assistência prestada e a segurança do paciente.

A OMS define Segurança do Paciente como ausência de danos preveníveis ao paciente, durante o processo de assistência à saúde e no ano de 2004, lançou a Aliança Mundial para a Segurança do Paciente, contando com a participação do Brasil dentre os países-membros deste grupo, com o propósito de coordenar, defender e auxiliar as melhorias referentes à segurança do paciente em todo o mundo (WHO, 2005; 2013). Confluindo com essas diretrizes, o Ministério da Saúde do Brasil define segurança do paciente como a redução, a um mínimo aceitável, do risco de dano desnecessário associado ao cuidado de saúde e destaca-se a conformação do Programa Nacional de Segurança do Paciente em 2013, traçando como meta a melhoria da qualidade da assistência, prevenindo e reduzindo a ocorrência de eventos adversos e IRAS em serviços de saúde públicos e privados através de ações, programas, normatizações e publicações para todo o país (Brasil, 2013).

A consolidação do Programa Nacional de Segurança do Paciente inicia-se com a publicação da RDC 36/2013 que tem por objetivo instituir ações para a promoção da segurança do paciente e a melhoria da qualidade nos serviços de saúde, prevendo a criação de núcleos formados por profissionais do serviço dedicados ao gerenciamento de risco, incluindo sistema de notificação, acompanhamento de eventos, planejamento de ações preventivas e disseminação da cultura de segurança, entre outros (Anvisa, 2014). 
Os Núcleos de Segurança do Paciente deverão ser instituídos em todos os serviços de saúde. No âmbito hospitalar, cada instituição deverá formar um núcleo, vinculado à direção, com uma conformação distinta, nas unidades básicas de saúde, e o gestor local poderá constituir um núcleo formado por unidades de uma mesma região de saúde (Anvisa, 2014).

Ainda no ano de 2013, foi publicada a Série Segurança do Paciente e Qualidade em Serviços de Saúde, desenvolvida pela parceria do Ministério da Saúde (MS), Anvisa e Fundação Oswaldo Cruz (Fiocruz), dividida em cinco módulos, distribuído em temas distintos: Assistência Segura, Critério de Diagnóstico de Infecção Relacionada à Assistência à Saúde, Neonatologia, Medidas de Prevenção de Infecção Relacionada à Assistência à Saúde e Investigação de Eventos Adversos em Serviços de Saúde (MS, Fundação Oswaldo Cruz, Anvisa, 2014).

A série está dividida em protocolos que trazem a temática de identificação do paciente, segurança na prescrição, uso e administração de medicamentos, cirurgia segura, prática de higiene das mãos nos serviços de saúde, prevenção de úlceras de pressão e prevenção (MS, Fundação Oswaldo Cruz, Anvisa, 2014).

Cada protocolo determina ações específicas, qual serviço de saúde é aplicado e indicadores de monitoramento voltados a cada tema. Estes protocolos foram aprovados através da Portaria no 1.377 de 9 de julho de 2013 do Ministério da Saúde (Brasil, 2013).

Os protocolos de cirurgia segura, prevenção de úlcera de pressão e prática de higiene das mãos em serviços de saúde foram instituídos em âmbito nacional e devem ser utilizados em todos os serviços de saúde do Brasil (Brasil, 2013).

No ano de 2013, a REBRAENSP do Polo do Rio Grande do Sul lançou o Manual para Profissionais da Saúde, denominado de "Estratégias para a Segurança do Paciente", disseminando entre os profissionais o cuidado seguro baseado em evidências e dividido em 12 estratégias que foram selecionadas a partir dos Desafios Globais, formulados pela Aliança Mundial para a Segurança do Paciente- Uma Assistência Limpa é uma Assistência mais Segura e Cirurgias Seguras salvam vidas, publicadas respectivamente em 2005-2006 e 2007-2008 (REBRAENSP, 2013). 
Relacionado a segurança do paciente e o trabalho da equipe de enfermagem em especial o enfermeiro, o Código de Ética dos Profissionais de Enfermagem no capítulo que trata das relações com a pessoa, família e coletividade, no que tange à responsabilidades e aos deveres, o artigo $12^{\circ}$ ressalta a responsabilidade e o dever do profissional em assegurar uma assistência livre de danos à pessoa, família e coletividade (COFEn, 2007), mostrando a importância de se discutir sobre o tema, bem como nortear as ações dos profissionais de enfermagem.

Ao encontro das normatizações nacionais, o Conselho Regional de Enfermagem de São Paulo (COREn- SP) em conjunto com a Rede Brasileira de Enfermagem e Segurança do Paciente (REBRAENSP) publicaram, no ano de 2010, a Cartilha 10 passos para a Segurança do Paciente, com a finalidade de informar e orientar os profissionais sobre a segurança do paciente, nos diversos ambientes de cuidado (COREn- SP, REBRAENSP, 2010).

O tema segurança do paciente na atenção hospitalar é o centro das atenções de profissionais e estudos, embora a discussão na Rede de Atenção à Saúde venha se ampliando, principalmente na Atenção Básica que possui especificidades que necessitam ser identificadas, com a finalidade de melhoria do processo de trabalho e o oferecimento de cuidados mais seguros (REBRAENSP, 2013).

Pesquisas e publicações sobre Segurança do Paciente na Atenção Básica são escassas, mesmo no âmbito internacional. Há iniciativas a serem destacadas como a do Reino Unido que publicou o guia de boas práticas intitulado "Sete Passos para a Segurança do Paciente na Atenção Primária" (NHS, 2006) e a do Primeiro encontro sobre Segurança do Paciente na Atenção Primária, realizado pela OMS em 2012, que prioriza as principais necessidades de conhecimento e desafios relacionados ao tema (WHO 2012).

Numa revisão narrativa da literatura nacional e internacional sobre segurança do paciente na atenção primária, foram identificadas 99 produções, entre 1994-2014, majoritariamente, publicadas entre 2010-2013. Nenhuma delas tratou especificamente das IRASs nos partos cesáreos (Cunha et al., 2014). 
A vigilância de IRAS como parte integrante do tema Segurança do Paciente tem sido pauta de discussões no mundo inteiro, como forma de garantir uma assistência à saúde, livre de danos e com qualidade. (WHO, 2013).

Confluindo com a segurança do paciente, há 18 anos, a Organização PanAmericana de Saúde (OPAS) desenvolve um trabalho no continente americano com o objetivo de aprimorar ou propor um sistema de vigilância epidemiológica das IRAS e de resistência microbiana (RM), em serviços de saúde e laboratórios. Nos anos de 2006 e 2007, a OPAS em conjunto com experts da área realizou um diagnóstico da atual situação dos programas de controle e prevenção das infecções relacionadas à saúde (OPAS, 2014).

Os resultados obtidos foram tomados como iniciativa para que os países desenvolvam ações para melhoria da situação encontrada e para que a OPAS desenhe sua estratégia para abordagem do problema regionalmente, recomendando em particular o aprimoramento da vigilância das infeções associadas à atenção à saúde materna (OPAS, 2014). Em 2010, a OPAS destaca, dentre as ações, a vigilância das infecções que ocorrem até 30 dias após o parto vaginal ou cesáreo (OPAS, 2014).

No Brasil, o primeiro Programa Nacional de Controle de Infecção Hospitalar foi instituído pelo Ministério da Saúde através da Portaria oㅡ 232 de 1998. No âmbito das infecções relacionadas à Atenção à Saúde, as Portarias no 196 de 1983 e ํㅜ 930 de 1992 foram publicadas com os objetivos de normatização das ações de prevenção e controle das IRASs (Brasil, 1983, 1992, 1998).

Ainda relacionado às IRASs, a Lei n 9.431 de 1997, a Portaria no 2.616 de 1998 e a RDC № 48 de 2000 versam sobre a obrigatoriedade de manutenção do programa de controle de infecção hospitalar em todo o país e o roteiro de inspeção do Programa de Controle de Infecção Hospitalar (Anvisa,1998, 2000; Brasil,1997,1998).

A Agência Nacional de Vigilância à Saúde (Anvisa), no ano de 2001, conduziu a realização de um diagnóstico acerca do controle das IRASs, contando com a participação de instituições hospitalares públicas e privadas de vários municípios dentro do território nacional. Os resultados encontrados apontam para o déficit no 
controle das IRASs, devido à falta de laboratórios de microbiologia, bem como Comissão de Controle de Infecção Hospitalar (CClH) implantada, um setor de vigilância epidemiológica ativo e um programa de controle das IRASs bem como um planejamento de educação permanente e plano de contingência de surtos (Anvisa, 2013).

Diante da situação encontrada, a Anvisa publicou, a partir de 2008, critérios diagnósticos de Infecção Relacionada à Assistência à Saúde em neonatologia, de trato respiratório, de corrente sanguínea, do trato urinário e de cirurgias com implante e próteses e infecção de sítio cirúrgico, este último, sem referência em particular ao parto cesáreo (Anvisa, 2013).

A Comissão Nacional de Prevenção e Controle de Infecções Relacionadas à Assistência à Saúde (CNCIRAS) foi instituída pela Anvisa para assessorar a elaboração de normas, diretrizes e medidas para prevenção das IRASs, resultando na elaboração do Programa Nacional de Prevenção e Controle de Infecções Relacionadas à Assistência à Saúde (PNPCIRAS), com o objetivo de redução da incidência de IRAS e resistência microbiana em todo o território nacional (Anvisa, 2013).

Desde o ano de 2010, alguns indicadores de IRAS passaram a ser de notificação obrigatória, como a infecção de corrente sanguínea (IPCS), em pacientes de terapia intensiva (UTI), pontuando a inserção progressiva de outros indicadores que serão incluídos no processo de notificação, como a infecção do trato respiratório, urinário e sítio cirúrgico, incluindo os partos cesáreos (Anvisa, 2010).

Para tanto, foram traçados três objetivos específicos a serem instituídos no período de 2013-2015: reduzir as Infecções Primárias da Corrente Sanguínea (IPCS), de Sítio Cirúrgico (ISC) e estabelecer o controle sobre a resistência Microbiana (RM) em serviços de saúde, A partir de 2014, todos os serviços de saúde que possuírem qualquer número de leitos de UTI devem notificar obrigatoriamente à Anvisa mensalmente seu dados sobre as infecções primárias da corrente sanguínea (IPCS) relacionadas ao uso de cateter venoso central (CVC) em UTI, marcadores de resistência microbiana relacionada a estas infecções e para os hospitais que realizam 
procedimentos cirúrgicos, as Infecções de Sítio Cirúrgico (ISC) relacionadas ao parto cesáreo (Anvisa, 2013, 2014).

Resoluções e documentos recentes demonstram a importância do tema, a exemplo, a RDC no 63/2011, que dispõe sobre os Requisitos de Boas Práticas de Funcionamento para os Serviços de Saúde, fundamentados na qualificação, na humanização da atenção e gestão, na redução e no controle de riscos aos usuários e meio ambiente. A Portaria no 158 de 2012 institui a Comissão Nacional de Prevenção e Controle de Infecções Relacionadas à Assistência à Saúde, auxiliando na elaboração de diretrizes, normas e medidas para prevenção e controle das IRASs (Anvisa, 2011; Brasil, 2012).

Ainda que o Ministério da Saúde tenha disponibilizado o site Notivisa desde 2007, para que o próprio cidadão ou familiar, de maneira voluntária, possa fazer sua notificação de evento adverso ou fato ocorrido na assistência prestada em uma gama de indicadores, incluindo-se as IRASs, e a RDC 36/2013 tenha instituído a obrigatoriedade dos serviços de saúde de notificarem os eventos adversos, poucos dados são conhecidos a respeito das infecções relacionadas à atenção à saúde, bem como escassa referência ao cuidado nas condições que envolvem especificamente o parto cesáreo e suas complicações (Anvisa, 2014).

A notificação realizada por todos os trabalhadores da saúde deve ser encaminhada ao Núcleo de Segurança do Paciente (NSP) que por sua vez irão enviála ao Sistema Nacional de Vigilância Saúde (SNVS), com o objetivo de gerir riscos, de cunho epidemiológico, melhoria da qualidade da assistência e segurança do paciente.

É essencial a priorização da Vigilância Epidemiológica (VE) das IRAS, com destaque para as Infecções de Sítio Cirúrgico (ISC), no entanto, no Brasil não há um VE das ISC no nível federal, contando apenas com iniciativas locais, como o Estado de São Paulo que no ano de 2004 estabeleceu um sistema de VE das ISC (Mello, 2013).

No Estado de São Paulo, onde 70\% dos hospitais são cirúrgicos e as infecções de sítio cirúrgico correspondem a $38 \%$ de todas as infecções hospitalares, implantouse, no ano de 2006, o Projeto Estadual de Prevenção de Infecção Cirúrgica- 
PROVITAE, como forma de prevenir as infecções de sítio cirúrgico através da avaliação de quatro componentes: profilaxia antimicrobiana, VI-vigilância epidemiológica, T-tricotomia, A- antissepsia das mãos do cirurgião e pele do paciente e esterilização de materiais (CVE, 2006).

No município de São Paulo, o núcleo de Controle de Infecção Hospitalar (NMCIH) da Gerencia de Vigilância Epidemiológica da Coordenadoria de Vigilância em Saúde (COVISA), utiliza-se de recomendações baseadas em evidências para a promoção de ações de prevenção da infecção de sítio cirúrgico com o envolvimento da equipe multiprofissional, realizando atividades com foco na segurança do paciente, através de ações educativas com profissionais, pacientes e familiares (COVISA, 2014).

O NMCIH estabeleceu ainda um sistema de vigilância e análise das causas de infecção de sítio cirúrgico (ISC), além de estudos sobre a adesão dos profissionais as medidas de prevenção contra este evento e o uso de protocolos, levando em consideração os riscos individuais para seu desenvolvimento, identificando as taxas de ISC, desenvolvendo medidas de prevenção deste tipo de infecção (COVISA, 2014).

A vigilância das ISC deve ser realizada em até 30 dias após o procedimento e 90 dias em casos de cirurgias de mama, cardíacas, revascularização do miocárdio, craniotomia, cirurgias videolaparoscópicas, artrose de coluna, osteossíntese, prótese de joelho e quadril, implante de marcapasso definitivo, cirurgia de bypass vascular periférica, e derivação ventrículo-peritoneal, para tanto é necessária a notificação pelos hospitais destes eventos em planilhas específicas e encaminhadas mensalmente para o município que remeterá ao Estado (CVE, 2015).

A infecção de sítio cirúrgico pós-parto cesáreo é notificada em planilha específica que faz parte do rol de procedimentos cirúrgicos selecionados juntamente com as cirurgias de apendicectomia, artroplastia de joelho e total de quadril, colecistectomia, colectomia, craniotomia, herniorrafias/ hernioplastias, histerectomia, mastectomia e revascularização do miocárdio (CVE, 2015).

O indicador gerado a partir dos dados é a incidência de infecção de sítio cirúrgico para os procedimentos cirúrgicos selecionados. No caso de parto cesáreo a 
fórmula de cálculo se dá pela divisão do número de ISC pelo número de procedimentos cirúrgicos (parto cesáreo) total multiplicado por 100 (CVE, 2015).

Os dados das infecções de sítio cirúrgico são escassos, sobretudo na Atenção Básica e não se tem a real magnitude do problema neste nível de atenção. Não há registro de notificação de diagnóstico neste ponto da rede de atenção. E os protocolos e diretrizes existentes estão focados na atenção hospitalar.

\subsection{O SISTEMA ÚNICO DE SAÚDE BRASILEIRO E A ASSISTÊNCIA À MULHER COM FOCO NO PUERPÉRIO}

Desde a constituição do SUS novos arranjos foram desenvolvidos para seu aprimoramento. Diante da heterogeneidade do território nacional, de necessidades de saúde distintas, nos diferentes territórios e dinamicidade do sistema, desde o ano de 2010, através da Portaria GM/MS no 4279, de 30 de dezembro de 2010, as Redes de Atenção à Saúde (RAS) estão em desenvolvimento e implantação (Brasil, 1988; 2010).

As RASs são arranjos organizativos de ações e serviços de saúde com o objetivo de se buscar a integralidade do cuidado e seu pleno funcionamento, levando sempre em consideração a população e o território definido, conhecendo as necessidades de saúde para a oferta de serviços de saúde que alcancem as ações de promoção à saúde, prevenção de doenças, diagnóstico, tratamento, gestão de casos, reabilitação e cuidados paliativos (Andrade, Bueno, Bezerra 2006).

Um dos objetivos da RAS é integrar os programas focados em doenças e riscos, prestando serviços de saúde individuais e coletivos, contando com recursos humanos suficientes, participação da comunidade e atenção à saúde centrada no indivíduo, família e comunidade (Andrade, Bueno, Bezerra 2006).[veja o título da paginação acima introdução 18]

Como parte integrante de um dos pontos desta rede, a Atenção Primária à Saúde (APS) no Brasil também denominada Atenção Básica (AB) está estruturada na 
Política Nacional da Atenção Básica (PNAB), desenvolvida de modo descentralizado, próxima à população, sempre orientada pelos princípios da universalidade, do acesso, vínculo, continuidade e integralidade do cuidado, responsabilizando os sujeitos de forma humanizada, equânime e estimulando a participação social (Starfield, 2002).

A AB deve reconhecer os determinantes da saúde e equidade, com uma gestão voltada para resultados, se responsabilizando pelo acompanhamento do processo saúde e doença das populações num dado território. Realiza procedimentos clínicos e cirúrgicos de diferentes complexidades, de situações agudas ou crônicas, avaliando o risco de agravamento imediato ou encaminhamento a outro serviço da rede de atenção à saúde (Tura, Soares, Casatelli et al., 2014).

Diante disso, a AB nas RASs está estruturada como porta de entrada principal e preferencial, primeiro nível de atenção do sistema, contando com uma equipe multiprofissional. Deve ser resolutiva, coordenar o cuidado, ordenar as redes, trabalhando em conjunto com os demais níveis de atenção à saúde, identificando assim as necessidades da comunidade para a oferta de outros serviços de saúde, promovendo ações intersetoriais, prestando cuidados seguros minimizando e prevenindo a ocorrência de IRAS (Padoveze e Figueiredo, 2014; Tura, Soares, Casatelli, 2014).

A prevenção das IRASs e a segurança do paciente podem ser incorporadas ao axioma latino Primun non nocere, traduzido na frase "antes de tudo não causar dano", que traduz a questão da segurança do paciente, onde a $A B$ tem papel primordial na prevenção das IRASs, diminuindo as intervenções hospitalares, prevenindo doenças, com destaque para as internações por condições sensíveis à Atenção Primária à Saúde (APS) (Padoveze e Figueiredo, 2014).

A diminuição das internações sensíveis à APS indica a qualidade da assistência prestada na $A B$ e por consequência sua prevenção, diminuindo a ocorrência de IRAS por redução nas internações hospitalares (Padoveze e Figueiredo, 2014).

Embora existam poucos estudos da ocorrência de IRAS na $A B$, estes são geralmente focados nos surtos e não há um sistema de vigilância para este agravo, 
dificultando sua definição neste nível de atenção, onde a definição das IRASs não está estabelecida (Padoveze e Figueiredo, 2014).

$A A B$ deve ser atuante no sistema de referência e contrarreferência deste agravo, contribuindo na vigilância pós-alta hospitalar, participando na detecção e notificação das IRASs, com especial destaque para as infecções de sítio cirúrgico pósparto cesáreo (Padoveze e Figueiredo, 2014).

A AB como porta principal da RAS se estrutura por eixos prioritários de atendimento, objetivando um cuidado integral, ampliando o acesso, com ênfase para a saúde do adulto, da criança, do idoso, da mulher, norteado sobre programas e protocolos.

Relacionado ao eixo prioritário da Saúde da Mulher, encontram-se os cuidados relacionados ao pré-natal, parto e puerpério, denominado Programa de Humanização no Pré-natal e Nascimento (PHPN), instituído pelo Ministério da Saúde através da Portaria GM no 569 de 2000. Traz como princípios o direito de toda gestante ao acesso a um atendimento de qualidade, de maneira humanizada durante a gestação, o parto e puerpério, bem como conhecer e ter assegurado o acesso à maternidade onde irá ocorrer o parto e a garantia ao recém-nascido a uma assistência neonatal humanizada e segura (Brasil, 2000).

O PHPN busca reduzir as taxas de morbidade e mortalidade materna e perinatal, a melhoria do acesso, da cobertura, da qualidade da assistência, do acompanhamento do pré-natal, da assistência ao parto, puerpério e neonatal (Brasil, 2000).

Em consonância com o PHPN, a Rede Cegonha do Ministério da Saúde, lançada no ano de 2011, fortalece a Política Nacional de Atenção Integral à Saúde da Mulher (Brasil, 2011).

A informação da assistência prestada é realizada através do cadastro de cada gestante na rede, através da inserção dos dados em um sistema on-line denominado Sistema de Acompanhamento do Programa de Humanização no Pré-Natal e Nascimento (SISPRENATAL) que monitora e avalia o atendimento da mulher, durante o pré-natal e puerpério (Brasil, 2000). 
O SISPrenatal tem o objetivo de contribuir para uma assistência mais segura, auxiliando na identificação de complicações e riscos maternos e perinatais, reduzindo assim as taxas de morbidade e mortalidade materna e infantil e promovendo 0 desenvolvimento de ações de promoção à saúde, prevenção de doenças e assistência integral à saúde de gestantes e recém-nascidos (Brasil, 2000).

Na esfera estadual, o Plano Estadual de Saúde do Estado de São Paulo 20122015 traçou como prioridade a implantação da rede temática de pré-natal, parto e puerpério, como objetivo de reduzir a mortalidade materna infantil (SES- SP, 2012).

No Município de São Paulo, programa semelhante foi lançado no ano de 2006, através do Decreto Municipal nำ 46.966, denominado Rede de Proteção Mãe Paulistana. Esta rede articula, integrando e monitorando as RASs do município, quer sejam serviços hospitalares municipais ou estaduais, com a finalidade de promover a melhoria na qualidade da assistência materno-infantil. O princípio é semelhante ao SISPRENATAL, com o cadastramento de toda gestante na sua Unidade Básica de Saúde (UBS) de referência, no momento de seu primeiro atendimento, e vinculação à maternidade onde irá ocorrer o parto, além de subsídio para transporte, garantindo o deslocamento até a consulta (SMS- SP, 2014).

No que tange à assistência da mulher no puerpério, a avaliação hospitalar desta no período de internação e na UBS após o parto é de extrema importância, influindo diretamente na qualidade do serviço prestado e tendo nas três esferas de governo normatizações que ditam sobre este atendimento.

A Secretaria de Estado da Saúde de São Paulo preconiza o retorno da mulher e recém-nascido ao serviço de saúde de 7 a 10 dias, após o parto, além de visita domiciliar na primeira semana após a alta hospitalar, justificada pela evidência da alta incidência de eventos nesse período, para a redução da morbidade e mortalidade maternas (SES- SP, 2010).

A avaliação da assistência pré-natal e puerperal foi realizada em um estudo com 20 municípios pertencentes à Direção Regional de Saúde (DIR XI) - Botucatu que aderiram ao PHPN até o ano de 2003, no qual foram entrevistados, nos anos de 2004 
e 2005, os gestores dos municípios, revelando uma inadequação do serviço prestado (Parada, 2008).

O resultado obtido, a partir do estudo de Parada (2008), reflete diretamente no cumprimento das normativas do PHPN, revelando que 58,7\% das mulheres realizaram seis consultas de pré-natal e consulta de puerpério, 13\% realizaram seis consultas de pré-natal e os exames preconizados pelo programa, 10,1\% realizaram seis consultas de pré-natal, consulta de puerpério e os exames e somente $3,6 \%$ das mulheres foram consideradas, segundo as diretrizes do programa como conclusão do atendimento no ciclo gravídico-puerperal, com a realização de seis consultas de prénatal, consulta de puerpério, exames e a dose imunizante da vacina antitetânica.

Ainda nessa pesquisa, foi apontada como indicativos da baixa cobertura a consulta de puerpério, devido, entre outros fatores, à perda da informação com a ocorrência de falha de registro no prontuário, bem como a falta de estrutura dos serviços de atenção básica para sua realização e a não ocorrência de busca ativa de puérperas que não procuraram o serviço, em nove municípios (Parada, 2008).

Um estudo realizado nos anos de 2001 e 2002 reforça os dados obtidos em uma pesquisa anterior realizada com 3.016 municípios, que avaliou os dados do SISPRENATAL. Do total de 720.871 mulheres, tendo com parâmetro as diretrizes do PHPN, 6,47\% e 9,43\%, nos anos 2001 e 2002 respectivamente, tiveram seis consultas de pré-natal e consulta de puerpério, chegando a 2,0\% e 4,07\% quando relacionado a gestantes que realizaram seis consultas de pré-natal, consulta de puerpério, todos os exames básicos, a $2^{\underline{a}}$ dose, ou dose de reforço ou a dose imunizante da vacina antitetânica. Ainda que tenha sido mensurado isoladamente 0 item consulta de puerpério, resultando em $19 \%$ de atendimentos, nesta modalidade o estudo revelou baixa frequência neste procedimento (Serruya, Cecatti, Lago, 2004).

Diante da importância da assistência ao pré-natal, parto e puerpério, estudos regionais foram realizados, demonstrando as fragilidades e potencialidades do serviço prestado. Em Cuiabá, no Mato Grosso do Sul, uma pesquisa realizada no ano de 2011, em 55 UBS, reforçou a inadequação da assistência ao puerpério no país, ligada, sobretudo, aos aspectos assistenciais, gerenciais, à estrutura e à capacidade dos 
serviços de saúde, ressaltando a fragilidade no acompanhamento da mulher no período pós-parto (Oliveira et al., 2013).

Já nas regiões Norte e Nordeste, duas pesquisas realizadas em nove municípios classificados entre os mais pobres da região, segundo o Fundo das Nações Unidas para a Infância (UNICEF) e Pastoral da Criança, nos anos de 2002 e 2005 , verificaram a qualidade dos serviços oferecidos e a avaliação de indicadores básicos de saúde materna e infantil, dentre eles aqueles relacionados à assistência pré-natal e ao parto entre 1.500 crianças menores de cinco anos. No que tange ao puerpério, o resultado revelou que somente $18 \%$ das mulheres, nos dois estudos, retornaram para a consulta de puerpério (Chrestani et al., 2008).

A região Sul do país, no município de Pelotas, trouxe a problemática do registro da consulta de puerpério em 392 prontuários de gestantes, em cinco Unidades Básicas de Saúde, sendo duas no modelo tradicional e três com Estratégia Saúde da Família (ESF). No primeiro quadrimestre de 2009, 60\% das consultas puerperais estavam com registro incompleto, e, destas, $61 \%$ não traziam a informação do tipo de parto, $80,1 \%$ não continham informações sobre complicações do parto bem como a realização do planejamento familiar em 66,6\% dos registros (Lopes et al., 2011).

Almeida e Silva (2008) ainda se referem à necessidade de humanização do cuidado, com a prestação de uma assistência integral à puérpera e demonstram a baixa frequência da consulta de puerpério nas UBS, devido à falta de estratégias para a promoção da atividade e à sua valorização pelos profissionais de saúde.

Ainda que existam os programas e protocolos ministeriais, estaduais e municipais referentes à Saúde da Mulher, a realidade referente à assistência ao prénatal, no país, mostra-se deficitária, sendo necessárias forças para o desenvolvimento de ações efetivas para a diminuição da morbidade e mortalidade maternas. Segundo Victora et al. (2011), praticamente todas as mortes maternas poderiam ser evitadas se o acesso aos serviços de saúde fosse precoce e de qualidade.

As complicações obstétricas são a principal causa de hospitalizações em mulheres em idade reprodutiva, onde eventos adversos graves ou potencialmente mortais ocorreram em $4 \%$ de todos os partos, sendo a mortalidade materna cerca de 
cinco a dez vezes maiores que em países de alta renda e há disparidades de acordo com a região do país, mostrando as desigualdades sociais e de acesso (Victora et al., 2011).

Os programas e protocolos relacionados à saúde da mulher estão instituídos na Atenção Básica, com o propósito de prestarem uma assistência mais segura, com qualidade, reduzindo assim as complicações no parto e puerpério, a mortalidade materna e perinatal.

Historicamente a enfermeira é um dos profissionais de saúde que acompanha a mulher no puerpério na Atenção Básica. No entanto, são escassos os estudos que tratam a temática das IRASs relacionadas ao puerpério neste nível de atenção. Estudo realizado em Alfenas-MG, a partir da observação do atendimento de enfermeiras em consulta de puerpério e visitas domiciliares, evidenciou uma prática não sistematizada, voltada principalmente para os cuidados do RN, sem ações para a promoção da saúde da mulher neste período (Duarte et al., 2014).

Os manuais e protocolos do Ministério da Saúde, da Secretária de Saúde do Estado de São Paulo e do município de São Paulo chamam a atenção sobre a importância dos cuidados da mulher no período puerperal, no entanto, não há um roteiro sistematizado, enfocando a consulta de puerpério. O prontuário Mãe Paulistana traz em seu atendimento de puerpério, em sua maioria, os cuidados com as mamas e maior ênfase para o atendimento do RN.

Diante da importância na melhoria da qualidade da assistência à saúde materna com vistas à diminuição da morbidade e mortalidade maternas, bem como a necessidade de obter subsídios para que o enfermeiro identifique no atendimento à puérpera sinais sugestivos de infecções de sítio cirúrgico pós-cesárea, este estudo se propõe a apresentar um roteiro que sistematize a assistência de enfermagem na consulta de puerpério.

Tem como finalidade qualificar as práticas do enfermeiro em consulta de puerpério de mulheres que tiveram parto cesáreo, voltado aos cuidados com a puérpera, atentando para as possíveis complicações deste período, principalmente a 
infecção de sítio cirúrgico, prestando cuidados seguros e uma assistência de qualidade. 
2 OBJETIVOS 



\section{OBJETIVOS}

\subsection{OBJETIVO GERAL}

Propor um roteiro que auxilie o enfermeiro da Atenção Básica a identificar, nas mulheres submetidas ao parto cesáreo, condições sugestivas de infecção de sítio cirúrgico pós-parto cesáreo, na consulta à puérpera na Atenção Básica.

\subsection{OBJETIVOS ESPECÍFICOS}

- Descrever o perfil das mulheres em relação às suas condições de vida, de saúde e perfil sociodemográfico durante a gestação, parto e puerpério, segundo variáveis selecionadas;

- Correlacionar presença de sinais e sintomas sugestivos de infecção do sítio cirúrgico com o perfil de mulheres submetidas ao parto cesáreo;

- Identificar informações a serem consideradas na consulta do enfermeiro que o auxilie a reconhecer sinais e sintomas sugestivos de infecção do sítio cirúrgico pós-parto cesáreo. 

3 MÉTODO 



\section{MÉTODO}

\subsection{TIPO DE ESTUDO}

Trata-se de um estudo com pesquisa exploratória, descritivo, transversal, retrospectivo e realizado por meio de revisão de prontuários.

\subsection{REFERENCIAL TEÓRICO-CONCEITUAL}

O presente estudo fundamenta-se no referencial teórico-conceitual sob a ótica da vulnerabilidade, buscando explicar os fatores desencadeantes do processo de adoecimento e morte e os mecanismos para o enfrentamento no âmbito individual, coletivo e social.

A vulnerabilidade pode ser definida em duas dimensões que norteiam sua análise e são interdependentes entre si, determinando a compreensão da vida das pessoas e da comunidade, a individual e coletiva (Ayres et al., 2006).

A dimensão individual traz os aspectos do modo de vida das pessoas e que contribuem para a exposição ao risco. Relaciona-se, ainda, ao acesso às informações, entendimento e promoção de práticas transformadoras que visam à prevenção dos agravos (Ayres et al., 2006). Já a dimensão coletiva abrange o social e programático para os processos saúde-doença como processos sociais e permeiam aspectos educacionais, religiosos, políticas sociais, econômicas, saúde, gênero, cultural, acesso aos meios de comunicação, fazendo com que se compreendam os fenômenos dos comportamentos (práticas que expõem os indivíduos a riscos) (Ayres et al., 2006; Nichiata et al., 2011).

O âmbito programático trata do acesso aos recursos e à rede de proteção de maneira eficaz que levem à diminuição da exposição aos riscos (Nichiata et al., 2008, 2011). Relaciona-se, também, com a avaliação de como as instituições se portam diante das condições socialmente dadas de vulnerabilidade (Ayres et al., 2006). 
Entende-se que vulnerabilidade das mulheres à infecção de sítio cirúrgico póscesárea resulta da sua condição e contexto em âmbito tanto individual quanto coletivo, ou seja, a condição social e a programática que concorrem para sua ocorrência. $O$ perfil das mulheres em relação às suas condições de vida, de saúde e perfil sociodemográfico durante a gestação, parto e puerpério e a presença de sinais sugestivos de infecção do sítio cirúrgico tratam da dimensão individual. Estas indicam necessidades do ponto de vista da dimensão programática, ou seja, ações que a Atenção Básica pode realizar e que interferem na dimensão individual da vulnerabilidade das mulheres à infecção pós-parto. A proposta do roteiro tem esta perspectiva, pois aprimorar a consulta do enfermeiro é uma ação que visa a diminuir a vulnerabilidade das mulheres à infecção puerperal.

\subsection{CENÁRIO DE ESTUDO}

O estudo foi realizado na região oeste do município de São Paulo, correspondente à Coordenadoria Regional de Saúde Oeste, composta pelas Supervisões de Saúde Lapa-Pinheiros e Butantã. Abrange uma área com um total de 1.493.471 habitantes. O estudo foi realizado na área de abrangência da Supervisão Técnica de Saúde do Butantã, compreendendo os distritos administrativos Raposo Tavares, Rio Pequeno, Vila Sônia, Butantã e Morumbi, totalizando uma população de 442.198 habitantes, destes 271.929 são mulheres em idade fértil (entre 10 e 49 anos) (CEInfo,2014).

A rede de atenção à saúde nesta supervisão conta com 13 Unidades Básicas de Saúde, quatro serviços de Assistência Médica Ambulatorial (AMA), um Serviço de Urgência e Emergência 24 horas, um Hospital, um Ambulatório de especialidades, um Centro de apoio psicossocial (CAPS) álcool e drogas, adulto e infantil, três equipamentos de saúde mental, um equipamento de saúde bucal, um centro de referência DST/AIDS e dois ambulatórios de reabilitação (CEInfo, 2014).

Dentre as unidades básicas de saúde, seis são geridas pelo modelo tradicional e sete contam com equipes de saúde da família, destas, cinco estão sob o contrato 
de gestão e três em contrato de parceria com o Projeto Região Oeste (PRO) da Faculdade de Medicina da Universidade de São Paulo.

Dentre as nove UBS da região, seis fizeram parte do estudo, escolhidas por operarem no modelo Estratégia Saúde da Família. Duas delas são consideradas ESF "puras", ou seja, a população moradora da área de abrangência está coberta em 100\% pelas equipes de saúde da família e quatro unidades são chamadas "mistas", quando há áreas cobertas por equipes de saúde da família e áreas de abrangência em que o atendimento da população é realizado por meio da unidade básica de saúde no modelo "tradicional", contando com médicos especialistas (clínico geral, ginecologista e pediatra), vacinação, exames, curativos e procedimentos. Totalizam 142.110 pessoas residentes nas áreas de abrangências das seis UBS e 32 equipes de Estratégia Saúde da Família- ESF (PRO, 2015).

\subsection{FONTE DOS DADOS E CRITÉRIOS DE INCLUSÃO E EXCLUSÃO}

Trata-se de estudo com dados secundários, de prontuários (geral e Mãe Paulistana), ficha A do SIAB e programa Geo health da Universidade de São Paulo de mulheres moradoras na área de abrangência das UBS que fizeram o pré-natal nas seis Unidades Básicas de Saúde com equipes de Estratégia Saúde da Família da Supervisão Técnica de Saúde Butantã, que tiveram parto cesáreo, realizado no período de $1^{\circ}$ de janeiro a 31 de dezembro de 2014 e que compareceram à consulta ou visita domiciliar de puerpério da equipe da ESF, em até 30 dias após o parto.

Como critérios de exclusão, mulheres que tiveram parto vaginal ou vaginal operatório e que não tiveram qualquer consulta de puerpério realizado por médico ou enfermeira ou tenham recebido visita de puerpério de um destes profissionais, no período superior a 30 dias, após a ocorrência do parto cesáreo, ou mulheres que não estavam cadastradas pelas equipes de Estratégia Saúde da Família. 


\subsection{POPULAÇÃO DE ESTUDO}

No Município de São Paulo, no ano de 2014, foram realizados 175.774 partos de nascidos vivos, distribuídos na rede privada (40,5\%) e no Sistema Único de Saúde (SUS) $(59,5 \%)$. Dentre os partos realizados, 54,7\% compreenderam parto cesáreo, cinco partos não foram informados o tipo (CElnfo, 2015).

$\mathrm{Na}$ Coordenadoria de Saúde Oeste, no mesmo ano, houve 14.374 partos, correspondendo a 7.102 partos na Supervisão Técnica de Saúde do Butantã. Dos 7.102 partos, $52,4 \%$ foram partos vaginais e $57,6 \%$, partos cesáreos (CEInfo, 2015).

As seis UBS estudadas da Supervisão Técnica de Saúde do Butantã foram responsáveis por 1.128 nascimentos, realizando 1.037 consultas de puerpério em suas unidades, correspondendo a 369 partos cesáreos (35,58\%), 593 partos vaginais $(57,19 \%)$ e 75 partos vaginais operatórios $(7,23 \%)$ (SINASC, 2015$)$.

A população elegível do estudo tomou como base a quantidade de partos cesáreos ocorrida nas seis UBS de estudos e nos índices de infecção de sítio cirúrgico por parto cesáreo, publicados pela Coordenadoria de Controle de Doenças (CCD) da Secretária de Estado da Saúde do Estado de São Paulo, em março de 2014. Foram 431 hospitais notificantes de parto cesáreo, num total de 304.198 procedimentos, destes, 2.185 apresentaram infecção de sítio cirúrgico $(0,71 \%)$ dentre elas, 734 $(33,6 \%)$ destas notificações foram realizadas pelas 135 instituições que realizaram vigilância pós-alta (VAP) do evento (CVE,2014).

A população de estudo foi definida a partir do universo de 369 partos cesáreos, tendo por referência as seis unidades de atendimento no puerpério. Seguiu a exigência do Comitê de Ética em Pesquisa da Prefeitura do Município de São Paulo, para que fosse apresentada a pesquisa às mulheres, com aceite por meio da assinatura do Termo de Consentimento Livre e Esclarecido (TCLE).

Foram realizadas reuniões com os agentes comunitários de saúde (ACS) para apresentação da pesquisa e discussão de qual seria a metodologia de busca das 
mulheres, ficando definido que o ACS iria realizar a visita domiciliar e apresentar a pesquisa e o TCLE, coletando as assinaturas.

Do universo de 369 mulheres que tiveram parto cesáreo, no ano de 2014, 39 mudaram de área, 29 mulheres não foram localizadas após três tentativas de visita domiciliar, 21 não atendiam os pré-requisitos para inclusão na pesquisa, 22 prontuários não foram encontrados, 21 mulheres não aceitaram participar da pesquisa e 148 mulheres não pertenciam a área de abrangência da ESF resultando em 89 participantes com TCLE.

\subsection{SELEÇÃO DOS PRONTUÁRIOS}

Os prontuários foram selecionados a partir dos dados fornecidos pelo Sistema Bi-Mãe Paulistana que identifica as puérperas das respectivas unidades básicas de saúde, determinando o tipo e local de parto. As UBS selecionaram os prontuários das mulheres pertencentes à Estratégia Saúde da Família, que tiveram parto cesáreo, no ano de 2014.

\subsection{INSTRUMENTO DE COLETA DOS DADOS}

O instrumento foi composto, conforme as categorias e variáveis (Quadro 1): 
Quadro 1 - Instrumento para coleta de dados dos prontuários de mulheres submetidas ao parto cesáreo, segundo categoria e variável.

\begin{tabular}{|c|c|}
\hline Categoria & Variável \\
\hline $\begin{array}{l}\text { Dados de } \\
\text { condições de vida }\end{array}$ & $\begin{array}{l}\text { Tipo de construção do domicílio: madeira, material } \\
\text { aproveitado, taipa, tijolo, outro } \\
\text { Número de cômodos: total de cômodos do domicílio. } \\
\text { Quantidade de moradores: Número de pessoas que convivem } \\
\text { no domicílio. } \\
\text { Energia elétrica: se possui energia elétrica no domicílio ou não. } \\
\text { Destino do lixo: Lixo coletado, queimado/enterrado, céu } \\
\text { aberto. } \\
\text { Destino fezes/urina: Coleta por sistema de esgoto, fossa, céu } \\
\text { aberto. } \\
\text { Abastecimento de água: recebe água através da rede geral, } \\
\text { poço ou nascente, outro. } \\
\text { Renda familiar: renda em número de salários-mínimos, } \\
\text { composta por todos os membros da família. }\end{array}$ \\
\hline $\begin{array}{l}\text { Dados } \\
\text { sociodemográficos }\end{array}$ & $\begin{array}{l}\text { Idade- número completo em anos, a partir da data de } \\
\text { nascimento até a data do parto. Média em anos. } \\
\text { Escolaridade- número de anos estudados. Média em anos. } \\
\text { Raça/cor (autorreferida): branca, negra, parda, amarela, } \\
\text { indígena (autorreferida). } \\
\text { Local de Nascimento: Estado de nascimento. } \\
\text { Trabalho: Situação de trabalho e ocupação referida. } \\
\text { Situação familiar: descrição com quem convive em ambiente } \\
\text { doméstico (companheiro, filhos, parentes, outras pessoas). } \\
\text { Estado civil: casada, solteira, união estável, } \\
\text { separada/divorciada, viúva. }\end{array}$ \\
\hline $\begin{array}{l}\text { Condições } \\
\text { saúde }\end{array}$ & $\begin{array}{l}\text { Peso: peso em gramas no momento da abertura do pré-natal. } \\
\text { Estatura: estatura medida em } \mathrm{cm} \text {. } \\
\text { Índice de massa corpórea (IMC): critério de avaliação do grau } \\
\text { de obesidade de um indivíduo, calculado pelo pesquisador a }\end{array}$ \\
\hline
\end{tabular}




\begin{tabular}{|c|c|}
\hline & 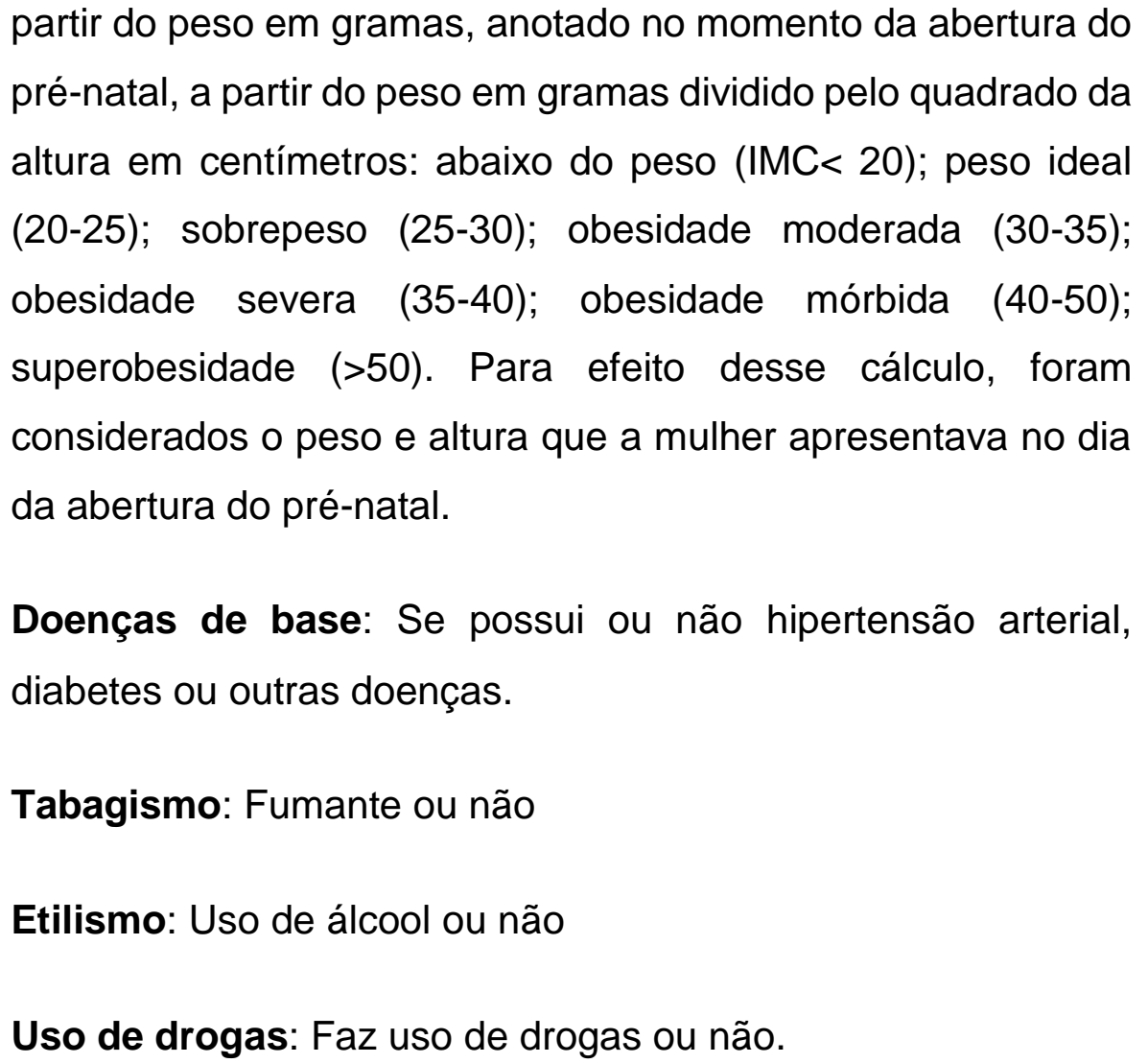 \\
\hline $\begin{array}{l}\text { Dados da última } \\
\text { gestação, parto e } \\
\text { puerpério }\end{array}$ & $\begin{array}{l}\text { Idade gestacional do início do pré-natal: número completo de } \\
\text { semanas de gestação a partir da data da última menstruação } \\
\text { (DUM) ou exame ultrassonográfico. Média em semanas. } \\
\text { Intervalo entre gestações: intervalo em anos entre as } \\
\text { gestações } \\
\text { Número de consultas de pré-natal: até } 3 \text { consultas, de } 3 \text { a } 5 \\
\text { consultas, mais que } 6 \text { consultas. } \\
\text { Infecção comunitária (sífilis, hepatite B, hepatite C, } \\
\text { infecção urinária): Presença de infecção comunitária durante } \\
\text { o período de realização do pré-natal. } \\
\text { Situação vacinal: Se está ou não imunizada contra hepatite B, } \\
\text { influenza, tétano e difteria e quantas doses recebeu. }\end{array}$ \\
\hline
\end{tabular}


Período entre o parto e $1^{\text {a }}$ consulta ou visita domiciliar de puerpério: Número de dias até o primeiro atendimento após o parto (até 7 dias, de 8 a 30 dias).

Tempo de internação hospitalar: número de dias de internação após o parto cesáreo. Média de dias.

Tempo de ruptura de membranas: número de horas decorrido entre o rompimento da bolsa do líquido amniótico e o início da cesárea, calculado em horas.

Cesárea de urgência: é aquela exigida para realização de um parto imediato, para reduzir o risco materno ou neonatal, como nos casos de placenta prévia ou sofrimento fetal. Sim ou não

Motivo indicação cesárea urgência: motivo que levou ao médico optar por uma cesárea de urgência.

Cesárea de gemelares: se parto de gêmeos ou não.

Indicador sugestivo de Infecção do Sítio Cirúrgico (ISC): é aquela que ocorre até 30 dias após a cirurgia, podendo ser uma infecção incisional superficial, incisional profunda e infecção relacionada ao órgão ou espaço manipulado durante a cirurgia. Essas informações foram obtidas pela pesquisadora por meio dos dados do prontuário geral e prontuário Mãe Paulistana: dor em baixo ventre, alterações urinárias, sangramento, leucorréia, febre (maior que $37,8^{\circ} \mathrm{C}$ ), dor (sítio cirúrgico), dor abdominal, presença de secreção, aspecto da secreção, hiperemia, calor, edema, deiscência, abcesso, data do início dos sintomas, data da retirada dos pontos, aspecto do local no momento da retirada dos pontos, profissional que observou o evento, encaminhado para avaliação/diagnóstico médico, encaminhado para outro serviço, tratamento realizado tipo de tratamento, notificação do evento. 


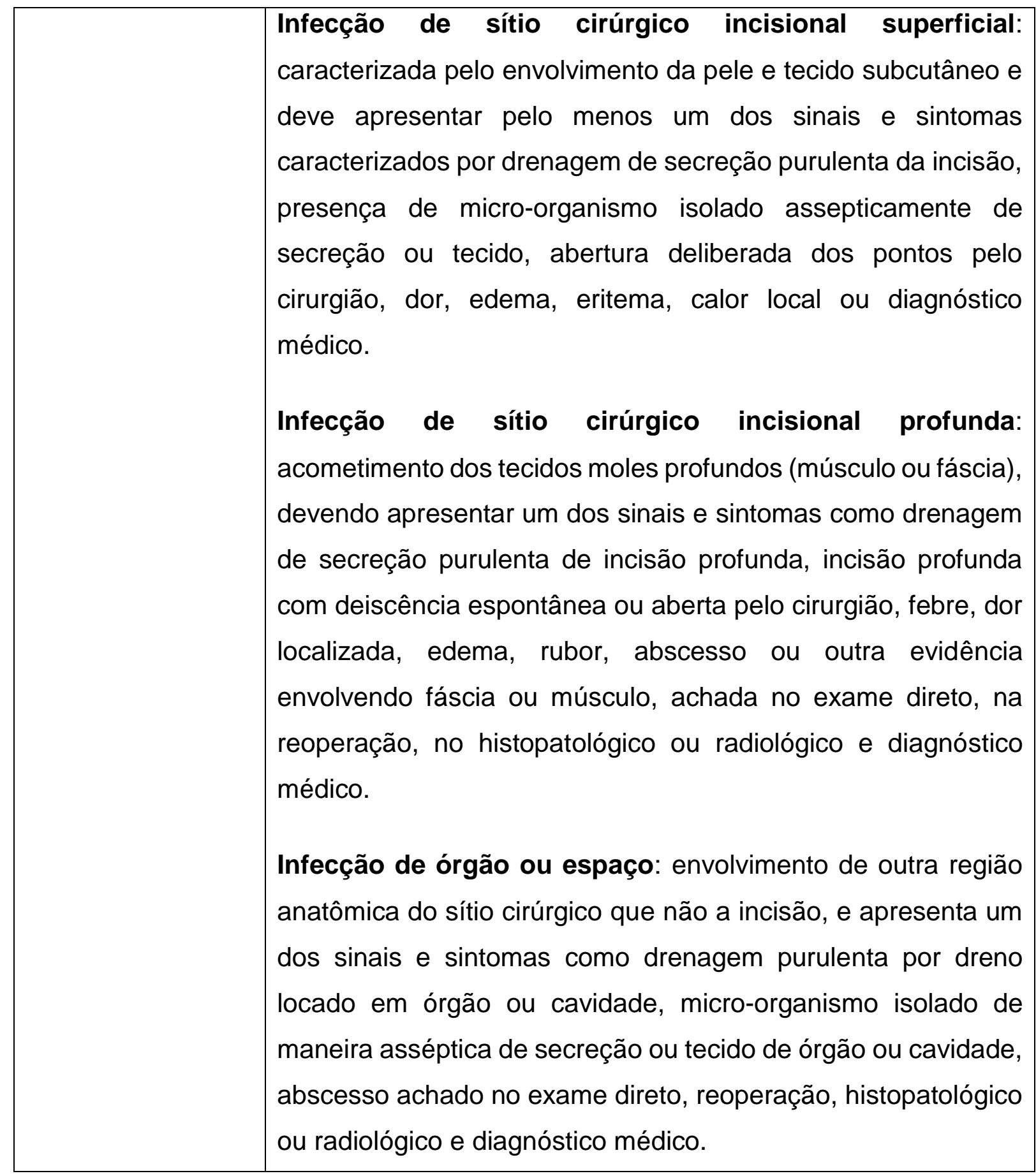

\subsection{PROCESSAMENTO E ANÁLISE DE DADOS}

Foi elaborado um banco de dados em Excel, a partir das informações contidas no instrumento de coleta, para a tabulação dos dados obtidos através do prontuário 
geral, prontuário Mãe Paulistana, ficha A do SIAB e programa Geo health da Universidade de São Paulo.

Os dados gerais de caracterização do perfil das mulheres em relação as suas condições de vida, de saúde e perfil sociodemográfico durante a gestação, parto e puerpério foram analisados por meio de estatística descritiva e inferencial, de frequência simples dos resultados.

Quanto à análise que trata da vulnerabilidade à infecção de sítio cirúrgico de mulheres submetidas ao parto cesáreo, os resultados foram analisados considerando dois grupos de prontuários: aqueles que continham informações de diagnóstico médico de infecção de sítio cirúrgico e condições em que havia pelo menos uma condição sugestiva de sinais e sintomas de infecção de sítio cirúrgico e outro grupo onde a informação não indicava qualquer uma das situações anteriores. Nesta análise, foram suprimidos os dados sem informação.

Os resultados foram apresentados na forma de tabelas de frequência relativa e absoluta entre os grupos. Utilizou-se o teste exato de Fisher para avaliar a distribuição dessas variáveis clínicas e sociodemográficas conforme diferentes grupos. Especificamente para Idade, Peso e Altura os resultados foram apresentados por medidas de posição (média, mínimo, máximo) e escala (desvio padrão e intervalo interquartil) e suas médias entre os Grupos foram comparadas segundo teste tstudent. (Bussab e Morettin, 2006).

No relatório incluíram-se as estimativas das razões de chance para as variáveis categóricas, considerando o primeiro nível de cada fator como referência. Como o tamanho amostral é pequeno, s alguns resultados apresentaram-se como "zeros", dificultando estimativas pontuais para essas estimativas, assim, para o cálculo das razões de chance e seus respectivos intervalos de confiança de 95\% utilizou-se um método de estimação iterativo mais robusto (Firth, 1992), utilizando o pacote do do $R$ brglm (Kosmidis, 2013). Ainda assim, algumas estatísticas não foram possíveis de serem calculadas.

As análises foram realizadas com auxílio do software R 3.2.1 (R Core Team, 2015). E os testes foram interpretados utilizando nível de significância de 5\%. 


\subsection{CONSIDERAÇÕES ÉTICAS}

A coleta de dados foi precedida pelo contato com as mulheres selecionadas para que fossem orientadas sobre a pesquisa e fosse obtido o Termo de Consentimento Livre e Esclarecido (TCLE) para manuseio do prontuário geral, prontuário Mãe Paulistana e Ficha A do SIAB. Foram realizadas visitas domiciliares em cooperação com os agentes comunitários de saúde de cada microárea das unidades de estudo, de acordo com o local de moradia da mulher que teve o parto cesáreo em 2014, para convite para participação na pesquisa.

A partir da obtenção do TCLE, foram agendados com a UBS dias predeterminados para a coleta de dados em instrumento próprio a partir do manuseio dos prontuários previamente autorizados.

O projeto foi aprovado pelo Comitê de Ética em Pesquisa da Escola de Enfermagem da Universidade de São Paulo (USP) (protocolo no.39140214.8.0000.5392) e pelo Comitê de Ética em Pesquisa da Secretaria Municipal da Saúde de São Paulo (protocolo no.39140214.8.3001.0086). 

4 RESULTADOS 



\section{RESULTADOS}

\subsection{PERFIL DE CONDIÇÃO DE VIDA E SOCIODEMOGRÁFICO DAS MULHERES QUE TIVERAM PARTO CESÁREO}

Foram investigados 89 prontuários de mulheres que aceitaram participar do estudo. Chama a atenção o percentual de $69,66 \%$ dos prontuários onde não havia dados de variáveis de condições de vida e da presença ou não de sinais de infecção (Tabela1).

Em 27 prontuários, foi possível identificar a presença (11 mulheres) ou a ausência (16 mulheres) de, pelo menos, um dos sinais e sintomas caracterizados como infecção de sítio cirúrgico. No primeiro grupo, as 11 mulheres que tiveram sinais e sintomas sugestivos de infecção de sítio cirúrgico incisional, seis tiveram diagnóstico médico.

Destaca-se o conjunto das características das 27 mulheres em relação aos dados de condição de vida, ao perfil sociodemográfico, histórico de saúde e da última gestação e puerpério.

A maioria das mulheres morava em domicílio construído com tijolo, em casas de três a quatro cômodos, acomodando de três a cinco pessoas por domicílio; maioria destas com eletricidade, residências abastecidas de água e com acesso à rede de esgoto. São pouco informadas a condição de destino do lixo e a renda familiar (Tabela 1).

$\mathrm{Na}$ Tabela 2, excluindo os dados sem informação e analisando a correlação entre as mulheres que tiveram ou não sinais e sintomas de infecção de sítio cirúrgico, dentre os 24 prontuários que continham a informação de tipo de construção, 23 referiram ser casa de tijolos, e somente uma casa de madeira era a residência de uma mulher que apresentou sinais sugestivos de infecção de sítio cirúrgico pós-parto cesáreo.

Quanto ao número de cômodos por domicílio, a média foi de 4,2 cômodos, sendo 2,1 cômodos nos domicílios de mulheres que apresentaram sinais de infecção 
e 3,4 cômodos nos domicílios de mulheres que não tiveram sinais de infecção. Ainda que houvesse diferença da média de número de cômodos nos dois grupos, esta não foi significativa estatisticamente após a aplicação do teste exato de Fischer (p.= 0,103), ao nível de significância de 5\%.

Tabela 1 - Número e proporção das mulheres que tiveram parto cesáreo, segundo condições de vida, Município de São Paulo, 2014.

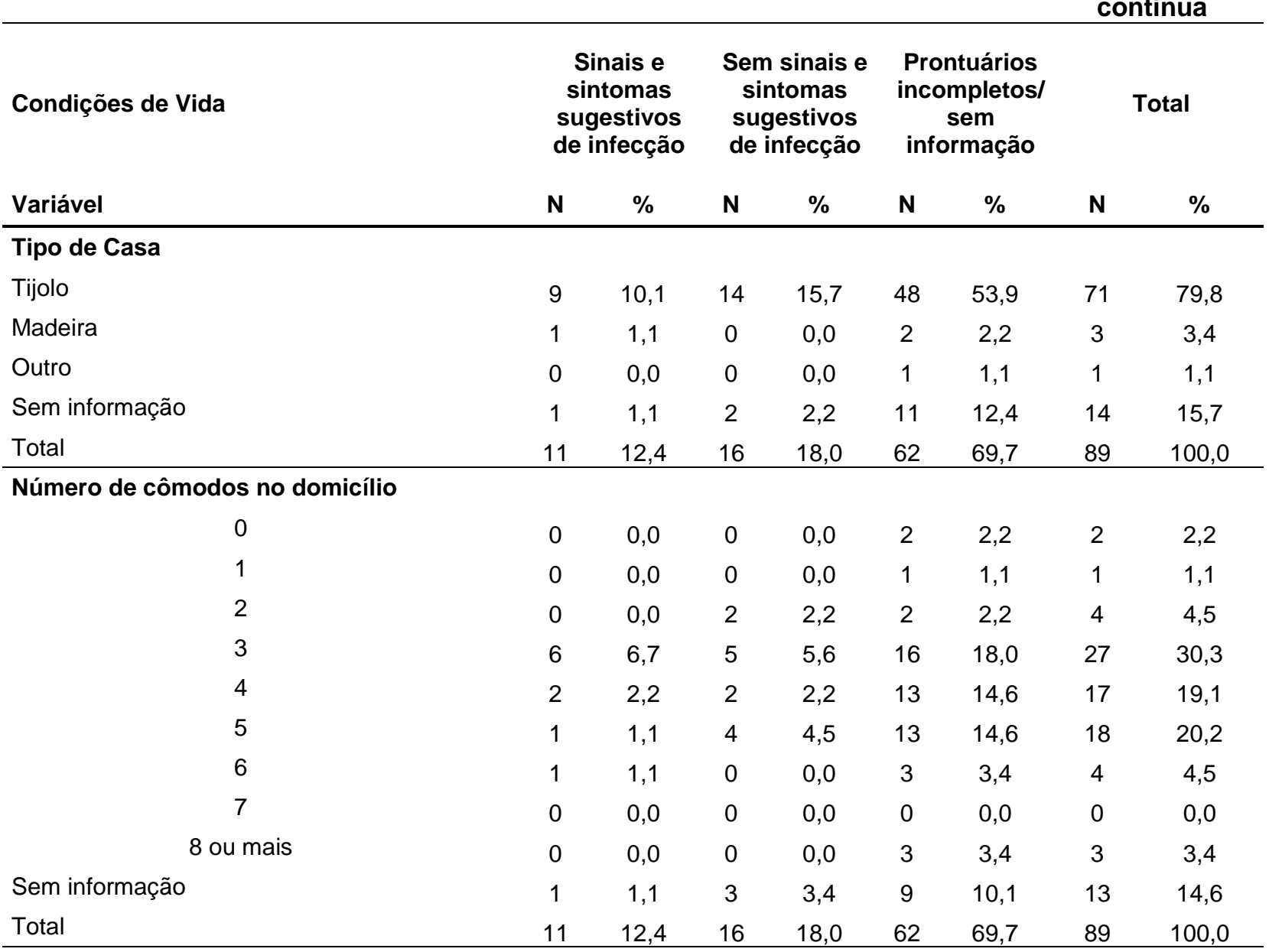

Número de pessoas no domicílio

2
3
4
5
6
7

8 ou mais

Sem informação

Total

$\begin{array}{cccccccc}0 & 0,0 & 0 & 0,0 & 2 & 2,2 & 2 & 2,2 \\ 3 & 3,4 & 2 & 2,2 & 15 & 16,9 & 20 & 22,5 \\ 1 & 1,1 & 6 & 6,7 & 14 & 15,7 & 21 & 23,6 \\ 0 & 0,0 & 3 & 3,4 & 9 & 10,1 & 12 & 13,5 \\ 2 & 2,2 & 1 & 1,1 & 6 & 6,7 & 9 & 10,1 \\ 2 & 2,2 & 0 & 0,0 & 1 & 1,1 & 3 & 3,4 \\ 2 & 2,2 & 1 & 1,1 & 5 & 5,6 & 8 & 9,0 \\ 1 & 1,1 & 3 & 3,4 & 10 & 11,2 & 14 & 15,7 \\ 11 & 12,4 & 16 & 18,0 & 62 & 69,7 & 89 & 100,0\end{array}$


continuação

\begin{tabular}{|c|c|c|c|c|c|c|c|c|}
\hline \multirow{2}{*}{$\begin{array}{l}\text { Condições de Vida } \\
\text { Variável }\end{array}$} & \multicolumn{2}{|c|}{$\begin{array}{c}\text { Sinais e } \\
\text { sintomas } \\
\text { sugestivos } \\
\text { de infecção }\end{array}$} & \multicolumn{2}{|c|}{$\begin{array}{c}\text { Sem sinais e } \\
\text { sintomas } \\
\text { sugestivos } \\
\text { de infecção }\end{array}$} & \multicolumn{2}{|c|}{$\begin{array}{c}\text { Prontuários } \\
\text { incompletos/ } \\
\text { sem } \\
\text { informação }\end{array}$} & \multicolumn{2}{|c|}{ Total } \\
\hline & $\mathbf{N}$ & $\%$ & $\mathbf{N}$ & $\%$ & $\mathbf{N}$ & $\%$ & $\mathbf{N}$ & $\%$ \\
\hline \multicolumn{9}{|l|}{ Energia elétrica } \\
\hline Sim & 10 & 11,2 & 14 & 15,7 & 54 & 60,7 & 78 & 87,6 \\
\hline Não & 0 & 0,0 & 0 & 0,0 & 0 & 0,0 & 0 & 0,0 \\
\hline Sem informação & 1 & 1,1 & 2 & 2,2 & 8 & 9,0 & 11 & 12,4 \\
\hline Total & 11 & 12,4 & 16 & 18,0 & 62 & 69,7 & 89 & 100,0 \\
\hline \multicolumn{9}{|l|}{ Destino do lixo } \\
\hline Céu aberto & 0 & 0,0 & 0 & 0,0 & 4 & 4,5 & 4 & 4,5 \\
\hline Coletado & 0 & 0,0 & 3 & 3,4 & 9 & 10,1 & 12 & 13,5 \\
\hline Sem informação & 11 & 12,4 & 13 & 14,6 & 49 & 55,1 & 73 & 82,0 \\
\hline Total & 11 & 12,4 & 16 & 18,0 & 62 & 69,7 & 89 & 100,0 \\
\hline \multicolumn{9}{|c|}{ Destino fezes/ urina (esgoto) } \\
\hline Céu aberto & 2 & 2,2 & 1 & 1,1 & 8 & 9,0 & 11 & 12,4 \\
\hline Rede de esgoto & 8 & 9,0 & 13 & 14,6 & 43 & 48,3 & 64 & 71,9 \\
\hline Sem informação & 1 & 1,1 & 2 & 2,2 & 11 & 12,4 & 14 & 15,7 \\
\hline Total & 11 & 12,4 & 16 & 18,0 & 62 & 69,7 & 89 & 100,0 \\
\hline \multicolumn{9}{|c|}{ Abastecimento de água } \\
\hline Rede geral & 10 & 11,2 & 14 & 15,7 & 54 & 60,7 & 78 & 87,6 \\
\hline Sem informação & 1 & 1,1 & 2 & 2,2 & 8 & 9,0 & 11 & 12,4 \\
\hline Total & 11 & 12,4 & 16 & 18,0 & 62 & 69,7 & 89 & 100,0 \\
\hline Renda familiar* & & & & & & & & 0,0 \\
\hline Até 1 salário mínimo & 0 & 0,0 & 1 & 1,1 & 2 & 2,2 & 3 & 3,4 \\
\hline de 1 a 3 salários & 3 & 3,4 & 8 & 9,0 & 25 & 28,1 & 36 & 40,4 \\
\hline acima de 3 salários & 0 & 0,0 & 1 & 1,1 & 2 & 2,2 & 3 & 3,4 \\
\hline Sem informação & 8 & 9,0 & 6 & 6,7 & 33 & 37,1 & 47 & 52,8 \\
\hline Total & 11 & 12,4 & 16 & 18,0 & 62 & 69,7 & 89 & 100,0 \\
\hline
\end{tabular}


Tabela 2 - Número, proporção, razão de chances e valor de $p$ de mulheres que apresentaram ou não sinais e sintomas de infecção de sítio cirúrgico pós-parto cesáreo, segundo condições de vida, Município de São Paulo, 2014.

\begin{tabular}{|c|c|c|c|c|c|}
\hline Variável & fator & $\begin{array}{c}\text { Sem } \\
\text { sinais }(n=16)\end{array}$ & $\begin{array}{c}\text { Sinais } \\
\text { sugestivos } \\
(n=11)\end{array}$ & $\begin{array}{l}\text { Razão de } \\
\text { chances } \\
\text { (IC de 95\%) }\end{array}$ & $\begin{array}{c}\text { valor } \\
\mathbf{p}^{1}\end{array}$ \\
\hline \multirow{2}{*}{ Tipo de Casa } & Madeira & 0/14 (0\%) & $1 / 10(10 \%)$ & - & 0,417 \\
\hline & Tijolo & $14 / 14(100 \%)$ & $9 / 10(90 \%)$ & - & \\
\hline \multirow{5}{*}{$\begin{array}{l}\text { Número de } \\
\text { Cômodos }\end{array}$} & 2 & $2 / 13$ (15,4\%) & $0 / 10(0 \%)$ & - & 0,453 \\
\hline & 3 & $5 / 13(38,5 \%)$ & $6 / 10(60 \%)$ & 0,37 [5,90; Inf] & \\
\hline & 4 & $2 / 13(15,4 \%)$ & $2 / 10(20 \%)$ & $0,22[5 ; \operatorname{lnf}]$ & \\
\hline & 5 & $4 / 13(30,8 \%)$ & $1 / 10(10 \%)$ & $0,05[1,66 ; \operatorname{lnf}]$ & \\
\hline & 6 & $0 / 13(0 \%)$ & $1 / 10(10 \%)$ & $0,31[15 ; \operatorname{lnf}]$ & \\
\hline \multirow{6}{*}{$\begin{array}{l}\text { Número de } \\
\text { Pessoas no } \\
\text { domicilio }\end{array}$} & 3 & $2 / 13(15,4 \%)$ & $3 / 10(30 \%)$ & - & 0,103 \\
\hline & 4 & $6 / 13(46,2 \%)$ & $1 / 10(10 \%)$ & $0,00[0,16 ; 1,60]$ & \\
\hline & 5 & $3 / 13(23,1 \%)$ & $0 / 10(0 \%)$ & $0[0,10 ; 1,83]$ & \\
\hline & 6 & $1 / 13(7,7 \%)$ & $2 / 10(20 \%)$ & $0,06[1,19 ; 41,6]$ & \\
\hline & 7 & $0 / 13(0 \%)$ & $2 / 10(20 \%)$ & $0,16[3,57 ; \operatorname{lnf}]$ & \\
\hline & 8 ou mais & $1 / 13(7,7 \%)$ & $2 / 10(20 \%)$ & $0,06[1,19 ; 41,6]$ & \\
\hline \multirow{2}{*}{$\begin{array}{c}\text { Destino fezes e } \\
\text { urina }\end{array}$} & Céu aberto & $1 / 14(7,1 \%)$ & $2 / 10(20 \%)$ & - & 0,55 \\
\hline & Rede de esgoto & $13 / 14(92,9 \%)$ & $8 / 10(80 \%)$ & $0,01[0,37 ; 3,72]$ & \\
\hline \multirow{3}{*}{ Renda familiar } & $\begin{array}{l}\text { Acima de } 3 \text { salários } \\
\text { mínimos }\end{array}$ & $1 / 10(10 \%)$ & $0 / 3(0 \%)$ & - & 0,999 \\
\hline & Até 1 salário mínimo & $1 / 10(10 \%)$ & $0 / 3(0 \%)$ & $0[0,99 ; \operatorname{lnf}]$ & \\
\hline & $\begin{array}{l}\text { De } 1 \text { a } 3 \text { salários } \\
\text { mínimos }\end{array}$ & $8 / 10(80 \%)$ & $3 / 3(100 \%)$ & $0,05[1,23 ; \operatorname{Inf}]$ & \\
\hline
\end{tabular}

(1) Teste exato de Fisher

O perfil sociodemográfico das 27 mulheres submetidas ao parto cesáreo, da mesma maneira que o perfil de condições de vida dos dados nos prontuários ou na Ficha A do SIAB, contém dados muito mal informados. (Tabela 3). A faixa etária predominante foi entre 15 e 30 anos, tiveram de quatro a 11 anos de estudo, com maior número na cor parda/negra, seguida da branca, nascidas em São Paulo e Minas Gerais, seguida de Estados do Nordeste. Trabalhavam 49 mulheres, maioria registrada como estado civil solteira ou casada, estando em convívio com um companheiro, com ou sem filhos (Tabela 3).

Correlacionando os grupos de mulheres que tiveram ou não sinais e sintomas sugestivos de infecção pós-parto cesáreo com as características sociodemográficas (Tabela 4), conclui-se que, mesmo apresentando diferenças numérica e proporcional entre os dois grupos, as variáveis escolaridade, local de nascimento, trabalho, ocupação, estado civil e pessoas com quem reside, não foram estatisticamente 
significantes, ao nível de significância de 5\%, portanto, não se pode inferir que as mulheres com sinais de infecção tenham menor escolaridade, não trabalham, nasceram em regiões menos favorecidas economicamente, são solteiras ou vivem só.

Já a variável raça/cor, as mulheres pardas e negras foram as mais frequentes do grupo que apresentaram sinais sugestivos de infecção, apresentando diferença estatística significativa (p. $=0,038)$.

Tabela 3 - Número e proporção de mulheres que tiveram parto cesáreo, segundo características sociodemográficas, Município de São Paulo, 2014.

continua

\begin{tabular}{|c|c|c|c|c|c|c|c|c|}
\hline \multirow{2}{*}{$\begin{array}{l}\text { Características sociodemográficas } \\
\text { Variável }\end{array}$} & \multicolumn{2}{|c|}{$\begin{array}{c}\text { Sinais e } \\
\text { sintomas } \\
\text { sugestivos } \\
\text { de } \\
\text { infecção }\end{array}$} & \multicolumn{2}{|c|}{$\begin{array}{l}\text { Sem sinais } \\
\text { e sintomas } \\
\text { sugestivos } \\
\text { de } \\
\text { infecção }\end{array}$} & \multicolumn{2}{|c|}{$\begin{array}{l}\text { Prontuários } \\
\text { incompletos/ } \\
\text { sem } \\
\text { informação }\end{array}$} & \multicolumn{2}{|c|}{ Total } \\
\hline & $\mathbf{N}$ & $\%$ & $\mathbf{N}$ & $\%$ & $\mathbf{N}$ & $\%$ & $\mathbf{N}$ & $\%$ \\
\hline \multicolumn{9}{|l|}{ Faixa etária } \\
\hline $15-20$ & 3 & 3,4 & 3 & 3,37 & 11 & 12,4 & 17 & 19,1 \\
\hline $20-25$ & 4 & 4,5 & 2 & 2,25 & 11 & 12,4 & 17 & 19,1 \\
\hline $25-30$ & 2 & 2,2 & 3 & 3,37 & 14 & 15,7 & 19 & 21,3 \\
\hline $30-35$ & 1 & 1,1 & 5 & 5,62 & 14 & 15,7 & 20 & 22,5 \\
\hline $35-40$ & 1 & 1,1 & 2 & 2,25 & 10 & 11,2 & 13 & 14,6 \\
\hline Maior que 40 anos & 0 & 0,0 & 1 & 1,12 & 2 & 2,2 & 3 & 3,4 \\
\hline Total & 11 & 12,4 & 16 & 17,98 & 62 & 69,7 & 89 & 100,0 \\
\hline \multicolumn{9}{|l|}{ Escolaridade em anos de estudos } \\
\hline 1 a 3 anos & 0 & 0,0 & 0 & 0,00 & 0 & 0,0 & 0 & 0,0 \\
\hline 4 a 7 anos & 3 & 3,4 & 6 & 6,74 & 9 & 10,1 & 18 & 20,2 \\
\hline 8 a 11 anos & 8 & 9,0 & 9 & 10,11 & 42 & 47,2 & 59 & 66,3 \\
\hline 12 ou mais anos & 0 & 0,0 & 1 & 1,12 & 8 & 9,0 & 9 & 10,1 \\
\hline Sem informação & 0 & 0,0 & 0 & 0,00 & 3 & 3,4 & 3 & 3,4 \\
\hline Total & 11 & 12,4 & 16 & 17,98 & 62 & 69,7 & 89 & 100,0 \\
\hline \multicolumn{9}{|l|}{ Raça/ cor (autorreferida) } \\
\hline Branca & 3 & 3,4 & 5 & 5,62 & 22 & 24,7 & 30 & 33,7 \\
\hline Negra & 4 & 4,5 & 1 & 1,12 & 12 & 13,5 & 17 & 19,1 \\
\hline Parda & 2 & 2,2 & 9 & 10,11 & 21 & 23,6 & 32 & 36,0 \\
\hline Amarela & 2 & 2,2 & 0 & 0,00 & 1 & 1,1 & 3 & 3,4 \\
\hline Indígena & 0 & 0,0 & 0 & 0,00 & 0 & 0,0 & 0 & 0,0 \\
\hline Sem informação & 0 & 0,0 & 1 & 1,12 & 6 & 6,7 & 7 & 7,9 \\
\hline Total & 11 & 12,4 & 16 & 17,98 & 62 & 69,7 & 89 & 100,0 \\
\hline \multicolumn{9}{|l|}{ Local de Nascimento- Estado } \\
\hline Alagoas & 0 & 0,0 & 0 & 0,00 & 4 & 4,5 & 4 & 4,5 \\
\hline Bahia & 1 & 1,1 & 2 & 2,25 & 7 & 7,9 & 10 & 11,2 \\
\hline Paraíba & 0 & 0,0 & 1 & 1,12 & 2 & 2,2 & 3 & 3,4 \\
\hline Pernambuco & 1 & 1,1 & 0 & 0,00 & 3 & 3,4 & 4 & 4,5 \\
\hline
\end{tabular}


continuação

\begin{tabular}{|c|c|c|c|c|c|c|c|c|}
\hline \multirow{2}{*}{$\begin{array}{l}\text { Características sociodemográficas } \\
\text { Variável }\end{array}$} & \multicolumn{2}{|c|}{$\begin{array}{c}\text { Sinais e } \\
\text { sintomas } \\
\text { sugestivo } \\
\text { s de } \\
\text { infecção }\end{array}$} & \multicolumn{2}{|c|}{$\begin{array}{c}\text { Sem } \\
\text { sinais e } \\
\text { sintomas } \\
\text { sugestivo } \\
\text { s de } \\
\text { infecção }\end{array}$} & \multicolumn{2}{|c|}{$\begin{array}{c}\text { Prontuários } \\
\text { incompletos } \\
\text { / Sem } \\
\text { informação }\end{array}$} & \multicolumn{2}{|c|}{ Total } \\
\hline & $\mathbf{N}$ & $\%$ & $\mathbf{N}$ & $\%$ & $\mathbf{N}$ & $\%$ & $\mathbf{N}$ & $\%$ \\
\hline Piauí & 0 & 0,0 & 0 & 0,00 & 1 & 1,1 & 1 & 1,1 \\
\hline Rio Grande do Norte & 0 & 0,0 & 0 & 0,00 & 2 & 2,2 & 2 & 2,2 \\
\hline Sergipe & 0 & 0,0 & 1 & 1,12 & 17 & 19,1 & $\begin{array}{l}1 \\
8\end{array}$ & 20,2 \\
\hline São Paulo & 2 & 2,2 & 4 & 4,49 & 0 & 0,0 & 6 & 6,7 \\
\hline Minas Gerais & 1 & 1,1 & 1 & 1,12 & 1 & 1,1 & 3 & 3,4 \\
\hline Sem informação & 6 & 6,7 & 7 & 7,87 & 25 & 28,1 & $\begin{array}{l}3 \\
8\end{array}$ & 42,7 \\
\hline Total & 11 & 12,4 & 16 & 17,98 & 43 & 48,3 & $\begin{array}{l}6 \\
5\end{array}$ & 73,0 \\
\hline \multicolumn{9}{|l|}{ Trabalha fora } \\
\hline Sim & 5 & 5,6 & 9 & 10,11 & 35 & 39,3 & $\begin{array}{l}4 \\
9\end{array}$ & 55,1 \\
\hline Não & 6 & 6,7 & 6 & 6,74 & 27 & 30,3 & $\begin{array}{l}3 \\
9\end{array}$ & 43,8 \\
\hline Sem informação & 0 & 0,0 & 1 & 1,12 & 0 & 0,0 & 1 & 1,1 \\
\hline Total & 11 & 12,4 & 16 & 17,98 & 62 & 69,7 & $\begin{array}{l}8 \\
9\end{array}$ & $\begin{array}{c}100 \\
0\end{array}$ \\
\hline \multicolumn{9}{|l|}{ Estado civil } \\
\hline Casada & 4 & 4,5 & 6 & 6,74 & 27 & 30,3 & $\begin{array}{l}3 \\
7\end{array}$ & 41,6 \\
\hline Separada/ divorciada & 0 & 0,0 & 0 & 0,00 & 1 & 1,1 & 1 & 1,1 \\
\hline Solteira & 5 & 5,6 & 5 & 5,62 & 22 & 24,7 & $\begin{array}{l}3 \\
2\end{array}$ & 36,0 \\
\hline União estável & 2 & 2,2 & 3 & 3,37 & 12 & 13,5 & $\begin{array}{l}1 \\
7\end{array}$ & 19,1 \\
\hline Sem informação & 0 & 0,0 & 2 & 2,25 & 0 & 0,0 & $\begin{array}{l}2 \\
8\end{array}$ & $\begin{array}{r}2,2 \\
100\end{array}$ \\
\hline Total & 11 & 12,4 & 16 & 17,98 & 62 & 69,7 & $\begin{array}{l}8 \\
9\end{array}$ & 0 \\
\hline \multicolumn{9}{|l|}{ Pessoas com quem reside } \\
\hline $\begin{array}{l}\text { Companheiro com laços conjugais sem } \\
\text { filhos }\end{array}$ & 3 & 3,4 & 5 & 5,62 & 21 & 23,6 & $\begin{array}{l}2 \\
9\end{array}$ & 32,6 \\
\hline Companheiro e filhos & 3 & 3,4 & 6 & 6,74 & 23 & 25,8 & $\begin{array}{l}3 \\
2\end{array}$ & 36,0 \\
\hline Companheiro com filhos e familiares & 0 & 0,0 & 0 & 0,00 & 2 & 2,2 & 2 & 2,2 \\
\hline Familiares sem companheiro & 3 & 3,4 & 3 & 3,37 & 11 & 12,4 & $\begin{array}{l}1 \\
7\end{array}$ & 19,1 \\
\hline Só & 1 & 1,1 & 0 & 0,00 & 0 & 0,0 & 1 & 1,1 \\
\hline Sem informação & 1 & 1,1 & 2 & 2,25 & 5 & 5,6 & 8 & 9,0 \\
\hline Total & 11 & 12,4 & 16 & 17,98 & 62 & 69,7 & $\begin{array}{l}8 \\
9 \\
\end{array}$ & $\begin{array}{c}100 \\
0\end{array}$ \\
\hline
\end{tabular}

Fonte: Prontuário Mãe Paulistana 
Tabela 2 - Número, proporção, razões de chance e valor de $p$, de mulheres que apresentaram ou não sinais e sintomas sugestivos de infecção de sítio cirúrgico pós-parto cesáreo, segundo características sociodemográficas, Município de São Paulo, 2014.

\begin{tabular}{|c|c|c|c|c|c|}
\hline Variável & fator & $\begin{array}{c}\text { Sem } \\
\text { sinais }(n=16)\end{array}$ & $\begin{array}{c}\text { Sinais } \\
\text { sugestivos } \\
(n=11)\end{array}$ & $\begin{array}{c}\text { Razão de } \\
\text { chances (IC de } \\
95 \%)\end{array}$ & $\begin{array}{l}\text { valor } \\
\mathbf{p}^{1}\end{array}$ \\
\hline \multirow{2}{*}{ Escolaridade } & 4 a 7 anos & $6 / 15(40 \%)$ & $3 / 11(27,3 \%)$ & & 0,683 \\
\hline & 8 a 11 anos & $9 / 15(60 \%)$ & $8 / 11(72,7 \%)$ & $0,34[1,66 ; 10,7]$ & \\
\hline \multirow{4}{*}{$\begin{array}{l}\text { Raça cor } \\
\text { informada }\end{array}$} & Amarela & $0 / 15(0 \%)$ & $2 / 11(18,2 \%)$ & & 0,038 \\
\hline & Branca & $5 / 15(33,3 \%)$ & $3 / 11(27,3 \%)$ & $0[0,12 ; 2,20]$ & \\
\hline & Negra & $1 / 15(6,7 \%)$ & $4 / 11(36,4 \%)$ & $0[0,59 ; 18,1]$ & \\
\hline & Parda & $9 / 15(60 \%)$ & $2 / 11(18,2 \%)$ & $0[0,05 ; 0,91]$ & \\
\hline \multirow{6}{*}{$\begin{array}{l}\text { Local do } \\
\text { Nascimento } \\
\text { Estado }\end{array}$} & Bahia & $2 / 9(22,2 \%)$ & $1 / 5(20 \%)$ & - & 0,999 \\
\hline & Minas Gerais & $1 / 9(11,1 \%)$ & $1 / 5(20 \%)$ & $0,04[1,66 ; 120]$, & \\
\hline & Paraíba & $1 / 9(11,1 \%)$ & $0 / 5(0 \%)$ & $0[0,55 ; 21,3]$ & \\
\hline & Pernambuco & $0 / 9(0 \%)$ & $1 / 5(20 \%)$ & $0,15[4,99 ; \operatorname{Inf}]$ & \\
\hline & São Paulo & $4 / 9(44,4 \%)$ & $2 / 5(40 \%)$ & $0,05[0,92 ; 29,7]$ & \\
\hline & Sergipe & $1 / 9(11,1 \%)$ & $0 / 5(0 \%)$ & $0[0,55 ; 21,3]$ & \\
\hline \multirow{2}{*}{ Trabalha } & Não & $6 / 15(40 \%)$ & $6 / 11(54,5 \%)$ & - & 0,692 \\
\hline & Sim & $9 / 15(60 \%)$ & $5 / 11(45,5 \%)$ & $0,10[0,57 ; 2,66]$ & \\
\hline \multirow{13}{*}{ Ocupação } & Não & $0 / 15(0 \%)$ & $1 / 10(10 \%)$ & - & 0,577 \\
\hline & auxiliar de dentista & $2 / 15(13,3 \%)$ & $0 / 10(0 \%)$ & $0[0,06 ; 3,20]$ & \\
\hline & auxiliar de limpeza & $0 / 15(0 \%)$ & $1 / 10(10 \%)$ & $0[1 ; \operatorname{lnf}]$ & \\
\hline & $\begin{array}{l}\text { auxiliar de serviços } \\
\text { gerais }\end{array}$ & $0 / 15(0 \%)$ & $1 / 10(10 \%)$ & $0[1 ; \operatorname{lnf}]$ & \\
\hline & auxiliar de vendas & $1 / 15(6,7 \%)$ & $0 / 10(0 \%)$ & $0[0,11 ; 6,77]$ & \\
\hline & balconista & $1 / 15(6,7 \%)$ & $0 / 10(0 \%)$ & $0[0,11 ; 6,77]$ & \\
\hline & buffet & $1 / 15(6,7 \%)$ & $0 / 10(0 \%)$ & $0[0,11 ; 6,77]$ & \\
\hline & comerciante & $0 / 15(0 \%)$ & $1 / 10(10 \%)$ & $0[1 ; \operatorname{lnf}]$ & \\
\hline & cozinheira & $1 / 15(6,7 \%)$ & $0 / 10(0 \%)$ & $0[0,11 ; 6,77]$ & \\
\hline & fiscal de caixa & $1 / 15(6,7 \%)$ & $0 / 10(0 \%)$ & $0[0,11 ; 6,77]$ & \\
\hline & líder de limpeza & $1 / 15(6,7 \%)$ & $0 / 10(0 \%)$ & $0[0,11 ; 6,77]$ & \\
\hline & Merendeira & $6 / 15(40 \%)$ & $6 / 10(60 \%)$ & $0[0,33 ; 7,41]$ & \\
\hline & vendedora & $1 / 15(6,7 \%)$ & $0 / 10(0 \%)$ & $0[0,11 ; 6,77]$ & \\
\hline \multirow{3}{*}{ Estado civil } & Casada & $6 / 14(42,9 \%)$ & $4 / 11(36,4 \%)$ & - & 0,999 \\
\hline & Solteira & $5 / 14(35,7 \%)$ & $5 / 11(45,5 \%)$ & $0,25[1,44 ; 9,34]$ & \\
\hline & $\begin{array}{l}\text { Solteira com união } \\
\text { estável }\end{array}$ & $3 / 14(21,4 \%)$ & $2 / 11(18,2 \%)$ & $0,09[1,03 ; 9,11]$ & \\
\hline \multirow{4}{*}{$\begin{array}{l}\text { Pessoas com } \\
\text { quem reside }\end{array}$} & $\begin{array}{l}\text { companheiro com } \\
\text { laços conjugais sem } \\
\text { filhos }\end{array}$ & $5 / 14(35,7 \%)$ & $3 / 10(30 \%)$ & - & 0,693 \\
\hline & Companheiro e filhos & $6 / 14$ (42,9\%) & $3 / 10(30 \%)$ & $0,10[0,84 ; 6,40]$ & \\
\hline & $\begin{array}{l}\text { Familiares sem } \\
\text { companheiro }\end{array}$ & $3 / 14(21,4 \%)$ & $3 / 10(30 \%)$ & $0,19[1,57 ; 15,6]$ & \\
\hline & Só & $0 / 14(0 \%)$ & $1 / 10(10 \%)$ & $0,07[4,71 ; \operatorname{Inf}]$ & \\
\hline
\end{tabular}

(1) Teste exato de Fisher 


\subsection{CONDIÇÕES DE SAÚDE, PARTO E PUERPÉRIO}

A Tabela 5 detalha as condições de saúde das mulheres que tiveram parto cesáreo. De acordo com o cálculo a partir do peso e altura do índice de massa corpórea (IMC), verificou-se que 39 mulheres tinham valor entre 18,50 e 24,99, ou seja, tem um peso ideal e 29 possuem sobrepeso ou algum grau de obesidade, quatro delas era do tipo mórbido. A maioria não tinha doenças de base como hipertensão, diabetes e outras.

Referente às doenças crônicas (Tabela 7), nenhuma mulher dos dois grupos relatou diabetes mellitus, duas tinham hipertensão arterial, sendo uma de cada grupo. Outras doenças referidas foram doença sexualmente transmissível, arritmia cardíaca, artrose, síndrome do pânico e hepatite B, que foram mais frequentes no grupo de mulheres que não tiveram sinais de infecção (3), do que nas que apresentaram (2). Nas variáveis tabagismo e etilismo, responderam afirmativamente em prontuário dentre os dois grupos de mulheres, $14,8 \%$ e 3,7\%. A ocorrência do uso de álcool e cigarro foi mais frequente no grupo de mulheres sem sinais de infecção.

O uso do tabaco esteve presente em quatro prontuários e em um prontuário fazia menção ao uso de álcool nos grupos de mulheres que apresentaram ou não sinais e sintomas sugestivos de infecção de sítio cirúrgico pós-parto cesáreo. Nenhuma mulher pertencente aos dois grupos referiu uso de drogas (Gráfico 1).

Dentre as variáveis selecionadas na Tabela 7, após a aplicação do teste exato de Fischer, com um nível de significância de 5\%, não houve diferenças estatísticas significativas entre os dois grupos.

Relativo ao peso e à altura (Tabela 6), a média das 25 mulheres que continham esta informação no prontuário Mãe Paulistana foi de 66.600 gramas e $158 \mathrm{~cm}$ respectivamente. As mulheres que apresentavam sinais sugestivos de infecção tinham em média 68.680 gramas e $159,46 \mathrm{~cm}$ de altura em contraponto àquelas que não apresentavam tais sinais, pesavam 64.960 gramas e mediam $156,86 \mathrm{~cm}$ de altura. 
Embora houvesse diferença de idade, peso e altura entre os dois grupos de mulheres estudados, não há evidência suficiente que aponte que as mulheres que tiveram sinais e sintomas sugestivos de infecção de sítio cirúrgico pós-parto cesáreo sejam mais ou menos jovens, altas ou pesadas, ao nível de significância de 5\%.

Tabela 3 - Número e proporção das mulheres que tiveram parto cesáreo, segundo condições de saúde, Município de São Paulo, 2014.

continua

\begin{tabular}{|c|c|c|c|c|c|c|c|c|}
\hline \multirow{2}{*}{$\begin{array}{l}\text { Condições de Saúde } \\
\text { Variável }\end{array}$} & \multicolumn{2}{|c|}{$\begin{array}{c}\text { Sinais e } \\
\text { sintomas } \\
\text { sugestivos } \\
\text { de infecção }\end{array}$} & \multicolumn{2}{|c|}{$\begin{array}{l}\text { Sem sinais } \\
\text { e sintomas } \\
\text { sugestivos } \\
\text { de infecção }\end{array}$} & \multicolumn{2}{|c|}{$\begin{array}{l}\text { Prontuários } \\
\text { incompletos/ } \\
\text { Sem } \\
\text { informação }\end{array}$} & \multicolumn{2}{|c|}{ Total } \\
\hline & $\mathbf{N}$ & $\%$ & $\mathbf{N}$ & $\%$ & $\mathbf{N}$ & $\%$ & $\mathbf{N}$ & $\%$ \\
\hline \multicolumn{9}{|l|}{ IMC } \\
\hline Abaixo de 17 & 0 & 0,0 & 1 & 1,1 & 0 & 0,0 & 1 & 1,1 \\
\hline Entre 17 e 18,,49 & 0 & 0,0 & 0 & 0,0 & 1 & 1,1 & 1 & 1,1 \\
\hline Entre 18,50 e 24,99 & 6 & 6,7 & 6 & 6,7 & 27 & 30,3 & 39 & 43,8 \\
\hline Entre 25 e 29,99 & 2 & 2,2 & 3 & 3,4 & 16 & 18,0 & 21 & 23,6 \\
\hline Entre 30 e 34,99 & 2 & 2,2 & 3 & 3,4 & 8 & 9,0 & 13 & 14,6 \\
\hline Entre 35 e 39,99 & 0 & 0,0 & 0 & 0,0 & 5 & 5,6 & 5 & 5,6 \\
\hline Maior que 40 & 1 & 1,1 & 1 & 1,1 & 2 & 2,2 & 4 & 4,5 \\
\hline Sem informação & 0 & 0,0 & 2 & 2,2 & 3 & 3,4 & 5 & 5,6 \\
\hline Total & 11 & 12,4 & 16 & 18,0 & 62 & 69,7 & 89 & 100,0 \\
\hline \multicolumn{9}{|l|}{ Hipertensão } \\
\hline Sim & 1 & 1,1 & 1 & 1,1 & 6 & 6,7 & 8 & 9,0 \\
\hline Não & 10 & 11,2 & 15 & 16,9 & 55 & 61,8 & 80 & 89,9 \\
\hline Sem informação & 0 & 0,0 & 0 & 0,0 & 1 & 1,1 & 1 & 1,1 \\
\hline Total & 11 & 12,4 & 16 & 18,0 & 62 & 69,7 & 89 & 100,0 \\
\hline \multicolumn{9}{|l|}{ Diabetes Mellitus } \\
\hline $\operatorname{Sim}$ & 0 & 0,0 & 0 & 0,0 & 1 & 1,1 & 1 & 1,1 \\
\hline Não & 11 & 12,4 & 16 & 18,0 & 60 & 67,4 & 87 & 97,8 \\
\hline Sem informação & 0 & 0,0 & 0 & 0,0 & 1 & 1,1 & 1 & 1,1 \\
\hline Total & 11 & 12,4 & 16 & 18,0 & 62 & 69,7 & 89 & 100,0 \\
\hline \multicolumn{9}{|l|}{ Outas doenças } \\
\hline Não & 10 & 11,2 & 13 & 14,6 & 57 & 64,0 & 80 & 89,9 \\
\hline Artrose & 0 & 0,0 & 1 & 1,1 & 0 & 0,0 & 1 & 1,1 \\
\hline Cardiopatia & 0 & 0,0 & 1 & 1,1 & 1 & 1,1 & 2 & 2,2 \\
\hline $\begin{array}{l}\text { Diabetes } \\
\text { gestacional }\end{array}$ & 0 & 0,0 & 0 & 0,0 & 1 & 1,1 & 1 & 1,1 \\
\hline DST & 0 & 0,0 & 1 & 1,1 & 0 & 0,0 & 1 & 1,1 \\
\hline Hepatite B + Síndrome do Pânico & 1 & 1,1 & 0 & 0,0 & 0 & 0,0 & 1 & 1,1 \\
\hline Hipertireoidismo & 0 & 0,0 & 0 & 0,0 & 1 & 1,1 & 1 & 1,1 \\
\hline Hipotireoidismo & 0 & 0,0 & 0 & 0,0 & 1 & 1,1 & 1 & 1,1 \\
\hline Sem informação & 0 & 0,0 & 0 & 0,0 & 1 & 1,1 & 1 & 1,1 \\
\hline Total & 11 & 12,4 & 16 & 18,0 & 62 & 69,7 & 89 & 100,0 \\
\hline
\end{tabular}


continuação

\begin{tabular}{|c|c|c|c|c|c|c|c|c|}
\hline \multirow{2}{*}{$\begin{array}{l}\text { Condições de Saúde } \\
\text { Variável }\end{array}$} & \multicolumn{2}{|c|}{$\begin{array}{c}\text { Sinais e } \\
\text { sintomas } \\
\text { sugestivos } \\
\text { de infecção }\end{array}$} & \multicolumn{2}{|c|}{$\begin{array}{l}\text { Sem sinais } \\
\text { e sintomas } \\
\text { sugestivos } \\
\text { de infecção }\end{array}$} & \multicolumn{2}{|c|}{$\begin{array}{c}\text { Prontuários } \\
\text { incompletos/ } \\
\text { sem } \\
\text { informação }\end{array}$} & \multicolumn{2}{|r|}{ Total } \\
\hline & $\mathbf{N}$ & $\%$ & $\mathbf{N}$ & $\%$ & $\mathbf{N}$ & $\%$ & $\mathbf{N}$ & $\%$ \\
\hline \multicolumn{9}{|l|}{ Tabagismo } \\
\hline Sim & 1 & 1,1 & \multicolumn{2}{|c|}{3,4} & \multicolumn{2}{|c|}{$6 \quad 6,7$} & 10 & 11,2 \\
\hline Não & 10 & 11,2 & 13 & 14,6 & \multicolumn{2}{|c|}{5561,8} & 78 & 87,6 \\
\hline Sem Informação & 0 & 0,0 & 0 & 0,0 & \multicolumn{2}{|c|}{$1 \quad 1,1$} & 1 & \multirow{2}{*}{$\begin{array}{l}1,1 \\
100,0\end{array}$} \\
\hline Total & 11 & 12,4 & 16 & 18,0 & \multicolumn{2}{|c|}{6269,7} & 89 & \\
\hline \multicolumn{9}{|l|}{ Etilismo } \\
\hline Sim & 1 & 1,1 & 1 & 1,1 & 4 & 4,5 & 6 & 6,7 \\
\hline Não & 0 & 0,0 & 15 & 16,9 & 57 & 64,0 & 72 & 80,9 \\
\hline Sem informação & 0 & 0,0 & 0 & 0,0 & 1 & 1,1 & 1 & 1,1 \\
\hline Total & 11 & 12,4 & 16 & 18,0 & 62 & 69,7 & 89 & 100,0 \\
\hline \multicolumn{9}{|l|}{ Drogas } \\
\hline Sim & 0 & 0,0 & 0 & 0,0 & 2 & 2,2 & 2 & 2,2 \\
\hline Não & 11 & 12,4 & 16 & 18,0 & 59 & 66,3 & 86 & 96,6 \\
\hline Sem informação & 0 & 0,0 & 0 & 0,0 & 1 & 1,1 & 1 & 1,1 \\
\hline Total & 11 & 12,4 & 16 & 18,0 & 62 & 69,7 & 89 & 100,0 \\
\hline
\end{tabular}

Fonte: Prontuário Mãe Paulistana conclusão

Gráfico 1 - Uso de tabaco, álcool e outras drogas por mulheres que apresentaram ou não sinais e sintomas sugestivos de infecção de sítio cirúrgico

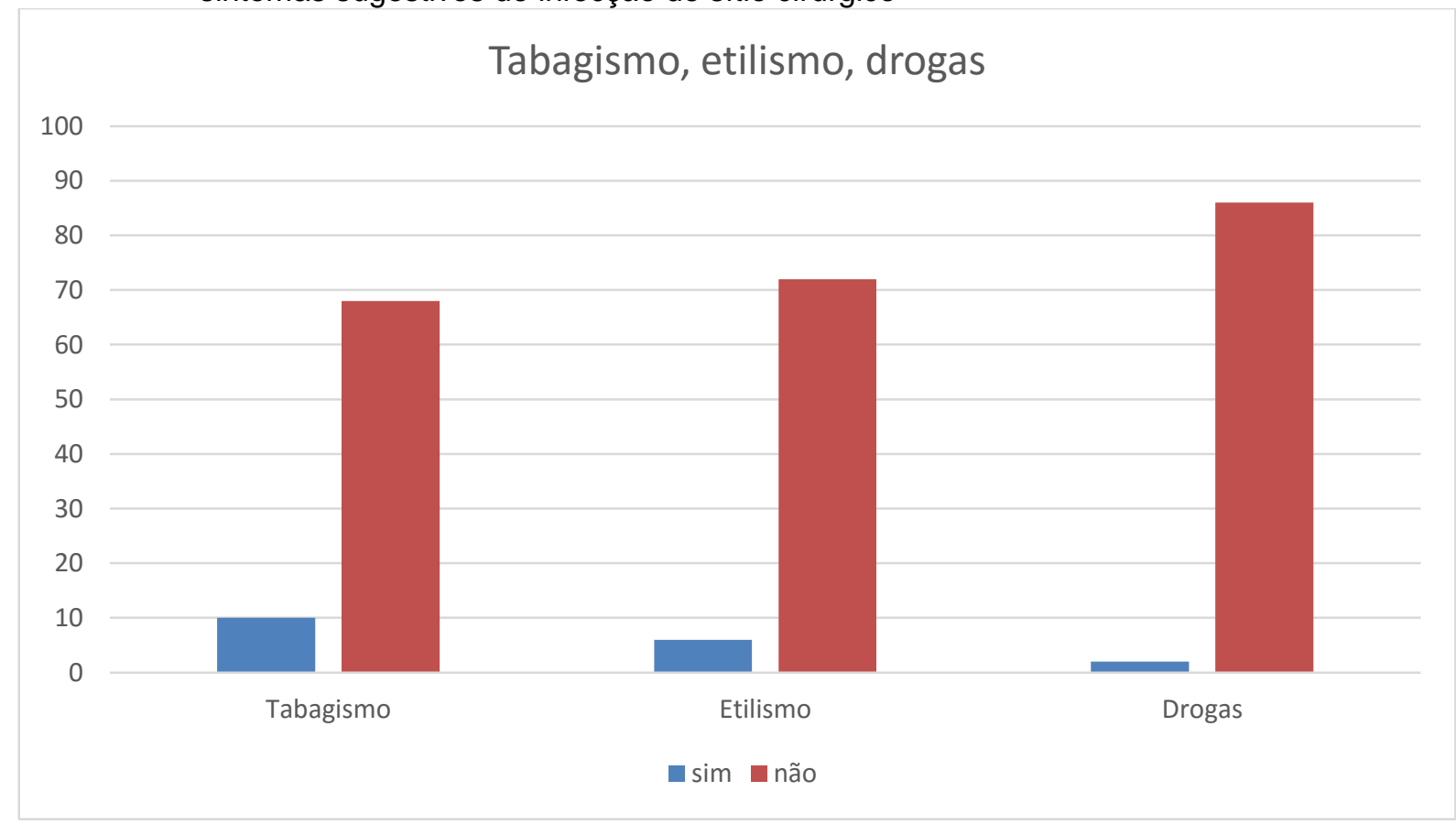


Tabela 4- Número, média, desvio-padrão, mediana, quartil e valor de $p$ de mulheres que apresentaram ou não sinais e sintomas sugestivos de infecção de sítio cirúrgico pós-parto cesáreo, segundo altura, peso e idade, Município de São Paulo, 2014.

\begin{tabular}{clccccccccc}
\hline Variável & \multicolumn{1}{c}{ Grupo } & N & Mínimo & Máximo & Média & $\begin{array}{c}\text { Desvio- } \\
\text { padrão }\end{array}$ & Mediana & $\begin{array}{c}1^{\circ} \\
\text { quartil }\end{array}$ & $\begin{array}{c}3^{\circ} \\
\text { quartil }\end{array}$ & $\begin{array}{c}\text { Valor } \\
\mathrm{p}^{1}\end{array}$ \\
\hline \multirow{3}{*}{ Altura } & Todos & $\mathbf{2 5 , 0}$ & $\mathbf{1 4 9 , 0}$ & $\mathbf{1 7 6 , 0}$ & $\mathbf{1 5 8 , 0}$ & $\mathbf{7 , 1}$ & $\mathbf{1 5 7 , 0}$ & $\mathbf{1 5 2 , 0}$ & $\mathbf{1 6 2 , 0}$ & \\
& Sem sinais & 14,0 & 149,0 & 167,0 & 156,9 & 6,1 & 155,0 & 152,0 & 161,5 & 0,396 \\
& Sinais sugestivos & 11,0 & 151,0 & 176,0 & 159,5 & 8,3 & 158,0 & 153,0 & 162,0 & \\
\hline \multirow{3}{*}{ Peso } & Todos & $\mathbf{2 5 , 0}$ & $\mathbf{4 5 , 0}$ & $\mathbf{1 0 5 , 0}$ & $\mathbf{6 6 , 6}$ & $\mathbf{1 6 , 9}$ & $\mathbf{6 2 , 0}$ & $\mathbf{5 6 , 0}$ & $\mathbf{7 2 , 0}$ & \\
& Sem sinais & 14,0 & 45,0 & 101,0 & 65,0 & 15,1 & 64,0 & 56,0 & 71,5 & 0,607 \\
& Sinais sugestivos & 11,0 & 51,0 & 105,0 & 68,7 & 19,5 & 62,0 & 56,0 & 76,5 & \\
\hline \multirow{2}{*}{ Idade } & Todos & $\mathbf{2 7 , 0}$ & $\mathbf{1 5 , 0}$ & $\mathbf{4 1 , 0}$ & $\mathbf{2 6 , 3}$ & $\mathbf{8 , 0}$ & $\mathbf{2 6 , 0}$ & $\mathbf{2 0 , 0}$ & $\mathbf{3 2 , 5}$ & \\
& Sem sinais & 16,0 & 16,0 & 41,0 & 28,1 & 8,3 & 29,5 & 22,0 & 33,0 & 0,142 \\
& Sinais sugestivos & 11,0 & 15,0 & 37,0 & 23,6 & 7,0 & 22,0 & 19,5 & 28,0 & \\
(1) Teste t-student & & & & & & & & & \\
\hline
\end{tabular}

Tabela 5 - Número, proporção, razão de chances e valor de $p$, de mulheres que apresentaram ou não sinais e sintomas sugestivos de infecção de sítio cirúrgico pós-parto cesáreo, segundo condições de saúde, Município de São Paulo, 2014.

\begin{tabular}{|c|c|c|c|c|c|}
\hline Variável & fator & $\begin{array}{c}\text { Sem } \\
\text { sinais }(n=16)\end{array}$ & $\begin{array}{c}\text { Sinais } \\
\text { sugestivos } \\
(n=11)\end{array}$ & $\begin{array}{l}\text { Razão de } \\
\text { chances } \\
\text { (IC de 95\%) }\end{array}$ & $\begin{array}{l}\text { valor } \\
\mathrm{p}^{1}\end{array}$ \\
\hline \multirow{5}{*}{ IMC } & Abaixo de 17 & $1 / 14(7,1 \%)$ & $0 / 11(0 \%)$ & - & \multirow[t]{5}{*}{0,999} \\
\hline & Entre 18,49 e 24,99 & $6 / 14$ (42,9\%) & $6 / 11(54,5 \%)$ & $0,04[3,00 ; \operatorname{Inf}]$ & \\
\hline & Entre 25 e 29,99 & $3 / 14(21,4 \%)$ & $2 / 11(18,2 \%)$ & $0,07[2,14 ; \operatorname{lnf}]$ & \\
\hline & Entre 30 e 34,99 & $3 / 14(21,4 \%)$ & $2 / 11(18,2 \%)$ & $0,07[2,14 ; \operatorname{Inf}]$ & \\
\hline & Maior que 40 & $1 / 14(7,1 \%)$ & $1 / 11(9,1 \%)$ & $0,03[3,00 ; \operatorname{Inf}]$ & \\
\hline \multirow{2}{*}{ Hipertensão } & Não & $15 / 16(93,8 \%)$ & $10 / 11(90,9 \%)$ & - & \multirow[t]{2}{*}{0,999} \\
\hline & Sim & $1 / 16(6,2 \%)$ & $1 / 11(9,1 \%)$ & $0,05[1,47 ; 40,9]$ & \\
\hline \multirow{2}{*}{ Diabetes Melitus } & Não & $16 / 16(100 \%)$ & $11 / 11(100 \%)$ & - & \multirow[t]{2}{*}{ - } \\
\hline & Sim & $0 / 16(0 \%)$ & $0 / 11(0 \%)$ & - & \\
\hline \multirow{2}{*}{ Tabagista } & Não & $13 / 16(81,2 \%)$ & $10 / 11(90,9 \%)$ & - & \multirow[t]{2}{*}{0,624} \\
\hline & Sim & $3 / 16(18,8 \%)$ & $1 / 11(9,1 \%)$ & $0,01[0,55 ; 3,99]$ & \\
\hline \multirow{2}{*}{ Alcoolista } & Não & $15 / 16(93,8 \%)$ & $11 / 11(100 \%)$ & - & \multirow[t]{2}{*}{0,999} \\
\hline & Sim & $1 / 16(6,2 \%)$ & $0 / 11(0 \%)$ & - & \\
\hline \multirow{2}{*}{ Drogadito } & Não & $16 / 16(100 \%)$ & $11 / 11(100 \%)$ & - & \\
\hline & Sim & $0 / 16(0 \%)$ & $0 / 11(0 \%)$ & - & \\
\hline \multirow{6}{*}{ Outra } & Não & $13 / 16(81,2 \%)$ & $10 / 11(90,9 \%)$ & $0,11[2,33 ; \operatorname{Inf}]$ & \multirow[t]{6}{*}{0,896} \\
\hline & DST & $1 / 16(6,2 \%)$ & $0 / 11(0 \%)$ & $0[1 ; \operatorname{lnf}]$ & \\
\hline & Arritmia cardíaca & $1 / 16(6,2 \%)$ & $0 / 11(0 \%)$ & $0[1 ; \operatorname{lnf}]$ & \\
\hline & Artrose & $1 / 16(6,2 \%)$ & $0 / 11(0 \%)$ & - & \\
\hline & $\begin{array}{l}\text { Síndrome do Pânico } \\
\text { e Hepatite B }\end{array}$ & $0 / 16(0 \%)$ & $1 / 11(9,1 \%)$ & $0,14[9,00 ; \operatorname{lnf}]$ & \\
\hline & Sim & $0 / 16(0 \%)$ & $0 / 2(0 \%)$ & - & \\
\hline
\end{tabular}

(1) Teste exato de Fisher 
O início do pré-natal deu-se na maioria (37/89) até 7 semanas e 6 dias de gestação, 81 das mulheres tiveram mais de seis consultas (Tabela 8).

A Tabela 9 traz as variáveis relativas entre o período de gestação e parto, desde o trimestre em que foram iniciadas as consultas de pré-natal até o tempo de internação após o parto.

O início do pré-natal deu-se, majoritariamente, no primeiro trimestre, nos dois grupos de mulheres estudadas, ocorrendo em $84,6 \%$ das vezes no grupo de mulheres sem sinais e $80 \%$ no grupo com sinais. Entre os 24 prontuários com os dados de intervalo entre o último parto e a gestação atual, 14 mulheres eram primigestas, 10 tinham mais de duas gestações, onde $60 \%$ destas haviam tido o último parto há mais de quatro anos, $20 \%$ menos de um ano e $20 \%$ entre três e quatro anos (Gráfico 2).

Ainda que as duas mulheres que apresentaram sinais e sintomas de infecção tenham tido o último parto há menos de um ano e as outras $50 \%$ entre três e quatro anos, a falta de informação do restante do grupo fez com que não se pudesse indicar que as mulheres tiveram mais infecção se menor ou maior tempo do último parto.

O número de consultas de pré-natal, nos dois grupos estudados, ocorreu mais de seis consultas em $87,5 \%$ das vezes no grupo de mulheres sem sinais e $90,9 \%$ das mulheres com sinais. Somente duas mulheres do grupo, que não apresentou sinais de infecção, realizaram até três consultas durante o pré-natal e uma do grupo que apresentou sinais e sintomas de infecção realizou de três a cinco consultas, não havendo assim diferença estatística significativa nesta variável.

As infecções comunitárias, de acordo com as informações coletadas de 25 prontuários de mulheres pertencentes aos dois grupos de estudo, tiveram sorologia não reagente para HIV, dois prontuários não continham esta informação. A sorologia para hepatite $\mathrm{C}$ apareceu registrada em sete prontuários, com resultado não reagente e 20 prontuários não continham informação.

O resultado de sorologia para sífilis demonstrou que, das 25 mulheres com informação em prontuário, 22 tiveram sorologia não reagente, três mulheres reagentes para sífilis. Das três mulheres que apresentaram resultado positivo de sorologia para 
sífilis, duas eram do grupo que apresentou sinais e sintomas sugestivos de infecção de sítio cirúrgico, pós-parto cesáreo (gráfico 3).

No caso da hepatite $B$, no grupo que não apresentou sinais e sintomas de infecção, nenhuma mulher teve resultado reagente para este evento (13), e três prontuários não continham informação sobre o exame. Em contrapartida, no grupo de mulheres com sinais sugestivos de infecção, sete tiveram resultado não reagente para sorologia de hepatite $B$, duas com resultado reagente e duas com prontuários que não continham informação (gráfico 3).

Na variável infecção urinária, das 24 informações coletadas nos prontuários sobre este evento, 17 mulheres não apresentaram este tipo de infecção, durante a gestação, e sete tiveram seus resultados de urina/urocultura positivos, distribuídos nos dois grupos, na proporção de 3/14 no grupo sem sinais e sintomas e 4/10 no grupo com sinais e sintomas sugestivos de infecção de sítio cirúrgico (gráfico 3).

Ainda que as mulheres que tiveram sinais sugestivos de infecção apresentassem mais infecção urinária, hepatite $B$ e sífilis, não há como afirmar que este grupo tenha infecção por ter apresentado as infecções comunitárias listadas.

Dentre os imunobiológicos preconizados na assistência ao pré-natal e para que a mulher seja considerada como imunizada, encontrou-se a vacina contra tétano e difteria, onde $74 \%$ das mulheres dos dois grupos receberam alguma dose da vacina, $63 \%$ contra hepatite B e $59 \%$ contra influenza.

Em 26\% do total de prontuários de mulheres sem sinais, não havia informação sobre a situação vacinal contra tétano e difteria e hepatite B contra $37 \%$ do grupo com sinais. Já a vacina contra influenza tinha a informação negativa de recebimento de dose em $7,5 \%$ dos prontuários e sem informação em 33,5\% (Tabela 9).

Cinco prontuários continham informação sobre a ocorrência de cesárea de urgência, sendo quatro deles do grupo de mulheres que não apresentaram sinais de infecção e uma do grupo com sinais.

$\mathrm{Na}$ informação sobre parto de gemelares, houve uma ocorrência, sendo esta no grupo sem sinais, que foi também uma cesárea de urgência. 
Quanto ao tempo de internação, $57,1 \%$ das mulheres estiveram três dias internadas após o parto, no total de 6/13 do grupo sem sinais e 6/8 no grupo com sinais, somente duas mulheres pertencentes ao grupo sem sinais ficaram mais de sete dias internadas, e foram suprimidos seis prontuários sem informação.

Tabela 6 - Número e proporção de mulheres que tiveram parto cesáreo, segundo dados da gestação e parto, Município de São Paulo, 2014.

continua

\begin{tabular}{|c|c|c|c|c|c|c|c|c|}
\hline \multirow[t]{2}{*}{ Gestação e parto } & \multicolumn{2}{|c|}{$\begin{array}{l}\text { Sinais e } \\
\text { sintomas } \\
\text { sugestivos de } \\
\text { infecção }\end{array}$} & \multicolumn{2}{|c|}{$\begin{array}{l}\text { Sem sinais e } \\
\text { sintomas } \\
\text { sugestivos de } \\
\text { infecção }\end{array}$} & \multicolumn{2}{|c|}{$\begin{array}{c}\text { Prontuários } \\
\text { incompletos/ } \\
\text { sem } \\
\text { informação }\end{array}$} & \multicolumn{2}{|c|}{ Total } \\
\hline & $\mathbf{N}$ & $\%$ & $\mathbf{N}$ & $\%$ & $\mathbf{N}$ & $\%$ & $\mathbf{N}$ & $\%$ \\
\hline \multicolumn{9}{|l|}{ Intervalo última gestação/parto } \\
\hline Menor que 1 ano & 1 & 1,1 & 1 & 1,1 & 0 & 0,0 & 2 & 2,2 \\
\hline De 1 a 2 anos & 0 & 0,0 & 0 & 0,0 & 5 & 5,6 & 5 & 5,6 \\
\hline De 3 a 4 anos & 1 & 1,1 & 1 & 1,1 & 1 & 1,1 & 3 & 3,4 \\
\hline Maior que 4 anos & 0 & 0,0 & 6 & 6,7 & 9 & 10,1 & 15 & 16,9 \\
\hline Não se aplica (primeira gestação) & 7 & 7,9 & 7 & 7,9 & 20 & 22,5 & 34 & 38,2 \\
\hline Sem informação & 2 & 2,2 & 1 & 1,1 & 27 & 30,3 & 30 & 33,7 \\
\hline \multicolumn{8}{|l|}{ Número de consultas de pré-natal } & 100,0 \\
\hline Até 3 consultas & 0 & 0,0 & 2 & 2,2 & 3 & 3,4 & 5 & 5,6 \\
\hline De 3 a 5 consultas & 1 & 1,1 & 0 & 0,0 & 2 & 2,2 & 3 & 3,4 \\
\hline Acima de 6 consultas & 10 & 11,2 & 14 & 15,7 & 57 & 64,0 & 81 & 91,0 \\
\hline Total & 11 & 12,4 & 16 & 18,0 & 62 & 69,7 & 89 & 100,0 \\
\hline \multicolumn{9}{|l|}{ Infecção Comunitária } \\
\hline \multicolumn{9}{|l|}{ Sífilis } \\
\hline Sim & 2 & 2,2 & 1 & 1,1 & 2 & 2,2 & 5 & 5,6 \\
\hline Não & 8 & 9,0 & 14 & 15,7 & 57 & 64,0 & 79 & 88,8 \\
\hline Sem informação & 1 & 1,1 & 1 & 1,1 & 3 & 3,4 & 5 & 5,6 \\
\hline Total & 11 & 12,4 & 16 & 18,0 & 62 & 69,7 & 89 & 100,0 \\
\hline \multicolumn{9}{|l|}{ HIV } \\
\hline Sim & 0 & 0,0 & 0 & 0,0 & 0 & 0,0 & 0 & 0,0 \\
\hline Não & 10 & 11,2 & 15 & 16,9 & 59 & 66,3 & 84 & 94,4 \\
\hline Sem informação & 1 & 1,1 & 1 & 1,1 & 3 & 3,4 & 5 & 5,6 \\
\hline Total & 11 & 12,4 & 16 & 18,0 & 62 & 69,7 & 89 & 100,0 \\
\hline \multicolumn{9}{|l|}{ Hepatite $B$} \\
\hline $\operatorname{Sim}$ & 2 & 2,2 & 0 & 0,0 & 1 & 1,1 & 3 & 3,4 \\
\hline Não & 7 & 7,9 & 13 & 14,6 & 56 & 62,9 & 76 & 85,4 \\
\hline Sem informação & 2 & 2,2 & 3 & 3,4 & 5 & 5,6 & 10 & 11,2 \\
\hline
\end{tabular}


continuação

$\begin{array}{lllcl} & \text { Sinais e } & \text { Sem sinais e } & \text { Prontuários } & \\ \text { Gestação e parto } & \begin{array}{l}\text { sintomas } \\ \text { sugestivos }\end{array} & \begin{array}{l}\text { sintomas } \\ \text { sugestivos de }\end{array} & \begin{array}{c}\text { incompletos/ } \\ \text { de infecção }\end{array} & \text { Total } \\ & \text { infecção } & \text { informação } & \end{array}$

\begin{tabular}{|c|c|c|c|c|c|c|c|c|}
\hline Variável & $\mathbf{N}$ & $\%$ & $\mathbf{N}$ & $\%$ & $\mathbf{N}$ & $\%$ & $\mathbf{N}$ & $\%$ \\
\hline Total & 11 & 12,4 & 16 & 18,0 & 62 & 69,7 & 89 & 100,0 \\
\hline \multicolumn{9}{|l|}{ Hepatite $C$} \\
\hline Sim & 0 & 0,0 & 0 & 0,0 & 0 & 0,0 & 0 & 0,0 \\
\hline Não & 4 & 4,5 & 3 & 3,4 & 11 & 12,4 & 18 & 20,2 \\
\hline Sem informação & 7 & 7,9 & 13 & 14,6 & 51 & 57,3 & 71 & 79,8 \\
\hline Total & 11 & 12,4 & 16 & 18,0 & 62 & 69,7 & 89 & 100,0 \\
\hline \multicolumn{9}{|l|}{ Infecção urinária } \\
\hline Sim & 4 & 4,5 & 3 & 3,4 & 17 & 19,1 & 24 & 27,0 \\
\hline Não & 6 & 6,7 & 11 & 12,4 & 43 & 48,3 & 60 & 67,4 \\
\hline Sem informação & 1 & 1,1 & 2 & 2,2 & 2 & 2,2 & 5 & 5,6 \\
\hline Total & 11 & 12,4 & 16 & 18,0 & 62 & 69,7 & 89 & 100,0 \\
\hline \multicolumn{9}{|l|}{ Situação Vacinal } \\
\hline Difteria|Tétano & & & & & & & & 0,0 \\
\hline $1^{\text {a }}$ dose & 2 & 2,2 & 1 & 1,1 & 11 & 12,4 & 14 & 15,7 \\
\hline $2^{a}$ dose & 2 & 2,2 & 1 & 1,1 & 5 & 5,6 & 8 & 9,0 \\
\hline $3^{a}$ dose & 0 & 0,0 & 0 & 0,0 & 0 & 0,0 & 0 & 0,0 \\
\hline Reforço & 3 & 3,4 & 5 & 5,6 & 12 & 13,5 & 20 & 22,5 \\
\hline Imune & 1 & 1,1 & 5 & 5,6 & 16 & 18,0 & 22 & 24,7 \\
\hline Sem informação & 3 & 3,4 & 4 & 4,5 & 18 & 20,2 & 25 & 28,1 \\
\hline Total & 16 & 18,0 & 16 & 18,0 & 62 & 69,7 & 89 & 100,0 \\
\hline \multicolumn{9}{|l|}{ Hepatite $B$} \\
\hline $1^{\mathrm{a}}$ dose & 2 & 2,2 & 2 & 2,2 & 13 & 14,6 & 17 & 19,1 \\
\hline $2^{\mathrm{a}}$ dose & 2 & 2,2 & 2 & 2,2 & 8 & 9,0 & 12 & 13,5 \\
\hline $3^{a}$ dose & 4 & 4,5 & 5 & 5,6 & 22 & 24,7 & 31 & 34,8 \\
\hline Sem informação & 3 & 3,4 & 7 & 7,9 & 19 & 21,3 & 29 & 32,6 \\
\hline Total & 11 & 12,4 & 16 & 18,0 & 62 & 69,7 & 89 & 100,0 \\
\hline \multicolumn{9}{|l|}{ Influenza } \\
\hline Sim & 6 & 6,7 & 10 & 11,2 & 26 & 29,2 & 42 & 47,2 \\
\hline Não & 1 & 1,1 & 1 & 1,1 & 10 & 11,2 & 12 & 13,5 \\
\hline Sem informação & 4 & 4,5 & 5 & 5,6 & 26 & 29,2 & 35 & 39,3 \\
\hline Total & 11 & 12,4 & 16 & 18,0 & 62 & 69,7 & 89 & 100,0 \\
\hline \multicolumn{9}{|c|}{ Tempo de ruptura de membranas } \\
\hline Sem informação & 11 & 12,4 & 16 & 18,0 & 62 & 69,7 & 89 & 100,0 \\
\hline Total & 11 & 12,4 & 16 & 18,0 & 62 & 69,7 & 89 & 100,0 \\
\hline \multicolumn{9}{|c|}{ Cesárea de urgência } \\
\hline Sim & 1 & 1,1 & 4 & 4,5 & 7 & 7,9 & 12 & 13,5 \\
\hline Não & 0 & 0,0 & 0 & 0,0 & 2 & 2,2 & 2 & 2,2 \\
\hline Sem informação & 10 & 11,2 & 12 & 13,5 & 53 & 59,6 & 75 & 84,3 \\
\hline
\end{tabular}


continuação

\begin{tabular}{|c|c|c|c|c|c|c|c|c|}
\hline \multirow[t]{2}{*}{ Gestação e parto } & \multicolumn{2}{|c|}{$\begin{array}{l}\text { Sinais e } \\
\text { sintomas } \\
\text { sugestivos de } \\
\text { infecção }\end{array}$} & \multicolumn{2}{|c|}{$\begin{array}{l}\text { Sem sinais e } \\
\text { sintomas } \\
\text { sugestivos de } \\
\text { infecção }\end{array}$} & \multicolumn{2}{|c|}{$\begin{array}{c}\text { Sem } \\
\text { informação }\end{array}$} & \multicolumn{2}{|c|}{ Total } \\
\hline & $\mathbf{N}$ & $\%$ & $\mathbf{N}$ & $\%$ & $\mathbf{N}$ & $\%$ & $\mathbf{N}$ & $\%$ \\
\hline Total & 11 & 12,4 & 16 & 18,0 & 62 & 69,7 & 89 & 100,0 \\
\hline \multicolumn{9}{|l|}{ Cesárea de gemelares } \\
\hline $\operatorname{Sim}$ & 0 & 0,0 & 1 & 1,1 & 0 & 0,0 & 1 & 1,1 \\
\hline Não & 11 & 12,4 & 14 & 15,7 & 59 & 66,3 & 84 & 94,4 \\
\hline Sem informação & 0 & 0,0 & 1 & 1,1 & 3 & 3,4 & 4 & 4,5 \\
\hline Total & 11 & 12,4 & 16 & 18,0 & 62 & 69,7 & 89 & 100,0 \\
\hline \multicolumn{9}{|c|}{ Tempo de internação hospitalar } \\
\hline De 2 a 3 dias & 7 & 7,9 & 7 & 7,9 & 43 & 48,3 & 57 & 64,0 \\
\hline De 4 a 5 dias & 1 & 1,1 & 5 & 5,6 & 10 & 11,2 & 16 & 18,0 \\
\hline De 6 a 7 dias & 1 & 1,1 & 1 & 1,1 & 3 & 3,4 & 5 & 5,6 \\
\hline De 8 a 9 dias & 0 & 0,0 & 0 & 0,0 & 0 & 0,0 & 0 & 0,0 \\
\hline Acima de 10 dias & 0 & 0,0 & 1 & 1,1 & 3 & 3,4 & 4 & 4,5 \\
\hline Sem informação & 2 & 2,2 & 2 & 2,2 & 3 & 3,4 & 7 & 7,9 \\
\hline Total & 11 & 12,4 & 16 & 18,0 & 62 & 69,7 & 89 & 100,0 \\
\hline
\end{tabular}

Fonte: Prontuário Mãe Paulistana conclusão

Tabela 7 - Número, proporção, razão de chances e valor de $p$ de mulheres que apresentaram ou não sinais e sintomas de infecção de sítio cirúrgico pós-parto cesáreo, segundo dados da gestação e parto, Município de São Paulo, 2014.

continua

\begin{tabular}{|c|c|c|c|c|c|}
\hline Variável & fator & $\begin{array}{c}\text { Sem } \\
\text { sinais }(n=16)\end{array}$ & $\begin{array}{c}\text { Sinais } \\
\text { sugestivos } \\
(n=11)\end{array}$ & $\begin{array}{l}\text { Razão de chances } \\
\text { (IC de 95\%) }\end{array}$ & $\begin{array}{l}\text { valor } \\
\mathrm{p}^{1}\end{array}$ \\
\hline \multirow{2}{*}{$\begin{array}{c}\text { Trimestre } \\
\text { Gestacional no } \\
\text { início do Pré-Natal }\end{array}$} & $1^{\circ}$ & $11 / 13(84,6 \%)$ & $8 / 10(80 \%)$ & - & 0,999 \\
\hline & $2^{\circ}$ & $2 / 13(15,4 \%)$ & $2 / 10(20 \%)$ & $0,14[1,35 ; 13,5]$ & \\
\hline \multirow{3}{*}{$\begin{array}{l}\text { Intervalo gestação } \\
\text { parto }\end{array}$} & 3 a 4 anos & $1 / 8(12,5 \%)$ & $1 / 2(50 \%)$ & - & 0,133 \\
\hline & $\begin{array}{l}\text { Maior que } 4 \\
\text { anos }\end{array}$ & $6 / 8(75 \%)$ & $0 / 2(0 \%)$ & $0[0,07 ; 2,09]$ & \\
\hline & $\begin{array}{l}\text { Menor que } \\
1 \text { ano }\end{array}$ & $1 / 8(12,5 \%)$ & $1 / 2(50 \%)$ & $0,01[1 ; 69,3]$ & \\
\hline \multirow{3}{*}{$\begin{array}{l}\text { Número de } \\
\text { consultas Pré-Natal }\end{array}$} & $\begin{array}{l}6 \text { ou mais } \\
\text { consultas }\end{array}$ & $14 / 16(87,5 \%)$ & $10 / 11(90,9 \%)$ & - & 0,307 \\
\hline & $\begin{array}{l}\text { Até } 3 \\
\text { consultas }\end{array}$ & $2 / 16(12,5 \%)$ & $0 / 11(0 \%)$ & $\operatorname{Inf}[0,27 ; \operatorname{Inf}]$ & \\
\hline & $\begin{array}{l}\text { De } 3 \text { a } 5 \\
\text { consultas }\end{array}$ & $0 / 16(0 \%)$ & $1 / 11(9,1 \%)$ & $0,11[4,14 ; \operatorname{Inf}]$ & \\
\hline
\end{tabular}


continuação

\begin{tabular}{|c|c|c|c|c|c|}
\hline Variável & fator & $\begin{array}{c}\text { Sem } \\
\text { sinais }(n=16)\end{array}$ & $\begin{array}{c}\text { Sinais } \\
\text { sugestivos } \\
(n=11)\end{array}$ & $\begin{array}{l}\text { Razão de chances } \\
\text { (IC de 95\%) }\end{array}$ & $\begin{array}{l}\text { valor } \\
\mathbf{p}^{1}\end{array}$ \\
\hline \multirow{3}{*}{ Sífilis } & Não & $14 / 15(93,3 \%)$ & 8/10 (80\%) & - & 0,543 \\
\hline & Sim & $1 / 15(6,7 \%)$ & $2 / 10(20 \%)$ & $0,29[2,84 ; 82,5]$ & \\
\hline & Sim & $3 / 14(21,4 \%)$ & $4 / 10(40 \%)$ & $0,40[2,27 ; 16,2]$ & \\
\hline \multirow{2}{*}{ HIV } & Não & $15 / 15(100 \%)$ & $10 / 10(100 \%)$ & - & - \\
\hline & Sim & $0 / 15(0 \%)$ & $0 / 10(0 \%)$ & - & \\
\hline \multirow{2}{*}{ Hepatite B } & Não & $13 / 13(100 \%)$ & $7 / 9(77,8 \%)$ & - & 0,156 \\
\hline & Sim & $0 / 13(0 \%)$ & 2/9 (22,2\%) & 0,62 [9; Inf] & \\
\hline \multirow{2}{*}{ Hepatite C } & Não & $3 / 3(100 \%)$ & $4 / 4(100 \%)$ & - & - \\
\hline & Sim & $0 / 3(0 \%)$ & $0 / 4(0 \%)$ & - & \\
\hline \multirow{2}{*}{ Infecção Urinária } & Não & $11 / 14(78,6 \%)$ & $6 / 10(60 \%)$ & - & 0,393 \\
\hline & Sim & $3 / 14(21,4 \%)$ & 4/10 (40\%) & $0,40[2,27 ; 16,2]$ & \\
\hline \multirow{4}{*}{ Difteria Tétano } & $1^{\text {a }}$ dose & $1 / 12(8,3 \%)$ & $2 / 8(25 \%)$ & - & 0,355 \\
\hline & $2^{\mathrm{a}}$ dose & $1 / 12(8,3 \%)$ & $2 / 8(25 \%)$ & $0,02[1 ; 40,3]$ & \\
\hline & Imune & $5 / 12(41,7 \%)$ & $1 / 8(12,5 \%)$ & $0,00[0,16 ; 2,17]$ & \\
\hline & reforço & $5 / 12(41,7 \%)$ & $3 / 8(37,5 \%)$ & $0,01[0,38 ; 4,53]$ & \\
\hline \multirow{3}{*}{ Hepatite B } & $1^{\text {a }}$ dose & $2 / 9(22,2 \%)$ & $2 / 8(25 \%)$ & - & 0,999 \\
\hline & $2^{\mathrm{a}}$ dose & 2/9 (22,2\%) & 2/8 (25\%) & $0,05[1 ; 17,8]$ & \\
\hline & $3^{\mathrm{a}}$ dose & $5 / 9(55,6 \%)$ & $4 / 8(50 \%)$ & $0,06[0,81 ; 9,32]$ & \\
\hline \multirow{2}{*}{ Influenza } & Não & $1 / 11(9,1 \%)$ & $1 / 7(14,3 \%)$ & - & 0,999 \\
\hline & Sim & $10 / 11(90,9 \%)$ & $6 / 7(85,7 \%)$ & $0,02[0,61 ; 17,1]$ & \\
\hline \multirow{2}{*}{$\begin{array}{c}10 \text { Consulta / } \\
\text { Visita Puerpério }\end{array}$} & Até 7 dias & $6 / 16(37,5 \%)$ & $3 / 11(27,3 \%)$ & - & 0,692 \\
\hline & $\begin{array}{l}\text { De } 8 \text { a } 30 \\
\text { dias }\end{array}$ & $10 / 16(62,5 \%)$ & $8 / 11(72,7 \%)$ & $0,31[1,50 ; 9,52]$ & \\
\hline \multirow{3}{*}{$\begin{array}{l}\text { Tempo de } \\
\text { Internação }\end{array}$} & 3 & $6 / 13(46,2 \%)$ & $6 / 8(75 \%)$ & - & 0,53 \\
\hline & 4 a 6 & $5 / 13(38,5 \%)$ & $2 / 8(25 \%)$ & $0,04[0,45 ; 2,74]$ & \\
\hline & 7 ou mais & 2/13 (15,4\%) & $0 / 8(0 \%)$ & $0[0,2 ; 3,12]$ & \\
\hline
\end{tabular}

(1) Teste exato de Fisher

conclusão 
Gráfico 2 - Intervalo entre a gestação e o último parto de mulheres que apresentaram ou não sinais e sintomas sugestivos de infecção de sítio cirúrgico pós-parto cesáreo.

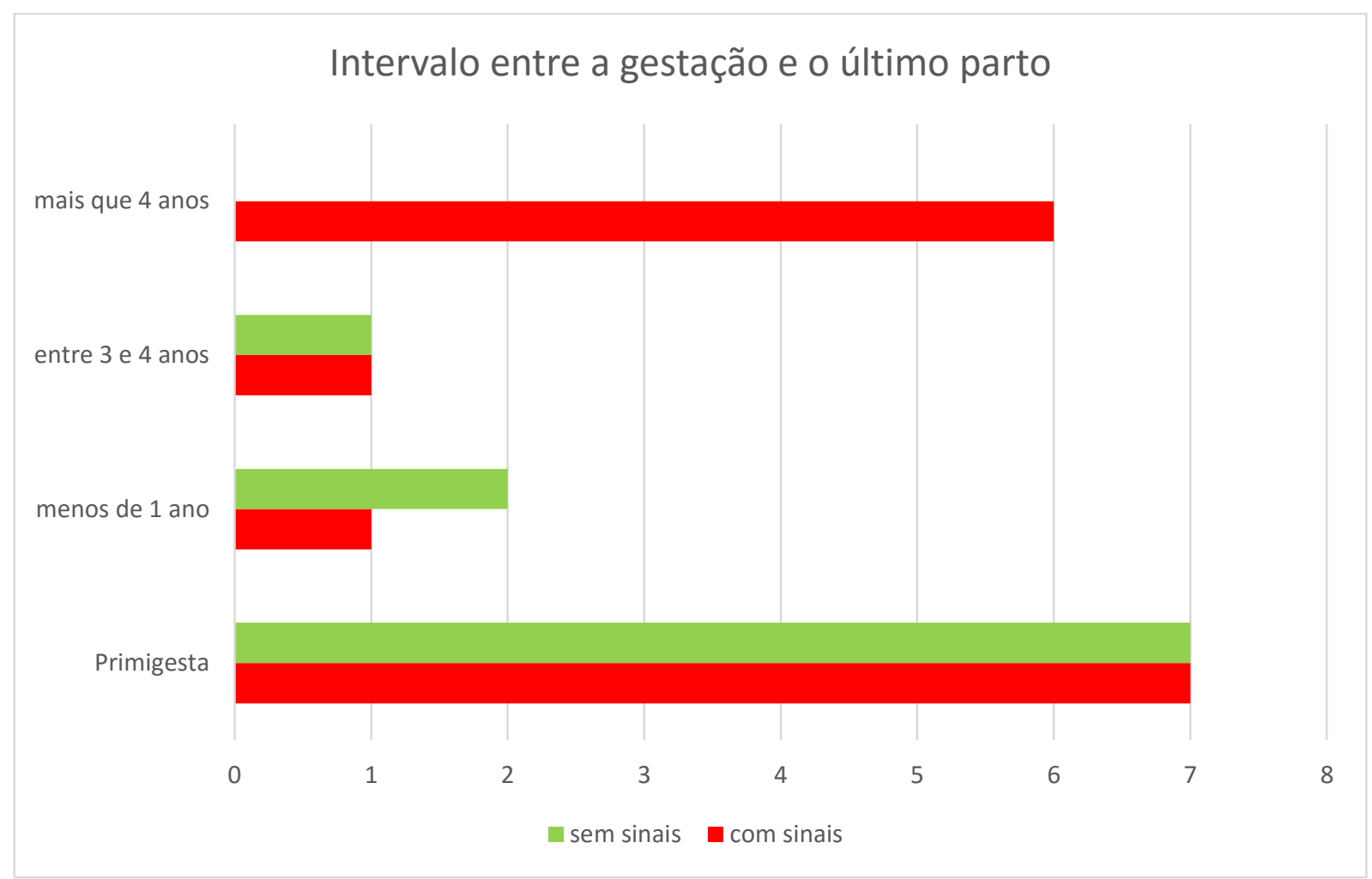

Gráfico 3 - Resultados de exames laboratoriais reagentes para sorologia de sífilis, hepatite B e infecção urinária de mulheres que apresentaram ou não sinais e sintomas sugestivos de infecção de sítio cirúrgico pós-parto cesáreo.

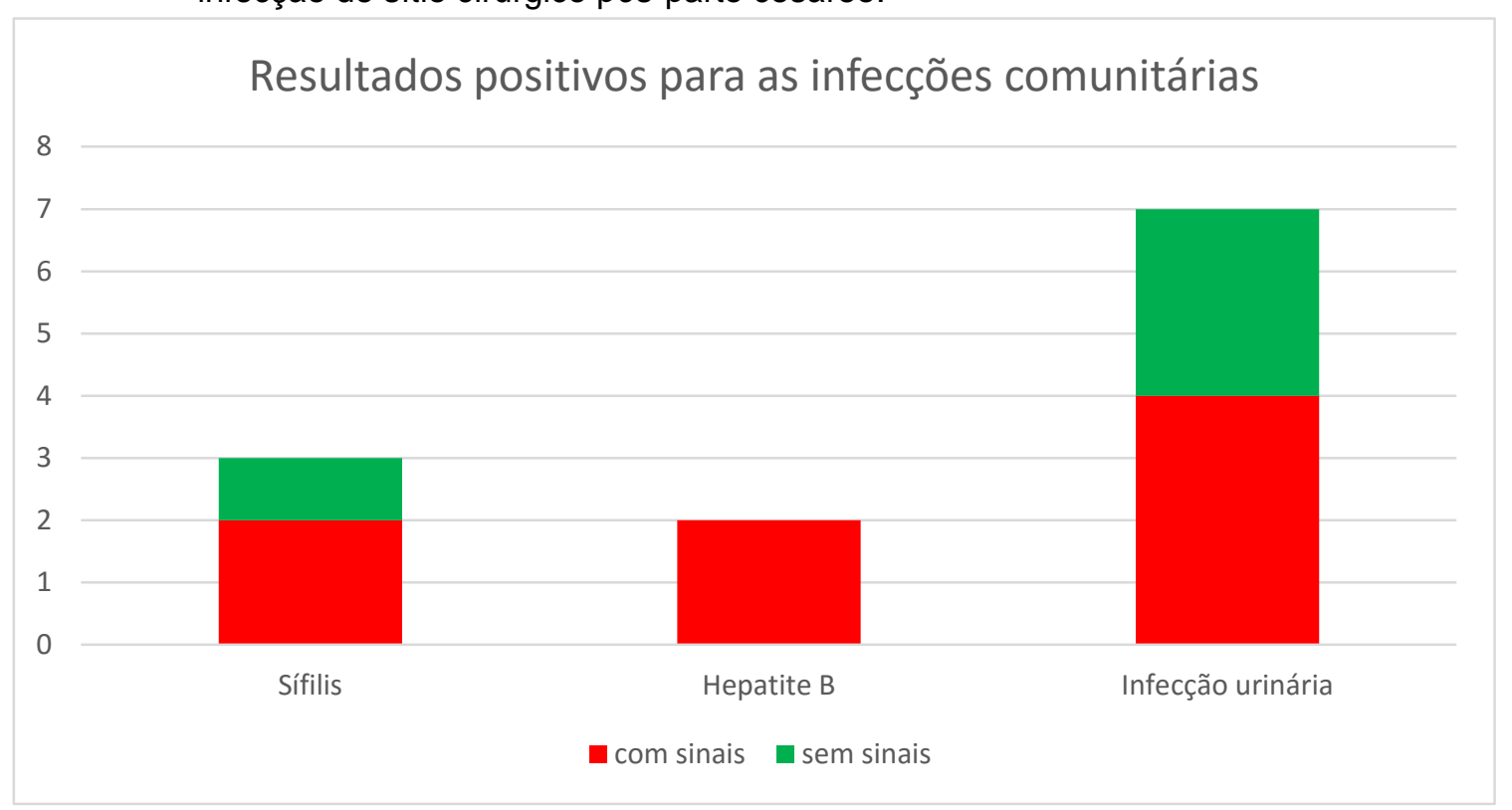

O período entre o parto e a primeira consulta ou visita domiciliar de puerpério aconteceu na maioria (66/89) entre 8 e 30 dias (Tabela 10). 
A maioria das 27 mulheres não teve dor em baixo ventre, dor abdominal, alterações urinárias, leucorréia e sangramento, febre, dor na incisão cirúrgica, hiperemia, calor local, deiscência ou abcesso (Tabela 11).

Entre as 11 mulheres que tiveram sinais ou sintomas sugestivos de infecção (Tabela 11), destacam-se quatro que tiveram dor no baixo ventre, uma delas apresentou associado, febre, dor na incisão cirúrgica e presença de secreção amarela purulenta. Uma com alguma alteração urinária, uma com sangramento, quatro com presença de secreção e duas tiveram deiscência (gráfico 4).

Em uma delas, o início destes sinais e sintomas aconteceu até sete dias, após o parto, e uma acima de 11 dias.

No grupo de mulheres que apresentou sinais e sintomas de infecção, a afirmativa para alterações urinárias ocorreu em 9,1\% (1), dor em baixo ventre em quatro mulheres, considerando assim que as mulheres que tiveram infecção apresentaram dor em baixo ventre $(p .=0,019)$ (Tabela 11).

A variável retirada de pontos estava presente em sete prontuários de mulheres que apresentavam sinais e sintomas de infecção e continham a descrição do aspecto do sítio cirúrgico desde a presença de hiperemia (1), fissura (1), deiscência (2), dor local (2), sinais flogísticos (1), secreção (1), odor fétido (1), ferida limpa e seca (1).

No grupo de mulheres sem sinais de infecção, a variável retirada de pontos estava registrada em cinco prontuários com informação do aspecto do sítio cirúrgico em três deles.

Entre as 11 mulheres, seis prontuários traziam a informação sobre o profissional que observou o evento. A equipe de enfermagem foi responsável pela identificação de sinais e sintomas sugestivos de infecção em $83,3 \%$ das mulheres, seguida por profissional médico, em $16,7 \%$ das mulheres.

Cinco das sete mulheres foram encaminhadas para avaliação e diagnóstico médico, duas não foram encaminhadas para atendimento do médico e quatro não continham informação no prontuário se haviam passado por avaliação médica, porém em seis prontuários havia o registro de diagnóstico de infecção realizado pelo médico, 
cinco destas tratadas com antibioticoterapia e/ou anti-inflamatório e curativo. Nenhuma das sete mulheres foi encaminhada para outro serviço.

Tabela 8 - Número e proporção de mulheres que tiveram parto cesáreo, segundo indicadores de sinais e sintomas sugestivos de infecção de sítio cirúrgico no puerpério, Município de São Paulo, 2014.

continua

\begin{tabular}{lcccc}
\hline Puerpério & $\begin{array}{c}\text { Sinais e } \\
\text { sintomas } \\
\text { sugestivos de } \\
\text { infecção }\end{array}$ & $\begin{array}{c}\text { Sem sinais e } \\
\text { sintomas } \\
\text { sugestivos de } \\
\text { infecção }\end{array}$ & $\begin{array}{c}\text { Sem } \\
\text { informação }\end{array}$ & Total
\end{tabular}

\begin{tabular}{|c|c|c|c|c|c|c|c|c|}
\hline Variável & $\mathbf{N}$ & $\%$ & $\mathbf{N}$ & $\%$ & $\mathbf{N}$ & $\%$ & $\mathbf{N}$ & $\%$ \\
\hline \multicolumn{9}{|c|}{ Período entre o parto e $1^{\text {a }}$ consulta ou visita domiciliar de puerpério } \\
\hline Até 7 dias & 3 & 3,4 & 6 & 6,7 & 14 & 15,7 & 23 & 25,8 \\
\hline De 8 a 30 dias & 8 & 9,0 & 10 & 11,2 & 48 & 53,9 & 66 & 74,2 \\
\hline Total & 11 & 12,4 & 16 & 18,0 & 62 & 69,7 & 89 & 100,0 \\
\hline \multicolumn{9}{|l|}{ Queixas e achados } \\
\hline Dor em baixo ventre & & & & & & & & 0,0 \\
\hline $\operatorname{Sim}$ & 4 & 4,5 & 0 & 0,0 & 9 & 10,1 & 13 & 14,6 \\
\hline Não & 7 & 7,9 & 16 & 18,0 & 53 & 59,6 & 76 & 85,4 \\
\hline Sem informação & 0 & 0,0 & 0 & 0,0 & 0 & 0,0 & 0 & 0,0 \\
\hline Total & 11 & 12,4 & 16 & 18,0 & 62 & 69,7 & 89 & 100,0 \\
\hline \multicolumn{9}{|l|}{ Alterações urinárias } \\
\hline Sim & 1 & 1,1 & 0 & 0,0 & 2 & 2,2 & 3 & 3,4 \\
\hline Não & 10 & 11,2 & 16 & 18,0 & 60 & 67,4 & 86 & 96,6 \\
\hline Sem informação & 0 & 0,0 & 0 & 0,0 & 0 & 0,0 & 0 & 0,0 \\
\hline Total & 11 & 12,4 & 16 & 18,0 & 62 & 69,7 & 89 & 100,0 \\
\hline \multicolumn{9}{|l|}{ Sangramento } \\
\hline $\operatorname{Sim}$ & 1 & 1,1 & 0 & 0,0 & 10 & 11,2 & 11 & 12,4 \\
\hline Não & 10 & 11,2 & 16 & 18,0 & 52 & 58,4 & 78 & 87,6 \\
\hline Sem informação & 0 & 0,0 & 0 & 0,0 & 0 & 0,0 & 0 & 0,0 \\
\hline Total & 11 & 12,4 & 16 & 18,0 & 62 & 69,7 & 89 & 100,0 \\
\hline \multicolumn{9}{|l|}{ Leucorreia } \\
\hline Sim & 0 & 0,0 & 0 & 0,0 & 1 & 1,1 & 1 & 1,1 \\
\hline Não & 11 & 12,4 & 16 & 18,0 & 61 & 68,5 & 88 & 98,9 \\
\hline Sem informação & 0 & 0,0 & 0 & 0,0 & 0 & 0,0 & 0 & 0,0 \\
\hline Total & 11 & 12,4 & 16 & 18,0 & 62 & 69,7 & 89 & 100,0 \\
\hline \multicolumn{9}{|l|}{ Febre } \\
\hline Sim & 2 & 2,2 & 0 & 0,0 & 0 & 0,0 & 2 & 2,2 \\
\hline Não & 3 & 3,4 & 16 & 18,0 & 1 & 1,1 & 20 & 22,5 \\
\hline Sem informação & 6 & 6,7 & 0 & 0,0 & 61 & 68,5 & 67 & 75,3 \\
\hline Total & 11 & 12,4 & 16 & 18,0 & 62 & 69,7 & 89 & 100,0 \\
\hline \multicolumn{9}{|l|}{ Dor (incisão cirúrgica) } \\
\hline $\operatorname{Sim}$ & 2 & 2,2 & 0 & 0,0 & 0 & 0,0 & 2 & 2,2 \\
\hline Não & 2 & 2,2 & 16 & 18,0 & 2 & 2,2 & 20 & 22,5 \\
\hline
\end{tabular}


continuação

Puerpério

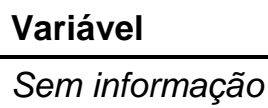

Total

Dor abdominal

Sim

Não

Sem informação

Total

Sítio Cirúrgico

Presença de secreção

Sim

Não

Sem informação

Total

Aspecto da secreção

Amarela purulenta

Sanguinolenta

Sem informação

Não se aplica

Total

Hiperemia

Sim

Não

Sem informação

Total

Calor

Sim

Não

Sem informação

Total

Edema

Sim

Não

Sem informação

Total

Deiscência

Sim

Não

Sem informação

\section{Sinais e sintomas}

sugestivos de infecção
Sem sinais e sintomas sugestivos de infecção
Sem informação Total

\begin{tabular}{lccccccc}
\multicolumn{1}{c}{$\mathbf{N}$} & $\%$ & $\mathbf{N}$ & $\%$ & $\mathbf{N}$ & $\%$ & $\mathbf{N}$ & $\%$ \\
\hline 7 & 7,9 & 0 & 0,0 & 62 & 69,7 & 69 & 77,5 \\
11 & 12,4 & 16 & 18,0 & 62 & 69,7 & 89 & 100,0
\end{tabular}

$\begin{array}{cccccccc}0 & 0,0 & 0 & 0,0 & 0 & 0,0 & 0 & 0,0 \\ 2 & 2,2 & 16 & 18,0 & 2 & 2,2 & 20 & 22,5 \\ 9 & 10,1 & 0 & 0,0 & 60 & 67,4 & 69 & 77,5 \\ 11 & 12,4 & 16 & 18,0 & 62 & 69,7 & 89 & 100,0\end{array}$

4

2

5

11

3

0

1

7

11

0

3

8

11

0

3

8

11

0

2

9

11

2

3

6

$$
4,5
$$

2,2

$$
5,6
$$

12,4

0

16

0

16

$$
3,4
$$

0,0

1,1

7,9

12,4

0,0

3,4

$$
9,0
$$

12,4

0

$$
0
$$

0

16

16

0,0

18,0

0,0

18,0

0,0

0,0

0,0

18,0

18,0

0,0

18,0

0,0

18,0

0,0

3,4

9,0

12,4

0,0

2,2

10,1

12,4

2,2

3,4

6,7

2,2
3,4
6,7

16

16

16

0,0

18,0

0,0

0

16

0

$\begin{array}{lll}0,0 & 4 & 4,5\end{array}$

$\begin{array}{llll}1 & 1,1 & 19 & 21,3\end{array}$

61

$\begin{array}{lll}68,5 & 66 & 74,2\end{array}$

62

$\begin{array}{lll}69,7 & 89 & 100,0\end{array}$

$\begin{array}{llll}0 & 0,0 & 3 & 3,4\end{array}$

$\begin{array}{llll}0 & 0,0 & 0 & 0,0\end{array}$

$\begin{array}{llll}1 & 1,1 & 1 & 1,1\end{array}$

$\begin{array}{llll}61 & 68,5 & 84 & 94,4\end{array}$

$\begin{array}{llll}62 & 69,7 & 89 & 100,0\end{array}$

$\begin{array}{cccccc}0 & 0,0 & 0 & 0,0 & 0 & 0,0 \\ 16 & 18,0 & 2 & 2,2 & 21 & 23,6 \\ 0 & 0,0 & 60 & 67,4 & 68 & 76,4 \\ 16 & 18,0 & 62 & 69,7 & 89 & 100,0\end{array}$

$\begin{array}{lllll}0,0 & 0 & 0,0 & 0 & 0,0\end{array}$

$\begin{array}{lllll}18,0 & 1 & 1,1 & 19 & 21,3\end{array}$

$\begin{array}{lllll}0,0 & 61 & 68,5 & 70 & 78,7\end{array}$

$\begin{array}{lllll}18,0 & 62 & 69,7 & 89 & 100,0\end{array}$

$\begin{array}{cccccc}0 & 0,0 & 0 & 0,0 & 2 & 2,2 \\ 16 & 18,0 & 1 & 1,1 & 20 & 22,5 \\ 0 & 0,0 & 61 & 68,5 & 67 & 75,3\end{array}$


continuação

\begin{tabular}{|c|c|c|c|c|c|c|c|c|}
\hline \multirow{2}{*}{$\begin{array}{l}\text { Puerpério } \\
\text { Variável } \\
\end{array}$} & \multicolumn{2}{|c|}{$\begin{array}{c}\text { Sinais e } \\
\text { sintomas } \\
\text { sugestivos } \\
\text { de infecção }\end{array}$} & \multicolumn{2}{|c|}{$\begin{array}{l}\text { Sem sinais } \\
\text { e sintomas } \\
\text { sugestivos } \\
\text { de infecção }\end{array}$} & \multicolumn{2}{|c|}{$\begin{array}{c}\text { Sem } \\
\text { informação }\end{array}$} & \multicolumn{2}{|c|}{ Total } \\
\hline & $\mathbf{N}$ & $\%$ & $\mathbf{N}$ & $\%$ & $\mathbf{N}$ & $\%$ & $\mathbf{N}$ & $\%$ \\
\hline Total & 11 & 12,4 & 16 & 18,0 & 62 & 69,7 & 89 & 100,0 \\
\hline \multicolumn{9}{|l|}{ Abcesso } \\
\hline Sim & 0 & 0,0 & 0 & 0,0 & 0 & 0,0 & 0 & 0,0 \\
\hline Não & 2 & 2,2 & 16 & 18,0 & 1 & 1,1 & 19 & 21,3 \\
\hline Sem informação & 9 & 10,1 & 0 & 0,0 & 61 & 68,5 & 70 & 78,7 \\
\hline Total & 11 & 12,4 & 16 & 18,0 & 62 & 69,7 & 89 & 100,0 \\
\hline \multicolumn{9}{|c|}{ Início dos sintomas em dias da data do parto } \\
\hline Até 7 dias & 1 & 1,1 & 0 & 0,0 & 0 & 0,0 & 1 & 1,1 \\
\hline De 8 a 10 dias & 0 & 0,0 & 0 & 0,0 & 0 & 0,0 & 0 & 0,0 \\
\hline Acima de 11 dias & 1 & 1,1 & 0 & 0,0 & 0 & 0,0 & 1 & 1,1 \\
\hline Não se aplica & 5 & 5,6 & 16 & 18,0 & 62 & 69,7 & 83 & 93,3 \\
\hline Sem informação & 4 & 4,5 & 0 & 0,0 & 0 & 0,0 & 4 & 4,5 \\
\hline Total & 11 & 12,4 & 16 & 18,0 & 62 & 69,7 & 89 & 100,0 \\
\hline \multicolumn{9}{|c|}{ Retirada de pontos em dias da data do parto } \\
\hline Até 7 dias & 1 & 1,1 & 0 & 0,0 & 0 & 0,0 & 1 & 1,1 \\
\hline De 8 a 10 dias & 2 & 2,2 & 2 & 2,2 & 3 & 3,4 & 7 & 7,9 \\
\hline Acima 11 dias & 4 & 4,5 & 3 & 3,4 & 11 & 12,4 & 18 & 20,2 \\
\hline Sem informação & 4 & 4,5 & 11 & 12,4 & 48 & 53,9 & 63 & 70,8 \\
\hline Total & 11 & 12,4 & 16 & 18,0 & 62 & 69,7 & 89 & 100,0 \\
\hline
\end{tabular}

Tabela 9 - Número, proporção e valor de $p$ de mulheres que apresentaram ou não sinais sugestivos de infecção de sítio cirúrgico pós-parto cesáreo, segundo dados de puerpério, Município de São Paulo, 2014.

continua

\begin{tabular}{|c|c|c|c|c|c|}
\hline Variável & fator & $\begin{array}{c}\text { Sem } \\
\text { sinais }(n=16)\end{array}$ & $\begin{array}{l}\text { Sinais sugestivos } \\
\qquad(n=11)\end{array}$ & $\begin{array}{c}\text { Razão de chances (IC } \\
\text { de 95\%) }\end{array}$ & $\begin{array}{l}\text { valor } \\
\mathbf{p}^{1}\end{array}$ \\
\hline \multirow{2}{*}{ 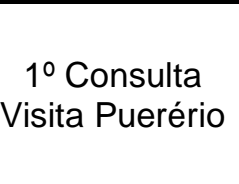 } & $\begin{array}{l}\text { Até } 7 \\
\text { dias }\end{array}$ & $6 / 16(37,5 \%)$ & $3 / 11(27,3 \%)$ & - & \multirow[t]{2}{*}{0,692} \\
\hline & $\begin{array}{l}\text { De } 8 \text { a } \\
30 \text { dias }\end{array}$ & $10 / 16(62,5 \%)$ & $8 / 11(72,7 \%)$ & $0,31[1,50 ; 9,52]$ & \\
\hline \multirow{3}{*}{$\begin{array}{l}\text { Tempo de } \\
\text { Internação }\end{array}$} & 3 & $6 / 13(46,2 \%)$ & $6 / 8(75 \%)$ & - & \multirow[t]{3}{*}{0,53} \\
\hline & 4 a 6 & $5 / 13(38,5 \%)$ & $2 / 8(25 \%)$ & $0,04[0,45 ; 2,74]$ & \\
\hline & $\begin{array}{l}7 \text { ou } \\
\text { mais }\end{array}$ & $2 / 13(15,4 \%)$ & $0 / 8(0 \%)$ & $0[0,2 ; 3,12]$ & \\
\hline \multirow{2}{*}{$\begin{array}{l}\text { Cesárea de } \\
\text { Urgência }\end{array}$} & Não & $0 / 4(0 \%)$ & $0 / 1(0 \%)$ & - & \\
\hline & Sim & $4 / 4(100 \%)$ & $1 / 1(100 \%)$ & - & \\
\hline \multirow{2}{*}{$\begin{array}{l}\text { Cesárea de } \\
\text { Gemelares }\end{array}$} & Não & 14/15 (93,3\%) & $11 / 11(100 \%)$ & - & \multirow[t]{2}{*}{0,999} \\
\hline & Sim & $1 / 15(6,7 \%)$ & $0 / 11(0 \%)$ & - & \\
\hline
\end{tabular}


continuação

\begin{tabular}{|c|c|c|c|c|c|}
\hline Variável & fator & $\begin{array}{c}\text { Sem } \\
\text { sinais }(n=16)\end{array}$ & $\begin{array}{c}\text { Sinais } \\
\text { sugestivos } \\
(n=11)\end{array}$ & $\begin{array}{c}\text { Razão de } \\
\text { chances (IC de } \\
95 \%)\end{array}$ & $\begin{array}{c}\text { valor } \\
\mathbf{p}^{1}\end{array}$ \\
\hline \multirow{2}{*}{ Dor em baixo ventre } & Não & $16 / 16(100 \%)$ & $7 / 11(63,6 \%)$ & - & 0,019 \\
\hline & Sim & $0 / 16(0 \%)$ & $4 / 11(36,4 \%)$ & $1,76[19,8 ; \operatorname{lnf}]$ & \\
\hline \multirow{2}{*}{ Alterações urinárias } & Não & $16 / 16(100 \%)$ & $10 / 11(90,9 \%)$ & - & 0,407 \\
\hline & Sim & $0 / 16(0 \%)$ & $1 / 11(9,1 \%)$ & - & \\
\hline \multirow{2}{*}{ Sangramento } & Não & $16 / 16(100 \%)$ & $10 / 11(90,9 \%)$ & - & 0,407 \\
\hline & Sim & $0 / 16(0 \%)$ & $1 / 11(9,1 \%)$ & - & \\
\hline \multirow{2}{*}{ Leucorréia } & Não & $16 / 16(100 \%)$ & $11 / 11(100 \%)$ & - & - \\
\hline & Sim & $0 / 16(0 \%)$ & $0 / 11(0 \%)$ & - & \\
\hline \multirow{2}{*}{ Febre } & Não & $16 / 16(100 \%)$ & $3 / 5(60 \%)$ & - & 0,048 \\
\hline & Sim & $0 / 16(0 \%)$ & $2 / 5(40 \%)$ & $1,50[23,5 ; \operatorname{Inf}]$ & \\
\hline \multirow{2}{*}{$\begin{array}{l}\text { Dor Incisão } \\
\text { Cirúrgica }\end{array}$} & Não & $16 / 16(100 \%)$ & $2 / 4(50 \%)$ & - & 0,032 \\
\hline & Sim & $0 / 16(0 \%)$ & $2 / 4(50 \%)$ & $1,97$ [33; Inf $]$ & \\
\hline \multirow{2}{*}{ Dor abdominal } & Não & $16 / 16(100 \%)$ & $2 / 2(100 \%)$ & - & - \\
\hline & Sim & $0 / 16(0 \%)$ & $0 / 2(0 \%)$ & - & \\
\hline \multirow{2}{*}{$\begin{array}{l}\text { Presença de } \\
\text { Secreção }\end{array}$} & Não & $16 / 16(100 \%)$ & $2 / 6(33,3 \%)$ & - & 0,002 \\
\hline & Sim & $0 / 16(0 \%)$ & $4 / 6(66,7 \%)$ & $4,40[59,3 ; \operatorname{lnf}]$ & \\
\hline \multirow{2}{*}{ Hiperemia } & Não & $16 / 16(100 \%)$ & $3 / 3(100 \%)$ & - & - \\
\hline & Sim & $0 / 16(0 \%)$ & $0 / 3(0 \%)$ & - & \\
\hline \multirow{2}{*}{ Calor } & Não & $16 / 16(100 \%)$ & $3 / 3(100 \%)$ & - & - \\
\hline & Sim & $0 / 16(0 \%)$ & $0 / 3(0 \%)$ & - & \\
\hline \multirow{2}{*}{ Edema } & Não & $16 / 16(100 \%)$ & $2 / 2(100 \%)$ & - & - \\
\hline & Sim & $0 / 16(0 \%)$ & $0 / 2(0 \%)$ & - & \\
\hline \multirow{2}{*}{ Deiscência } & Não & $16 / 16(100 \%)$ & $3 / 3(100 \%)$ & - & - \\
\hline & Sim & $0 / 16(0 \%)$ & $0 / 3(0 \%)$ & - & \\
\hline \multirow{2}{*}{ Abcesso } & Não & $16 / 16(100 \%)$ & $2 / 2(100 \%)$ & - & - \\
\hline & Sim & $0 / 16(0 \%)$ & $0 / 2(0 \%)$ & - & \\
\hline \multirow{4}{*}{$\begin{array}{l}\text { Profissional que } \\
\text { observou o evento }\end{array}$} & Enfermeiro & 0/0 (NaN\%) & $3 / 7$ (42,9\%) & - & - \\
\hline & Hospital & 0/0 (NaN\%) & $1 / 7(14,3 \%)$ & - & \\
\hline & Médico & 0/0 (NaN\%) & $1 / 7(14,3 \%)$ & - & \\
\hline & $\begin{array}{l}\text { Técnico ou } \\
\text { Auxiliar de } \\
\text { Enfermagem }\end{array}$ & 0/0 (NaN\%) & $2 / 7$ (28,6\%) & - & \\
\hline \multirow{2}{*}{$\begin{array}{l}\text { Encaminhado para } \\
\text { avaliação de } \\
\text { diagnóstico médico }\end{array}$} & Não & 0/0 (NaN\%) & 2/7 (28,6\%) & - & - \\
\hline & Sim & 0/0 (NaN\%) & $5 / 7(71,4 \%)$ & - & \\
\hline \multirow{2}{*}{$\begin{array}{l}\text { Diagnóstico de } \\
\text { infecção realizado } \\
\text { pelo médico }\end{array}$} & Não & 0/0 (NaN\%) & $2 / 8(25 \%)$ & - & - \\
\hline & Sim & 0/0 (NaN\%) & $6 / 8$ (75\%) & - & \\
\hline
\end{tabular}


continuação

\begin{tabular}{|c|c|c|c|c|c|}
\hline Variável & fator & $\begin{array}{c}\text { Sem } \\
\text { sinais }(n=16)\end{array}$ & $\begin{array}{c}\text { Sinais } \\
\text { sugestivos } \\
(n=11)\end{array}$ & $\begin{array}{l}\text { Razão de } \\
\text { chances (IC } \\
\text { de 95\%) }\end{array}$ & $\begin{array}{c}\text { valor } \\
\mathbf{p}^{1}\end{array}$ \\
\hline \multirow{2}{*}{$\begin{array}{c}\text { Encaminhado } \\
\text { para outro } \\
\text { serviço }\end{array}$} & Não & 0/0 (NaN\%) & $7 / 7$ (100\%) & - & - \\
\hline & Sim & 0/0 (NaN\%) & $0 / 7(0 \%)$ & - & \\
\hline \multirow{4}{*}{$\begin{array}{l}\text { Tratamento } \\
\text { realizado }\end{array}$} & Não & 0/0 (NaN\%) & $2 / 7(28,6 \%)$ & - & - \\
\hline & Sim & 0/0 (NaN\%) & $5 / 7(71,4 \%)$ & - & \\
\hline & Antibioticoterapia 10 dias & 0/0 (NaN\%) & $1 / 5(20 \%)$ & - & - \\
\hline & $\begin{array}{l}\text { Antibioticoterapia } \\
\text { Cefalexina+ Curativo }\end{array}$ & 0/0 (NaN\%) & $1 / 5(20 \%)$ & - & \\
\hline \multirow[t]{3}{*}{$\begin{array}{l}\text { Tipo de } \\
\text { Tratamento }\end{array}$} & $\begin{array}{l}\text { Antibioticoterapia com } \\
\text { cefalexina }\end{array}$ & 0/0 (NaN\%) & $1 / 5(20 \%)$ & - & \\
\hline & $\begin{array}{l}\text { Antinflamatorio + } \\
\text { Antibioticoterapia } \\
\text { (Diclofenaco + cefalexina) }\end{array}$ & 0/0 (NaN\%) & $1 / 5(20 \%)$ & - & \\
\hline & ATB- Cefalexina & 0/0 (NaN\%) & $1 / 5(20 \%)$ & - & \\
\hline
\end{tabular}

(1) Teste exato de Fisher

conclusão

Gráfico 4- Sinais e sintomas sugestivos de infecção de sítio cirúrgico pós-parto cesáreo apresentados por mulheres do grupo com sinais.

\section{SINAIS E SINTOMAS}
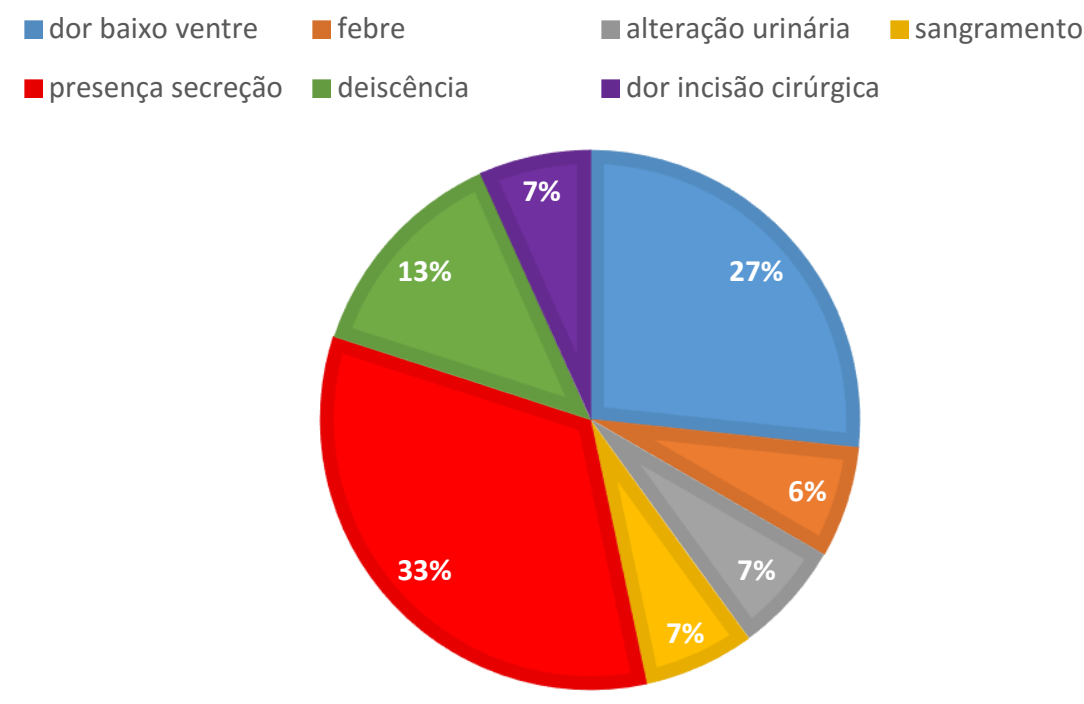

Os resultados apresentados até aqui mostram que há falta de informação nos prontuários que possam esclarecer com mais detalhes sobre o perfil sociodemográfico das 27 mulheres submetidas ao parto cesáreo, da mesma maneira que o perfil de condições de vida dos dados nos prontuários ou na Ficha A do SIAB. Esta ausência de dados dificultou a constatação real da proporção de mulheres que apresentou ou 
não sinais e sintomas sugestivos de infecção, podendo inferir na ocorrência deste evento.

A despeito disso, foi possível identificar ocorrência de mulheres com sinais e sintomas de infecção de sítio cirúrgico pós-parto cesáreo.

No capítulo seguinte, discutem-se os resultados apresentados, sobre a falta de informação e do perfil possível que foi extraído a partir do estudo, relativo a condições de vida, saúde e sociodemográficos de mulheres que tiveram parto cesáreo. Apresenta-se uma proposta de superação das lacunas encontradas nos prontuários que é um Roteiro para auxiliar a Consulta de Enfermagem no puerpério pós-parto cesáreo. 



\section{DISCUSSÃO}





\section{DISCUSSÃO}

Iniciando a discussão sobre a vulnerabilidade das mulheres às infecções de sítio cirúrgico pós-parto cesáreo, destaca-se a dificuldade de identificar precisamente os contextos e as condições destas situações, dada a baixa qualidade dos dados e informações constantes nos documentos que registram seu acompanhamento. Isto denota vulnerabilidade de âmbito programático, ou seja, há fragilidades em termos do que vem sendo informado ou não.

Os registros dos prontuários geral e Mãe Paulistana e da Ficha A do SIAB, atual eSUS AB, embora tenham como obrigatoriedade o preenchimento das variáveis de características sociodemográficas e de condições de vida e saúde, estes de modo geral não são informados.

Identificou-se um alto percentual de não preenchimento de algumas informações importantes, como destino de lixo, escolaridade, local de nascimento e renda familiar para a análise de vulnerabilidade e da qualidade da assistência prestada a estas mulheres. Utilizando metodologia semelhante, Petter et al. (2013) também encontraram alto índice de prontuários sem informações, sendo esta uma limitação nos estudos desta natureza.

Justamente esses são dados que, de alguma forma, se aproximam da condição social das mulheres e de suas famílias. Isso de alguma forma retrata a pouca importância dada a estas informações pelos profissionais da saúde em geral, responsáveis pelo atendimento e registro nestes documentos. Estudos demonstram correlação entre baixo status socioeconômico e o aumento da incidência de infecções de sítio cirúrgico (Petter et al., 2013; Carvalho, Souza, Medeiros, 2014).

Dado que não há anotação sobre a investigação de algumas condições, não é possível afirmar se foram ou não realizadas. Este é outro aspecto que denota vulnerabilidade programática. Embora o Conselho Federal de Enfermagem deixe claro que se devem anotar no prontuário os procedimentos e a abordagem realizada, conforme destacado: imediatamente após a prestação do cuidado, recebimento de informação ou observação de intercorrência e deixar claro na anotação se a 
observação foi feita pela pessoa que anota ou se é informação transmitida pelo paciente, familiar ou outro membro da equipe de saúde (Fernandes et al. ,1981; COREn-SP,2000). Estudos mostram que o registro no prontuário não retrata o que é ou não realizado (Ribeiro Filho, 2004).

O Conselho destaca a importância do registro das informações para respaldo da prática do enfermeiro e como cuidado em relação ao usuário dos serviços de saúde (COFEn, 2009).

A falta de informação nos prontuários interfere diretamente na qualidade da assistência prestada, seja por não anotação para além do instrumento existente atualmente que não contempla em suas questões, variável importante e determinante para a identificação de sinais e sintomas sugestivos de infecção de sítio cirúrgico pósparto cesáreo, seja como uma consulta de enfermagem que esteja de acordo com as normas. Portanto, a vulnerabilidade individual da mulher à infecção pós-parto tem relação com a vulnerabilidade programática.

Diante da importância da consulta de enfermagem no puerpério, verificou-se a fragilidade deste procedimento, demonstrando ocorrência de vulnerabilidade de âmbito programático, traduzido nas lacunas de informações encontradas nos prontuários.

A não anotação em prontuário pode ser um indício de que o profissional enfermeiro aborda e observa, em sua consulta de puerpério, sinais e sintomas que indiquem infecção, porém não descreve ou ainda não está atento para as condições que pudessem incorrer em tal evento, não realiza o exame físico, faz seu atendimento voltado à saúde do neonato, abordando somente as questões de amamentação, infringindo de uma forma ou outra as normas do Conselho Federal de Enfermagem, que determina a Sistematização da Assistência de Enfermagem, em todas as suas etapas (COFEn, 2009).

Por exemplo, não há informações sobre a ocorrência de investigação dos aspectos nutricionais e de higiene, imprescindíveis para o estabelecimento do diagnóstico, para a análise sobre possível ocorrência de infecção e sobre as condutas a serem tomadas. A alimentação de má qualidade interfere no estado nutricional e 
imunológico da puérpera, e as más condições de higiene ligadas ao sítio e ao processo de cicatrização favorecem as deiscências (Carvalho, Souza, Medeiros, 2014; Lima et al.,2014). No estudo, identificaram-se prontuários sem esta anotação, fazendo com que se questione se esta questão foi investigada. A análise sobre estas condições vai além da identificação do IMC constante no prontuário.

Tecida esta breve consideração sobre informações não constantes nos documentos analisados, o estudo identificou mulheres com presença de sinais e sintomas sugestivos de infecção de sítio cirúrgico pós-parto cesáreo, algumas delas com diagnóstico médico.

A infecção de sítio cirúrgico é a segunda causa de infecção hospitalar e a primeira causa de pacientes cirúrgicos, correspondendo a $8 \%$ de todas as infecções pós-parto cesáreo (Carvalho, Souza, Medeiros, 2014; Pereira, Capuzzi, Silveira, 2012; Petter et al., 2013).

As mulheres que apresentaram sinais e sintomas sugestivos de infecção eram jovens, com idade entre 15 e 25 anos, não estando em consonância com os estudos que referem uma incidência aumentada para o risco de infecção em mulheres acima de 35 anos (Petter et al., 2013).

A variável raça/cor apresentou resultados com significância estatística para mulheres pardas e negras, podendo ser este um elemento de vulnerabilidade à infecção de sítio cirúrgico. Estudos junto à população de mulheres negras mostram que estas vivem contextos agregados de vulnerabilidade social - baixa renda e escolaridade, gravidez na adolescência, dificuldade de acesso ao pré-natal e as informações sobre os sinais do parto, sem trabalho remunerado e sem companheiro (Leal, Gama, Cunha,2005; Melo, 2005; Lopes, 2004; IPEA, et al. 2011; Secretaria de Políticas para as Mulheres, 2013).

Embora os resultados não tenham apresentado diferenças estatísticas significantes, as mulheres que apresentaram sinais e sintomas sugestivos de infecção eram, em sua maioria, solteiras, viviam com companheiro ou com companheiro e filhos e não exerciam atividade remunerada, coincidindo com os estudos já publicados 
(Sanches, Mamede, Vivancos, 2012). Em relação à escolaridade, o estudo mostrou que a maior parte das mulheres havia estudado mais de oito anos.

A maioria das mulheres que apresentaram sinais e sintomas sugestivos de infecção era considerada, segundo seu índice de massa corporal (IMC), com sobrepeso ou obesas.

A obesidade é considerada pela literatura como importante fator de risco para o desenvolvimento de infecção de sítio cirúrgico, devido à circulação tecidual ineficaz, maior acúmulo de seromas, hematomas e presença de tecido subcutâneo maior que dois centímetros, promovendo um risco maior de deiscências, porém mulheres com peso normal podem ter um acúmulo de gordura e em consequência a mesma quantidade de tecido implicando em risco igual (Carvalho, Souza, Medeiros,2014; Lima et al., 2014; Petter et al., 2013; Vermillion et al., 1995).

Relativo à presença de doenças crônicas, poucas mulheres apresentaram hipertensão arterial, e nenhuma mulher apresentou diabetes mellitus, a literatura evidencia que na ocorrência de diabetes há um aumento em cinco vezes o risco de infecção de sítio cirúrgico, e a hipertensão é responsável por muitas cesáreas de urgência (Silva Filho, 2010).

O uso de tabaco, álcool e outras drogas tem impacto direto no risco de desenvolvimento de infecção de sítio cirúrgico relatado em trabalhos que indicam que o tabaco, associado a alterações vasculares, compromete o processo de cicatrização, aumentando o risco de desenvolvimento de infecções locais, além de o uso de drogas e álcool estar relacionado à vulnerabilidade social (Petter et al., 2013).

As cesáreas realizadas de urgência, de gemelares, o tempo de ruptura de membranas maior que 12 horas, o trabalho de parto prolongado, toques vaginais em excesso, líquido amniótico com presença de mecônio são situações que elevam o risco para o desenvolvimento de infecções (Lima et al., 2014).

Embora o estudo só tenha levado em questão o tempo de ruptura de membranas, se cesárea de urgência ou de gemelares, a informação deste item é quase inexistente nos prontuários, deixando clara a falta de anotação destas questões e talvez da abordagem sobre estas condições, questionando-se se houve averiguação 
sobre o tempo do trabalho de parto, aspecto do líquido amniótico e número de toques vaginais realizados.

As questões relacionadas ao pré-natal interferem diretamente nas complicações pós-parto, como as infecções de sítio cirúrgico pós-parto cesáreo. 0 estudo mostrou que as mulheres tiveram em sua grande maioria seis ou mais consultas de pré-natal, iniciadas na maioria no primeiro trimestre, o que sugere um acompanhamento em termos quantitativos em consonância com os protocolos que tratam da Saúde da Mulher, em especial no pré-natal (Coelho, 2007).

Não há informações no prontuário sobre a participação das mulheres durante o pré-natal e puerpério em grupos de educação em saúde que devem ser espaços para troca de experiências, para sanar dúvidas e obter informações, promovendo a autonomia da mulher (Busanello et al., 2011). Um dos temas que deveriam ser abordados nas atividades de grupo, durante o pré-natal, é sobre a prevenção da infecção de sítio cirúrgico pós-parto cesáreo bem como os cuidados pós-operatórios e a identificação precoce de sinais e sintomas.

As infecções comunitárias, dentre elas hepatite B, C, sífilis, HIV, infecção do trato urinário que diferem das infecções hospitalares, por estar em ocorrência ou em incubação no momento da internação hospitalar, são importantes em relação ao desenvolvimento de infecções de sítio cirúrgico, pois propiciam a infecção endógena.

Identificaram-se mulheres que apresentaram sinais de infecção de sítio cirúrgico pós-parto cesáreo com sorologias positivas para sífilis e hepatite $B$, assim como infecção do trato urinário.

A situação vacinal e as infecções, dentre a referência utilizada, não são bem definidas e quase nunca abordadas. No estudo, as mulheres em sua maioria haviam recebido alguma dose contra tétano/difteria, hepatite $B$ e influenza.

É importante ressaltar que a imunização de gestantes é primordial para a saúde da mulher, evitando ou diminuindo os riscos de contaminação do vírus da hepatite $B$, onde na sua ocorrência predispõe a infecções, bem como o tétano que pode infectar o sítio cirúrgico. 
As mulheres que realizaram sua consulta de puerpério entre 8 e 30 dias, excetuando-se as variáveis obrigatórias no prontuário Mãe Paulistana como dor em baixo ventre, alterações urinárias, sangramento e leucorréia e que tiveram a anotação quanto ao aparecimento ou não de tais queixas, as variáveis febre, dor na incisão cirúrgica, dor abdominal e presença de secreção, tiveram um grande número de prontuários sem esta informação, dificultando a análise, diagnóstico de mulheres que apresentassem sinais e sintomas de infecção de sítio cirúrgico pós-parto cesáreo, bem como apresentação de diferença estatística significante.

Ainda que a referência utilizada nesta pesquisa mostre os diversos fatores de risco para o desenvolvimento de infecção de sítio cirúrgico pós-parto cesáreo, no presente estudo as variáveis, dor em baixo ventre, dor em incisão cirúrgica e presença de secreção tiveram diferença estatística significante no grupo de mulheres.

As variáveis relacionadas aos sinais e sintomas que sugeriram infecção também se apresentaram com alto índice sem informação, interferindo na qualificação da infecção, consequentemente poucas mulheres tiveram o diagnóstico realizado pelo médico.

A retirada de pontos, como importante momento para a observação do sítio cirúrgico, teve raras anotações da data de retirada e aspecto do sítio, influindo diretamente na qualidade da assistência e identificação de possível infecção de sítio cirúrgico.

A assistência no puerpério é imperativa para a identificação de fatores e riscos que possam afetar as mulheres e o recém-nascido, assim como uma intervenção rápida que garanta sua saúde (SES- SP, 2010).

Na saúde da mulher, durante o processo de gestação, parto e puerpério, parece que este último fica relegado a um segundo plano, sendo o foco neste momento voltado aos cuidados do recém-nascido. Este, portanto, é um período em que a mulher pode-se apresentar vulnerável à infecção, e o enfermeiro tem um papel importante na sua prevenção e controle (Souza, 2012).

É muito clara a atuação do enfermeiro, durante os períodos de pré-natal e parto, determinante nas atividades de prevenção da infecção pós-parto, com orientações e 
cuidados no pós-parto, bem definidos nos protocolos de atendimento e na consulta do enfermeiro. E o puerpério é um momento em que o enfermeiro deve estar vigilante e conheça os riscos, sinais e sintomas de uma possível infecção de sítio cirúrgico pósparto cesáreo, sua prevenção e a iminência de ocorrência, avaliando na consulta de puerpério através da anamnese, exame físico geral e específico, eventos que propiciem o desenvolvimento da infecção ou até mesmo identifique a infecção em curso.

Entende-se que uma consulta no puerpério, de boa qualidade, realizada pelo enfermeiro, como um dos elementos da dimensão programática, interfere na dimensão da vulnerabilidade individual da mulher à infecção de sítio cirúrgico.

Segundo a Resolução 358/2009 do Conselho Federal de Enfermagem, é necessário que o enfermeiro, ao realizar o atendimento, faça-o conforme a Sistematização da Assistência de Enfermagem (SAE), por meio do processo de enfermagem (PE), garantindo assim a segurança do paciente e a qualidade na assistência. Já salientava Wanda de Aguiar Horta (1979) que o modelo de processo de enfermagem deve apresentar as etapas do histórico de enfermagem, diagnóstico de enfermagem, plano assistencial, plano de cuidados ou prescrição de enfermagem, evolução e prognóstico de enfermagem. Para tanto, o enfermeiro deve conhecer o contexto onde se insere seu trabalho, sua clientela, com vistas ao ambiente em que o indivíduo vive, sua família e comunidade.

A consulta de puerpério deve obedecer aos requisitos do processo de enfermagem que constitui, em sua primeira etapa, a coleta de dados ou o histórico de enfermagem, caracterizada pelas informações da pessoa, família, comunidade e o processo saúde-doença. A etapa seguinte trata do diagnóstico de enfermagem que tem como objetivo subsidiar a tomada de decisão, de maneira a alcançar os resultados esperados (COFEn, 2009).

O planejamento de enfermagem, $3^{\text {a }}$ etapa, determina os resultados que se pretende alcançar, enquanto a implementação trata da realização das ações planejadas na etapa anterior (COFEn, 2009). 
$A$ avaliação de enfermagem, última etapa do $P E$, verifica as ações e seus resultados, se os mesmos obtiveram êxito ou carecem de mudanças ou adaptações no processo (COFEn, 2009).

No que tange ao diagnóstico de enfermagem, a Classificação Internacional de Práticas de Enfermagem em Saúde Coletiva (CIPESC®), potente instrumento de inovação tecnológica que organizam o trabalho dos enfermeiros e sistematizam a assistência, avaliando os processos de resultados, benefícios e impactos da assistência prestada pelos enfermeiros no Sistema único de Saúde (Cubas, 2009).

A CIPESC $\AA$ tem como base as necessidades de saúde individuais, da família e coletividade, traz diagnósticos e intervenções voltados à prática diária do enfermeiro na Atenção Básica. É um potente instrumento utilizado na consulta de puerpério (Albuquerque e Cubas, 2005).

Ainda relacionado ao diagnóstico, a Classificação Internacional de Atenção Primária (CIAP) publicada em 1987 pela Organização Mundial de Médicos de Família (WONCA) traz temas relacionados à Atenção Básica, está baseada em sintomas e condições dos usuários e não às doenças (WONCA,2009).

O CIAP trouxe a possibilidade para que os profissionais da Atenção Básica classifiquem seu atendimento alicerçado em três elementos de uma consulta: os motivos que levaram ao agendamento da consulta (MC), os diagnósticos ou problemas, os procedimentos realizados, seu uso é da equipe multiprofissional (WONCA, 2009).

A Classificação Internacional de Doenças (CID 10), ainda que contemple doenças e problemas de saúde que se encaixam nos atendimentos realizados na Atenção Básica, não é a classificação mais apropriada para este nível de atenção, portanto necessário a utilização com o CIAP, fornecendo assim informações e classificações completas sobre o usuário (WONCA, 2009).

No ano de 1995, foi lançado o CIAP 2, estabelecendo assim uma ligação com o CID 10, incluindo novas classificações e está estruturado em dois eixos com 17 capítulos, representados por letras que tratam dos órgãos ou sistemas e seus 
componentes, iguais para todos os capítulos, definidos pelos números de um ao sete (WONCA,2009).

O primeiro componente trata das queixas e sintomas, o segundo por procedimentos diagnósticos e preventivos, o terceiro por medicações, tratamentos e procedimentos terapêuticos, seguido dos componentes, resultado de exame, administrativo, acompanhamento e outros motivos de consulta, por fim, o componente de diagnósticos e doenças (WONCA, 2009).

O objetivo do uso do CIAP 2 na Atenção primária é reunir informações adequadas e completas através de categorias para estudo estatístico, e informações detalhadas no prontuário do usuário para tanto o Ministério da Saúde implantou seu uso nas equipes de Atenção Básica, sendo sua utilização obrigatória para a digitação de produção individual no Sistema de Informação em Saúde para a Atenção Básica, através do software eSUS AB (WONCA, 2009).

O profissional enfermeiro por ser, na maioria das vezes, o primeiro a ter contato com a gestante, no momento da realização do teste de gravidez, iniciando o pré-natal, deve estar atento para a necessidade de melhoria na coleta de dados do pré-natal, durante o pré-natal e na consulta de puerpério, para uma correta assistência e intervenção, garantindo assim uma assistência segura e livre de danos.

A consulta de puerpério deve conter um resumo da alta hospitalar, tempo de ruptura das membranas, número de toques vaginais, se ocorrência de cesárea de urgência e qual motivo, idade gestacional no momento do parto, queixas relatadas pela mulher bem como exame físico geral e específico que indique as variáveis de sinais e sintomas de uma possível infecção de sítio cirúrgico pós-parto cesáreo e posterior data da retirada dos pontos e aspecto do sítio cirúrgico.

Com a finalidade de promover uma melhor qualidade na assistência, sistematizando a assistência de enfermagem no puerpério, auxiliando o enfermeiro na identificação das infecções de sítio cirúrgico pós-parto cesáreo, alertando para a necessidade de prevenção e vigilância deste agravo, o estudo propõe um roteiro para auxílio à consulta de puerpério com indicadores simples, de fácil preenchimento que contemple as etapas do processo de enfermagem e que esteja voltado 
exclusivamente ao cuidado da mulher, no período de puerpério (Quadro 2). Foi elaborado um Instrutivo para preenchimento do Roteiro para Consulta do enfermeiro no puerpério pós-parto cesáreo (Apêndice 3).

Foi elaborado para que a coleta das informações e a anotação da consulta do roteiro sejam de fácil preenchimento. Há questões de múltipla escolha, algumas com exemplos para atentar aos sinais e sintomas que não estão de acordo com o que se considera como não presença de sinais sugestivos de infecção de sítio cirúrgico, além de contar com espaço para a descrição de situações e observações do profissional e da mulher.

O roteiro para consulta de enfermagem no puerpério pós-parto cesáreo foi composto em sua primeira parte pela identificação da mulher, data de nascimento, número do prontuário, número do cartão SUS e data da realização da consulta.

A segunda parte, que trata do Histórico de Enfermagem, compõe itens identificados no perfil identificado no presente estudo e na literatura científica que auxiliam na identificação de potenciais riscos para o desenvolvimento ou curso de infecção de sítio cirúrgico pós-parto cesáreo. Fazem parte do histórico de enfermagem o resumo de alta, o puerpério e o exame físico.

O resumo de alta traz informações importantes para alertar o profissional enfermeiro quanto aos indicadores que elevam o risco de infecção de sítio cirúrgico pós-parto cesáreo.

No resumo de alta, está contemplada a data do parto (dia, mês e ano), a identificação do estabelecimento onde ocorreu o parto, o tempo de ruptura de membranas e de trabalho de parto, o aspecto do líquido amniótico, o tempo de internação em dias, a identificação de cesárea de urgência e motivo, a idade gestacional no nascimento, a ocorrência de RN único ou gemelar e a anotação de intercorrências (descrição).

Relativo ao puerpério aborda o período entre o parto e a primeira consulta de puerpério em dias, alimentação e higiene se adequadas ou inadequadas, se mantém ou não suplementação com sulfato ferroso e o estado emocional se normal ou deprimido. 
Em queixas e achados, questiona se a puérpera teve febre, dor em baixo ventre, dor em sítio cirúrgico, alterações urinárias como disúria, polaciúria, leucorréia, sangramento ou qualquer outra questão referida pela mulher.

No exame físico avaliam-se as mamas, observando se normais, ingurgitadas, com presença de fissuras ou mastite. Avaliação do abdômen (flácido ou distendido), do sítio cirúrgico (presença de hiperemia, calor local, edema, deiscência), se visualizada secreção em sítio e aspecto da mesma (serosa, sanguinolenta, amarelopurulenta).

O exame físico contempla o exame ginecológico (normal, alterado ou não realizado), avaliação de presença de lóquios e aspecto, bem como outros achados.

A terceira parte do roteiro contém os principais diagnósticos de enfermagem que envolve o cuidado no período puerperal, segundo a Classificação Internacional das Práticas de Enfermagem em Saúde Coletiva (CIPESC®) e a Classificação Internacional da Atenção Primária (CIAP). Facilitará a identificação das principais complicações no puerpério, assim como o item de avaliação completa de saúde, sem presença de anormalidades, favorecendo a digitação no sistema eSUS e consequente complementação dos dados no sistema nacional.

A quarta e a quinta partes do roteiro tratam da prescrição de enfermagem e os encaminhamentos da consulta, objetivando o acompanhamento longitudinal desta mulher.

A última parte do roteiro traz atenção especial ao item de retirada de pontos, trazendo à tona não só a data de retirada dos mesmos, mas o aspecto do sítio cirúrgico que contribui para a identificação de infecção neste período e encaminhamentos possíveis ou necessários. 
Quadro 2 - Roteiro para consulta do enfermeiro no puerpério pós-parto cesáreo.

\section{ROTEIRO PARA CONSULTA DE ENFERMAGEM NO PUERPÉRIO PÓS PARTO}

\section{CESÁREO}

Nome:

DN:

Cartão SUS/ CNS Prontuário:

Data:

\section{HISTÓRICO DE ENFERMAGEM}

\section{RESUMO DE ALTA}

Data do parto:

Estabelecimento do parto:

Tempo de trabalho de parto:

horas

Ruptura

prematura de

( ) $\operatorname{sim}$

( ) não

membranas

Quanto tempo:

horas

( ) sem informação

Aspecto líquido

( ) normal

amniótico:

( ) presença de mecônio

( ) sem informação

Tempo de internação:

dias

Cesárea realizada ( ) sim

de urgência:

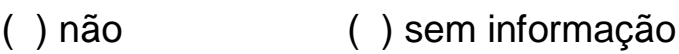

Motivo realização cesárea de

( ) sem informação urgência:
$\mathrm{RN}$
( ) único
( ) gemelar
Idade gestacional no nascimento:
Intercorrências: semanas
( ) $\operatorname{sim}$
( ) não

\section{PUERPÉRIO}
Consulta
( ) até 7 dias
( ) 8 a 30 dias
( ) 31 a 42 dias
( ) acima
puerpério
( ) adequada
( ) inadequada
Alimentação
( ) $\operatorname{sim}$
( ) não
( ) normal ( ) deprimido
Estado emocional
( ) adequada
( ) inadequada
Higiene

\section{QUEIXAS E ACHADOS}
Febre:
( ) $\operatorname{sim}$
( ) não
Dor em baixo
( ) $\operatorname{sim}$
( ) não
ventre
Dor sítio cirúrgico
( ) $\operatorname{sim}$
( ) não
Alterações
urinárias (disúria,
( ) $\operatorname{sim}$
( ) não
polaciúria...) 


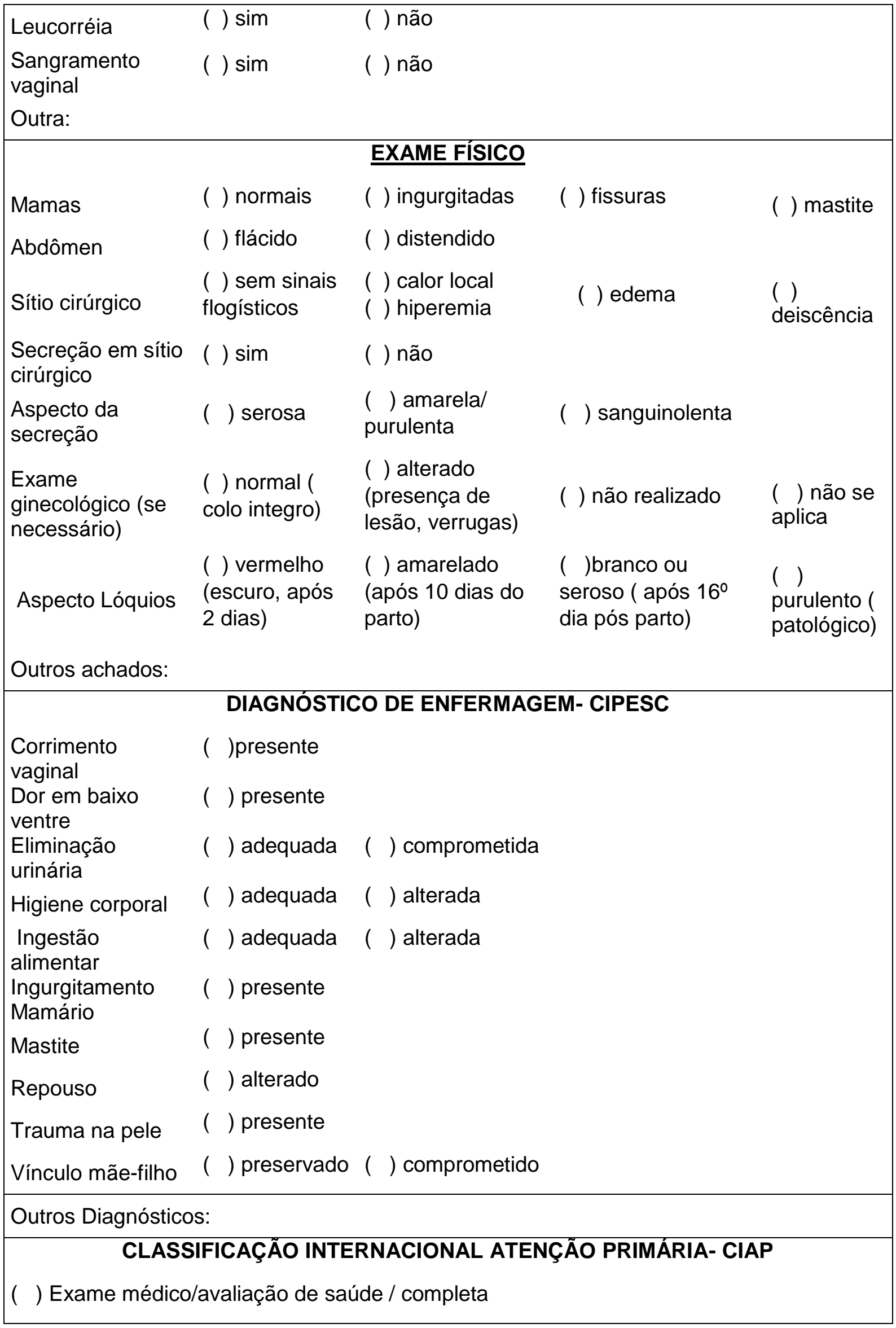


( ) W17 HEMORRAGIA PÓS-PARTO (sangramento pós-parto critérios: hemorragia franca no, durante ou até 6 semanas após o parto)

( ) W19 SINAIS/SINTOMAS DA MAMA/LACTAÇÃO (galactorreia, ablactação, desmame)

( ) W70 SÉPSIS/INFECÇÃO PUERPERA (critérios: infecção do canal de nascimento ou dos órgãos reprodutores até 6 semanas pós-parto)

( )W71 INFECÇÕES QUE COMPLICAM A GRAVIDEZ infecções maternas que complicam a gravidez ou o puerpério)

( ) W92 PARTO DE NASCIDO VIVO (parto assistido; parto pélvico; cesariana; distocia; parto induzido; lesões causadas pelo parto; placenta prévia durante o parto)

W94 MASTITE PUERPERAL (abcesso na mama; critérios: dor, inflamação da mama nas 6 semanas após o parto ou durante o aleitamento).

W95 OUTROS PROBLEMAS DA MAMA DURANTE A GRAVIDEZ/PUERPÉRIO (problemas da mama durante o puerpério, mamilo rachado)

Outras Classificações:

PRESCRIÇÃO DE ENFERMAGEM

\begin{tabular}{|l|}
\hline \\
\hline ENCAMINHAMENTOS \\
\hline \\
\hline \\
\hline Assinatura e carimbo do profissional: \\
\hline $\begin{array}{l}\text { Data retirada de } \\
\text { pontos: } \\
\text { Aspecto sítio } \\
\text { cirúrgico: }\end{array}$ \\
\hline \\
\hline Encaminhamentos: \\
\hline \\
\hline Assinatura e carimbo do profissional \\
\hline
\end{tabular}


O roteiro busca complementar o Prontuário Mãe Paulistana, assim como os dados coletados durante a assistência pré-natal em conjunto com as informações colhidas na consulta de puerpério que serão utilizadas para que o profissional enfermeiro se atente para o risco de desenvolvimento de infecção de sítio cirúrgico ou qualquer outro sinal de complicação pós-parto, subsidiando assim a tomada de decisão, quer seja no ambiente do domicílio ou na UBS. 


\section{CONCLUSÃO E CONSIDERACÕES FINAIS}




\section{CONCLUSÃO E CONSIDERAÇÕES FINAIS}

O estudo obteve como descrição sobre o perfil das mulheres submetidas ao parto cesáreo em relação às suas condições de vida, de saúde e perfil sociodemográfico durante a gestação, parto e puerpério, segundo variáveis selecionadas. As mulheres que tiveram parto cesárea no ano de 2014 tinham em média 25 anos; residia em casa de alvenaria, com acesso a rede elétrica, de esgotos e geral de água, em domicílios de três a quatro cômodos, acomodando de três a cinco pessoas. Em geral, companheiros e filhos de mulheres que se declaram casadas ou solteiras, metade delas exerciam atividade remunerada, com renda familiar de um a três salários mínimos.

As mulheres nasceram nas Regiões Sudeste e Nordeste do Brasil, declarando como cor da pele/raça parda, seguida da branca e negra, com nível de escolaridade em $60 \%$ das mulheres de 8 a 11 anos.

Apresentava na sua maioria um IMC considerado como peso saudável, porém $28 \%$ indicava sobrepeso ou algum grau de obesidade. As doenças crônicas como hipertensão e Diabetes foram pouco frequentes no grupo de mulheres, bem como uso de tabaco, álcool e outras drogas.

O pré-natal foi iniciado no primeiro trimestre, tiveram seis ou mais consultas e eram primigestas. Nas infecções comunitárias, nenhuma mulher teve resultado reagente para HIV, Hepatite $C$ e reagente para Sífilis em 13,6\% das mulheres e Hepatite B reagente em 2 mulheres, a infecção urinária foi diagnosticada em 29\% das mulheres.

Relacionado à imunização preconizada no pré-natal, mais de $65 \%$ das mulheres receberam alguma dose de vacina, dupla adulto, Hepatite B ou Influeza. A internação após o parto foi em média de 3 dias, com consulta ou visita de puerpério de 8 a 30 dias após o parto, com poucas informações sobre o momento da retirada dos pontos, o que dificultou a análise desta variável. 
Correlacionando a presença de sinais e sintomas sugestivos de infecção do sítio cirúrgico com o perfil de mulheres submetidas ao parto cesáreo, evidenciou um maior número de mulheres que se declaram pardas, com média etária de 24 anos, indo contrário aos estudos que indicam fator de risco idade materna maior que 35 anos, não exercendo atividade remunerada e solteiras, convivendo com companheiro com ou sem filhos e outros familiares.

Das mulheres que apresentaram sinais e sintomas de infecção de sítio cirúrgico, $50 \%$ tinham peso adequado e os outros $50 \%$ sobrepeso ou algum grau de obesidade, fator este considerado de risco nos estudos. A incidência de doenças neste grupo foi pequena, bem como o uso de tabaco. Não houve referência positiva quanto ao uso de álcool e outras drogas. A presença de sorologia reagente para Sífilis e Hepatie $B$ foram mais frequentes, assim como infecção urinária neste grupo de mulheres.

As queixas das mulheres iniciaram em até 7 dias após o parto cesáreo, apresentaram dentre os sintomas e sinais, dor em baixo ventre, febre, alteração urinária, sangramento, secreção amarela purulenta, dor no sítio cirúrgico, deiscência e tiveram diagnóstico médico de infecção em $50 \%$ dos casos com tratamento de escolha com antibioticoterapia.

As informações a serem consideradas na consulta do enfermeiro que o auxilie a reconhecer sinais e sintomas sugestivos de infecção do sítio cirúrgico pós-parto cesáreo, foram selecionadas a partir dos estudos realizados que indicaram fatores de risco para o desenvolvimento deste evento além dos dados necessários para um processo de enfermagem adequado, promovendo a segurança do paciente, com uma assistência pautada na qualidade e redução de danos.

De tal forma apresenta-se uma proposta de um roteiro que auxilie o enfermeiro da Atenção Básica a identificar, nas mulheres, condições sugestivas de infecção de sítio cirúrgico pós-parto cesáreo, na consulta à puérpera na Atenção Básica. Cabe, posteriormente, a validação do instrumento por profissionais da assistência na atenção básica e especialistas. 



\section{REFERÊNCIAS}

Albuquerque LM, Cubas MR. Cipescando em Curitiba: Construção e implementação da nomenclatura de diagnósticos e intervenções de enfermagem na Rede básica de Saúde. Curitiba: ABEn; 2005.

Almeida MS, Silva IA. Necessidades de mulheres no puerpério imediato em uma maternidade pública de Salvador, Bahia, Brasil. Rev Esc Enferm USP [Internet]. 2008 [citado 2014 ago. 01];42(2):347-54. Disponível em: http://www.scielo.br/pdf/reeusp/v42n2/a18.pdf.

Andrade LOM, Bueno ICHC, Bezerra RC. Atenção Primária à Saúde e Estratégia Saúde da Família. In: GWS, Minayo MCS, Akerman M, Drumond MJ, Carvalho YM. Tratado de Saúde Coletiva. Rio de Janeiro: Hucitec; Fiocruz; 2006. p. 783-836.

Anversa ETR, Bastos GAN, Pizzol TSD. Qualidade do processo da assistência prénatal: unidades básicas de saúde e unidades de Estratégia Saúde da Família em município no Sul do Brasil. Cad Saude Publica [Internet]. 2012 [citado 2014 set. 07];28(4):789-800.Disponível em: http://www.scielo.br/pdf/csp/v28n4/18.pdf.

Anvisa. Agência Nacional de Vigilância Sanitária. Segurança do Paciente e Qualidade em Serviços de Saúde. Critérios Diagnósticos de Infecção Relacionada à Assistência à Saúde [Internet]. Brasília; 2013. [citado 2014 abr. 05]. Disponível em: http://www20.anvisa.gov.br/segurancadopaciente/images/documentos/livros/Livro2CriteriosDiagnosticosIRASaude.pdf.

Anvisa. Agência Nacional de Vigilância Sanitária. Portal de serviços. Formulário de Notificação de Eventos Adversos em Serviços de Saúde para Cidadão [Internet]. Brasília; 2014. [citado 2014 ago. 20]. Disponível em: http://www16.anvisa.gov.br/notivisaServicos/cidadao/notificacao/eventoadverso/formulario.

Anvisa Agência Nacional de Vigilância Sanitária. Gerência de Vigilância e Monitoramento em Serviços de Saúde [GVIMS], Gerência Geral de Tecnologia em Serviços de Saúde [GGTES]. Critérios Diagnósticos de Infecções Relacionadas à Assistência à Saúde Neonatologia [Internet]. Brasília; 2013. [citado 2014 jn. 10]. Disponível em: http://www20.anvisa.gov.br/segurancadopaciente/images/documentos/livros/Livro3Neonatologia.pdf.

Anvisa. Agência Nacional de Vigilância Sanitária. RDC no 63 de 25 de novembro de 2011. Dispõe sobre os Requisitos de Boas Práticas de Funcionamento para os Serviços de Saúde. Diário Oficial da União; Brasília, 28 nov. 2011.

Anvisa. Agência Nacional de Vigilância Sanitária. Portaria ํo. 158, de 15 de agosto de 2012. Institui a Comissão Nacional de Prevenção e Controle de Infecção Relacionada à Assistência à Saúde (CNCIRAS). Diário Oficial da União. Brasília 15 ago. 2012. Seção 2. 
Anvisa. Agência Nacional de Vigilância Sanitária. Portal de serviços. Formulário de Notificação de Eventos Adversos em Serviços de Saúde para Cidadão [Internet]; Brasília; 2014. [citado 2014 ago. 20]. Disponível em: http://www16.anvisa.gov.br/notivisaServicos/cidadao/notificacao/eventoadverso/formulario.

Anvisa. Agência Nacional de Vigilância Sanitária. Nota técnica no 01/2014-Vigilância e Monitoramento das Infecções Relacionadas à Assistência à Saúde (IRAS) e Resistência Microbiana (RM) em serviços de saúde [Internet]; Brasília; 2014. [citado 2014 ago. 15]. Disponível em: http://portal.anvisa.gov.br/wps/wcm/connect/3885258043128c5986bdae4e9319b768/ NOTA+TECNICA+IRAS+E+RM+-+FEV+2014+II+(2).pdf?MOD=AJPERES.

Anvisa. Agência Nacional de Vigilância Sanitária. Programa Nacional de Prevenção e Controle de Infecções Relacionadas à Assistência à Saúde 2013-2015 [Internet]; Brasília; 2013 [citado 2014 mar. 10]. Disponível em: http://portal.anvisa.gov.br/wps/wcm/connect/cee7130041ab2617a746bfde61db78cc/ PNCIRAS++nov+2013.pdf?MOD=AJPERES.

Ayres JRCM, Calazans GJ, Saletti Filho HC, França Junior I. O risco, vulnerabilidade e práticas de prevenção e promoção da saúde. In: Campos GWS, Minayo MCS, Akerman M, Drumond MJ, Carvalho YM. Tratado de Saúde Coletiva. Rio de Janeiro: Hucitec; Fiocruz; 2006. p. 375-417.

Belizán JM, Althabe F, Barros FC, Alexander S. Rates and implicationsof caesarean sections in Latin America: ecological study. BMJ [Internet]. 199 [citado 2014 jun. 14];317(7222):1397-400. Disponível em: http://www.ncbi.nlm.nih.gov/pmc/articles/PMC28283/.

Brasil. Constituição, 1988. Constituição da República Federativa do Brasil. Brasília: Senado;1988.

Brasil. Lei Federal no9.431, de 06 de janeiro de 1997. Dispõe sobre a obrigatoriedade da manutenção de programa de controle de infecções hospitalares pelos hospitais do País. Diário Oficial da União; Brasília, 07 jan. 1997. Seção 1:265.

Brasil. Ministério da Saúde. Portaria oㅡ 2.616 de 12 de maio de 1998. Dispõe sobre a obrigatoriedade da manutenção pelos hospitais do país, de programa de controle de infecções hospitalares. Diário Oficial da União; Brasília, 13 maio 1998. Seção 1:135.

Brasil. Ministério da Saúde. Portaria no 930 de 27 de agosto de 1992. Dispõe sobre a expansão das normas para o controle das infecções hospitalares. Diário Oficial da União; Brasília, 04 set. 1992. Seção 1:111.

Brasil. Ministério da Saúde. Portaria oo196 de 24 de junho de 1983. Institui a implantação de Comissão de Infecção Hospitalar em todos os hospitais do país, independentemente da sua natureza jurídica. Diário Oficial da União; Brasília, 24 jun. 1983. Seção 1:39. 
Brasil. Ministério da Saúde. Agenda Nacional de Prioridades de Pesquisa em Saúde. 2‥ Brasília: MS; 2008.

Brasil. Ministério da Saúde. Pesquisa Nacional de Demografia e Saúde da Criança e da Mulher - PNDS 2006: dimensões do processo reprodutivo e da saúde da criança [Internet. Brasília; 2009 [citado 2015 set. 22]. Disponível em: http://bvsms.saude.gov.br/bvs/publicacoes/pnds crianca mulher.pdf.

Brasil. Ministério da Saúde. Programa Nacional de Segurança do paciente [Internet]. Brasília; 2013. [citado 2013 set. 20]. Disponível em: http://portalsaude.saude.gov.br/portalsaude/arquivos/pdf/2013/Abr/01/PPT COLETI VA SEGURANCA PACIENTE FINAL.pdf.

Brasil. Ministério da Saúde. Portaria no 1.377, de 9 de julho de 2013. Aprova os Protocolos de Segurança do Paciente. Diário Oficial da União. Brasília, 10 jul. 2013. Seção 1: 47.

Brasil. Ministério da Saúde. Portaria no 4.279, de 30 de dezembro de 2010. Estabelece diretrizes para a organização da Rede de Atenção à Saúde no âmbito do Sistema Único de Saúde (SUS). Diário Oficial da União. Brasília, 31 dez. 2010. Seção 1: 88.

Brasil. Ministério da Saúde. Portaria no 569 de 01 de junho de 2000. Institui o Programa de Humanização no Pré-natal e Nascimento, no âmbito do Sistema Único de Saúde. Diário Oficial da União. Brasília, 18 ago. 2000.

Busanello J, Lunardi Filho WD, Kerber NPC, Lunard VL, Santos SS. Participação da mulher no processo decisório no ciclo gravídico-puerperal: revisão integrativa do cuidado de enfermagem. Rev Gaucha Enferm [Internet]. 2011 [citado 2015 out. 10];32(4):807-14. Disponível em: http://www.scielo.br/pdf/rgenf/v32n4/v32n4a23.pdf.

Carvalho ICBM, Souza NL, Medeiros ATN. Fatores predisponentes para infecção da ferida operatória pós-cesárea: uma revisão integrativa. Revista de pesquisa, cuidado é fundamental online [Internet]. 2014 [citado 2015 set. 10];6(2):812-20. Disponível em: http://www.seer.unirio.br/index.php/cuidadofundamental/article/viewFile/2826/pdf 12 $\underline{91}$.

CDC. Surgical Site Infection (SSI) Event. Centers for Disease Control and Prevention [Internet]. EUA; s.d. [citado 2015 out. 10]. Disponível em: http://www.cdc.gov/nhsn/PDFs/pscManual/9pscSSlcurrent.pdf.

Chrestani MA, Santos IS, Cesar JA, Winckler LS, Gonçalves TS, Neumann NA. Assistência a gestação e ao parto: resultado de dois estudos transversais em áreas pobres das Regiões Norte e Nordeste do Brasil. Cad Saude Publica [Internet]. 2008 [citado $2014 \quad$ set. 27];24(7):1609-1618.Disponível em: http://www.scielo.br/pdf/csp/v24n7/16.pdf.

Coelho ICCAN. Infecção de sítio cirúrgico em pacientes submetidas à cesárea com sutura uterina exteriorizada versus sutura in situ: ensaio clínico randomizado [tese]. Pernambuco: Universidade Federal de Pernambuco;2007. 
Comitê Internacional de Classificação da Organização Mundial de Associações Nacionais, Academias e Associações Acadêmicas de Clínicos Gerais/Médicos de Família (WONCA). Classificação Internacional da Atenção Primária. Florianópolis: SBMFC; 2009.

Conselho Federal de Enfermagem (COFEn). Código de Ética dos Profissionais de Enfermagem. Rio de Janeiro: COFEn; 2007.

Conselho Federal de Enfermagem (COFEn). Resolução COFEn 258/2009. Dispõe sobre a Sistematização da Assistência de Enfermagem e a implementação do Processo de Enfermagem em ambientes, públicos ou privados, em que ocorre o cuidado profissional de Enfermagem, e dá outras providências. COFEn [Internet]. Brasília- DF; 2009 [citado 2015 out. 01].Disponível em: http://www.cofen.gov.br/resoluo-cofen-3582009 4384.html.

Conselho Regional de Enfermagem de São Paulo, Rede Brasileira de Enfermagem e Segurança do Paciente. 10 passos para a segurança do paciente. São Paulo: COREnSP, Rebraensp; 2010.

Conselho Regional de Enfermagem de São Paulo (COREn- SP). DIR/001/2000. Normatiza, no Estado de São Paulo, os princípios gerais para ações que constituem a documentação de enfermagem. COREn- SP [Internet]. São Paulo; 2000. [citado 2015 jun. 01]. Disponível em: http://www.coren-sp.gov.br/node/30747.

Costa CSC, Vila VSC, Rodrigues CAM, Pinho LMO. Características do atendimento pré-natal na Rede Básica de Saúde. Revista eletrônica de enfermagem: órgão da Faculdade de Enfermagem da Universidade Federal de Goiás. [electronic resource] [Internet]. 2013 [citado 2014 set. 10];15(2):516-22. Disponível em: https://www.fen.ufg.br/fen revista/v15/n2/pdf/v15n2a26.pdf.

Cubas MR. Instrumentos de Inovação tecnológica e política no trabalho em saúde e em enfermagem- a experiência da CIPE®/CIPESC®. Rev. Bras. Enferm [Internet]. 2009 [citado 2016 jan 03]; 62 (5): 745-7. Disponível em: http://www.scielo.br/scielo.php?pid=S0034-71672009000500016\&script=sci arttext.

Cunha MR, Nichiata LYI, Pereira EG, Padoveze MC. Infecção relacionada á assistência e a contribuição de serviços de atenção primária na educação profissional em saúde. [Apresentado no 14ํ Senaden; 2014 ago 07; Maceió.

Del Monte MCC. Vigilância após Alta em Cesáreas: Incidência e fatores Associados à Infecção do Sítio Cirúrgico [dissertação]. Campinas: Universidade Estadual de Campinas;2009.

Domingues RMSM, Hartz ZMA, Dias MAB, Leal MC. Avaliação da adequação da assistência pré-natal na rede SUS do Município do Rio de Janeiro. Cad Saude Publica [Internet]. 2012 [citado 2014 set. 10];28(3):425-437. Disponível em: http://www.scielo.br/pdf/csp/v28n3/03.pdf.

Eriksen H, Saether AR, Lower HL, Vangen S, Hjetland R, Lundmark H, et al. Infections after caesarean sections. Tidsskr Nor Laegeforen. 2009;129(7):618-622. 
Fernandes RA, Salum MJ, Teixeira MB, Lemmi RC, Miura M. Anotações de enfermagem. Rev Esc Enferm USP. 1981;15(1):63-68.

Hofelman DA. Tendência temporal de partos cesáreos no Brasil e suas Regiões: 1994 a 2009. Epidemiologia e serviços de saúde: revista do Sistema Unico de Saúde do Brasil. 2012;21(4):561-568.

Horta WA. Processo de Enfermagem. São Paulo: EPU; 1979.

Houaiss A, Villar MS.Dicionário Houaiss da língua portuguesa.1 $1^{a}$ edição Rio de Janeiro: Objetiva, 2009

Instituto de Pesquisa Econômica Aplicada - Ipea, ONU Mulheres, Secretaria de Políticas para as Mulheres - SPM, Secretaria de Políticas de Promoção da Igualdade Racial - SEPPIR. Retrato das desigualdades de gênero e raça. 4aㅡ ed. Brasília: Ipea; 2011.

Leal MC, Gama SGN, Cunha CB. Desigualdades raciais, sociodemográficas e na assistência ao pré-natal e parto, 1999-2001. Rev Saude Publica [Internet]. 2005 [citado 2015 set. 25];39(1):100-7.Disponível em: http://www.scielo.br/pdf/rsp/v39n1/13.pdf.

Lima DM, Wall ML, Hey A, Falcade AC, Chaves AC, Souza MAR. Fatores de risco para infecção no puerpério cirúrgico. Cogitare enfermagem : revista do Departamento de Enfermagem da UFPR [Internet]. 2014 [citado 2015 set. 12];19(4):734-40. Disponível em: http://ojs.c3sl.ufpr.br/ojs/index.php/cogitare/article/view/35170/23940.

Lopes F. Experiências desiguais ao nascer, viver, adoecer e morrer: tópicos em saúde da população negra no Brasil. [I Seminário Saúde da População Negra 2004]

Lopes CV, Meincke SMK, Quadros LCM, Vargas NRC, Schneider CC, Heck RM. Avaliação da consulta de revisão puerperal no programa de pré-natal. Journal of nursing and health/ Revista de Enfermagem e Saúde (JONAH / REnS) [Internet]. 2011 [citado 2014 set. 30];1(1):77-83. Disponível em: http://www.periodicos.ufpel.edu.br/ojs2/index.php/enfermagem/article/view/3409/280 $\underline{0}$.

MacDormam MF, Declercq E, Menacker F, Malloy MH. Infant and Neonatal Mortality for Primary Caesarean and Vaginal Births to Women with "No Indicated Risk" . Birth. 2006;33(3):175-82.

MacDormam MF, Declercq E, Menacker F, Malloy MH. Neonatal Mortality for Primary Caesarean and Vaginal Births to Low-Risk Women: Aplication of an "Intention-toTreat" Model. Bird. 2008;35(1):03-08.

Mandú ENT, Antiqueira UMA, Lanza RAC. Mortalidade materna: Implicações para o Programa Saúde da Família. Rev. enferm. UERJ [Internet]. 2009 [citado 2014 set. 28];17(2):278-84. Disponível em: http://www.facenf.uerj.br/v17n2/v17n2a25.pdf. 
Melo HP. Gênero e Pobreza no Brasil- Relatório Final do Projeto Governabilidad Democratica de Género en America Latina y el Caribe. Brasília: CEPAL- SPM; 2005.

Mello DS. Monitoramento das infecções de sítio cirúrgico no Estado de São Paulo: seleção de indicadores. [dissertação]. São Paulo: Escola de Enfermagem da Universidade de São Paulo; 2013.

Ministério da Saúde, Fundação Oswaldo Cruz, Agência Nacional de Vigilância à Saúde. Documento de Referência para o Programa Nacional de Segurança do Paciente; Brasília; 2014.

National Patient Safety Agency. Seven Steps to Patient Safety for Primary Care. Inglaterra: National Patient Safety Agency ; 2006.

Nichiata LYI, Bertolozzi MR, Takahashi RF, Fracolli LA. A utilização do conceito "Vulnerabilidade" pela enfermagem. Rev Lat Am Enfermagem [Internet]. 2008 [citado 2014 set. 20];15(5). Disponível em: http://www.scielo.br/pdf/rlae/v16n5/pt 20.

Nichiata LYI, Bertolozzi MR, Gryschek ALP, Araújo NVAL, Padoveze MC, Ciosak SI, Takahashi RF. Potencialidades do conceito de vulnerabilidade para compreensão das doenças transmissíveis. Rev Esc Enferm USP [Internet]. 2011 [citado 2014 set. 20];45(Esp 2):1769-73.Disponível http://www.revistas.usp.br/reeusp/article/view/40903/44373.

Oliveira DC, Mandú ENT, Corrêa ACP, Tomiyoshi JT, Teixeira RC. Estrutura organizacional da atenção pós-parto na Estratégia Saúde da Família. Esc Anna Nery [Internet]. 2013 [citado 2014 set. 29];17(3):446-454. Disponível em: http://www.scielo.br/pdf/ean/v17n3/1414-8145-ean-17-03-0446.pdf.

Organização Pan Americana da Saúde. Vigilância Epidemiológica de las infecciones Associadas a la Atención de la Salud en el Puerpério- Módulo V. Washington: OPS; 2014.

Padoveze MC, Figueiredo RM. O papel da Atenção Primária na prevenção de Infecções Relacionadas à Asssitência à Saúde. Rev Esc Enferm USP [Internet]. 2014 [citado 2015 ago. 01];48(6):1137-44. Disponível em: http://www.scielo.br/pdf/reeusp/v48n6/pt 0080-6234-reeusp-48-06-1137.pdf.

Parada CMGL. Avaliação da Assistência pré-natal e puerperal desenvolvida em região do interior do Estado de São Paulo em 2005. Revista brasileira de saúde materno infantil [Internet]. 2008 [citado 2014 set. 28];8(1):113-124. Disponível em: http://www.scielo.br/pdf/rbsmi/v8n1/13.pdf.

Patah LEM, Malik AM. Modelos de assistência ao parto e taxa de cesárea em diferentes países. Rev Saude Publica [Internet]. 2011 [citado 2014 maio 20];45(1):18594. Disponível em: http://www.scielo.br/pdf/rsp/v45n1/1759.pdf.

Pereira AH, Capuzzi IF, Silveira C. Fatores de risco relacionados ao ato cirúrgico em puérperas com infecção de sítio cirúrgico. Perspectivas médicas. [Internet]. 2012 
[citado 2015 set. 02];23(1):5-10. Disponível em: http://fmj.br/revista/pdfs/revista 2012 1.pdf.

Petter CE, Farret TCF, Scherer JS, Antonello VS. Fatores relacionados a infecção de sítio cirúrgico após procedimentos obstétricos. Sci Med [Internet]. 2013 [citado 2015 set. 10];23(1):28-33. Disponível em: http://revistaseletronicas.pucrs.br/ojs/index.php/scientiamedica/article/viewFile/12715 $\underline{19043}$.

Portal Brasil [Internet]. Brasília; s.d. [citado 2014 jul. 05]. Disponível em: http://www.brasil.gov.br/saude/2011/10/brasil-garante-pre-natal-a-mais-gestantes.

Programa das Nações Unidas para o Desenvolvimento. Melhorar a Saúde Materna. Programa das Nações Unidas para o Desenvolvimento [Internet]. Brasília; s.d. [atualizado 2015; citado 2014 jul. 10]. Disponível em: http://www.pnud.org.br/ODM5.aspx.

Projeto Região Oeste: Ensino, pesquisa e assistência- Faculdade de Medicina da USP [Internet]. São Paulo; s.d. [citado 2014 set. 24].Disponível em: http://pro.fm.usp.br/.

Rede Brasileira de Enfermagem e Segurança do Paciente. Estratégias para Segurança do Paciente: Manual para Profissionais da Saúde. Porto Alegre: ediPUCRS; 2013.

Ribeiro Filho B. Avaliação de Qualidade da Atenção Pré-Natal em quatro Unidades do Programa de Saúde da Família do município de Manaus-AM [dissertação]. Manaus: Centro de Pesquisa Leônidas e Maria Deane;2004.

Romanelli RMC, Aguiar RLP, Leite HV, Silva DG, Nunes RVP, Brito Jl et al. Estudo Prospectivo da implantação da vigilância ativa de infecções de feridas cirúrgicas póscesáreas em hospital universitário no Estado de Minas Gerais. Epidemiologia e serviços de saúde : revista do Sistema Unico de Saúde do Brasil [Internet]. 2012 [citado 2014 junho 10];21(4):569-578. Dispon'pivel em: http://scielo.iec.pa.gov.br/pdf/ess/v21n4/v21n4a06.pdf.

Sanches NC, Mamede FV, Vivancos RBZ. Perfil das mulheres submetidas à cesariana e assistência obstétrica na maternidade pública de Ribeirão Preto. Texto \& contexto enfermagem / UFSC [Internet]. 2012 [citado 2015 out. 18];21(2):418-26. Disponível em: http://www.scielo.br/pdf/tce/v21n2/a21v21n2.pdf. São Paulo. Secretária da Saúde do Estado de São Paulo. Atenção à gestante e a puérpera no SUS- SP: Manual Técnico do pré-natal e puerpério. São Paulo; 2010.

São Paulo. Secretária da Saúde do Estado de São Paulo. Coordenadoria de Controle das Doenças [CCD]. Vigilância das Infecções Hospitalares do Estado de São Paulo Dados 2004 - 2012. Boletim Epidemiológico Paulista [Internet]. 2014 [citado 2015 jun. 16]: 
São Paulo. Secretária de Saúde do Estado de São Paulo. Centro de Vigilância Epidemiológica [CVE]- Divisão de Infecção Hospitalar. Manual de Orientações e Critério Diagnóstico- Hospital Geral. [Internet]. São Paulo; 2015. [citado 2016 jan 03] Disponível em: http://www.cve.saude.sp.gov.br/htm/ih/pdf/manual15 hospgeral crit diag.pdf.

São Paulo. Secretária de Saúde do Estado de São Paulo. Centro de Vigilância Epidemiológica [CVE]- Divisão de Infecção Hospitalar. Projeto PROVITAE [Internet]. São Paulo; 2014. [citado 2014 nov. 17]. Disponível em: http://www.cve.saude.sp.gov.br/htm/ih/provitae index.htm.

São Paulo. Secretária de Saúde do Estado de São Paulo. Plano Estadual de Saúde 2012-2015 [Internet]. São Paulo; 2012. [citado 2014 ago. 20]. Disponível em: http://www.cvs.saude.sp.gov.br/up/pes 2012 2015\%20(site\%20SES-

$\underline{\text { SP\%2029ago13).pdf }}$

São Paulo. Secretária Municipal de Saúde. Coordenação de Epidemiologia e Informação.Boletim CEinfo Saúde em Dados. São Paulo; 2014.

São Paulo. Secretária Municipal de Saúde. Coordenação de Epidemiologia e Informação.Boletim CEinfo Saúde em Dados. São Paulo; 2015.

São Paulo. Secretária Municipal de Saúde. Coordenação de Epidemiologia e Informação. Sistema Nacional de Nascidos Vivos-Município de São Paulo [Internet]. São Paulo; 2015. [citado 2015 jun. 18]: Disponível em: http://tabnet.saude.prefeitura.sp.gov.br/cgi/deftohtm.exe?secretarias/saude/TABNET/ sinasc/nascido.def.

São Paulo. Secretária Municipal de Saúde de São Paulo. Coordenação de Vigilância em Saúde (COVISA). Informe Técnico no 42. Recomendações baseadas em evidências para a prevenção contra a infecção hospitalar do sítio cirúrgico. COVISA [Internet\}. São Paulo- SP; 2014 [citado 2016 jan 02]. Disponível em:

http://www.prefeitura.sp.gov.br/cidade/secretarias/upload/chamadas/informe tcnico 42 isc shea idsa - 092014 1447334278.pdf.

São Paulo. Secretária Municipal de Saúde de São Paulo. Rede de Proteção Mãe Paulistana [Internet]. São Paulo; 2014. [citado 2014 set. 18]. Disponível em: http://www.prefeitura.sp.gov.br/cidade/secretarias/saude/programas/mae paulistana/ index.php?p=5657.

Secretária de políticas para as mulheres- Presidência da República. Relatório Anual Socioeconômico da Mulher. Brasília-DF: SPM; 2013.

Serruya SJ, Cecatti JG, Lago TG. O Programa de Humanização no pré-natal e nascimento do Ministério da Saúde no Brasil: resultados iniciais. Cad Saude Publica [Internet]. 2004 [citado 2014 set. 15];20(5):1281-1289. Disponível em: http://www.scielo.br/pdf/csp/v20n5/22.pdf.

Setz VG, D'Innocenzo M. Avaliação da qualidade dos registros de enfermagem no prontuário por meio de auditoria. Acta paulista de enfermagem [Internet]. 2009 [citado 
2015

out.

10];22(3):313-7.

Disponível

em:

http://www.scielo.br/pdf/ape/v22n3/a12v22n3.pdf.

Silva Filho AL, Linhares LQ, Machado LRG, Guimarães LC, Azevedo LMM, Costa MAB et al. Infecção pós-cesariana: relato de caso. Rev. méd. Minas Gerais [Internet]. 2010 [citado 2015 out. 01];20(2 Supl 1):S117-S119. Disponível em: http://bases.bireme.br/cgi-

bin/wxislind.exe/iah/online/? IsisScript=iah/iah. $x i s \& s r c=$ google\&base $=$ LILACS\&lang $=p$ \&nextAction=Ink\&exprSearch=614070\&indexSearch=ID.

Silva OS, Borges EL, Lima MP. Fatores de risco para complicações das feridas cirúrgicas abdominais: uma revisão sistemática da literatura. REME [Internet]. 2008 [citado 2015 jul .10];12(4):539-546. Disponível em: http://www.reme.org.br/artigo/detalhes/299.

Souza AMB. Implantação de uma diretriz de assistência de enfermagem no puerpério na Atenção Primária à Saúde [dissertação]. Minas Gerais: Universidade Federal de Juiz de Fora;2012.

Souza JP, Gulmezoglu AM, Lumbiganon P, Laopaiboon M, Carroli G, Fawole B, et al. Caesarean section without medical indications is associated whit an increased risk of adverse short-term maternal outcomes: the 2004-2008 Who Global Survey on Maternal and Perinatal Health. BMC Med [Internet]. 2010 [citado 2014 jun. 10];8(71). Disponível em: http://www.biomedcentral.com/1741-7015/8/71.

Starfield B. Atenção Primária. Equilíbrio entre as necessidades de saúde e serviços de tecnologia. Brasília: UNESCO; 2002.

Teixeira JDR, Camargo FA, Trinchin DMR, Melleiro MM. A elaboração de indicadores de qualidade da Assistência de Enfermagem nos períodos puerperal e neonatal. Rev. enferm. UERJ [Internet]. 2006 [citado 2015 ago. 23];14(2):271-8. Disponível em: http://www.facenf.ueri.br/v14n2/v14n2a18.pdf.

Tura LMT, Soares K, Casartelli CH. Atenção Primária à Saúde. In: Souza MF, Franco MS, Mendonça AVM. Saúde da Família nos Municípios Brasileiros: Os reflexos dos 20 anos no espelho do Futuro. Campinas: Saberes; 2014. p. 178-205.

Vermillion ST, Lamoutte C, Soper DE, Verdeja A. Wound infection after cesarean: effect of the depth of subcutaneous tissue thickness. World J Obstet Gynecol [Internet]. 1995 [citado 2015 out. 01];95(6):923-6. Disponível em: http://www.ncbi.nlm.nih.gov/pubmed/10831993.

Victora CG, Aquino EML, Leal MC, Monteiro CA, Barros FC, Szwarcwald CL. Saúde das mães e crianças no Brasil: progressos e desafios. The Lancet. 2011;1(2):32-46.

Villar J, Carroli G, Zavaleta N, Donner A, Wojdyla D, Faundes A, et al.. Maternal and neonatal individual risks and benefits associated with caesarean delivery: multicenter prospective study. BMJ [Internet]. 2007 [citado 2014 ago. 10];1-11. Disponível em: http://www.bmj.com/content/bmj/335/7628/1025.full.pdf. 
World Health Organization. Prevention of hospital-acquired infections [Internet]. Geneva; 2002 [citado 2014 março 20]. Disponível em: http://www.who.int/csr/resources/publications/whocdscsreph200212.pdf.

World Health Organization. Safer Primary Care [Internet].Geneva; 2013. [citado 2013 set. 20]. Disponível em: http://www.who.int/patientsafety/safer primary care/en/index.html.

World Health Organization. Safer Primary Care: a Global Challenge [Internet]. Geneva; 2012. [citado 2013 Set 20]. Disponível em: http://www.who.int/patientsafety/summary report of primary care consultation.pdf.

World Health Organization. World Aliance for Patient Safety - Forward Programme [Internet]. Geneva, 2005. [citado 2013 set. 19]. Disponível em: http://www.who.int/patientsafety/en/brochure final.pdf. 



\section{APÊNDICES}

\section{APÊNDICE 1 - INSTRUMENTO DE COLETA DE DADOS}

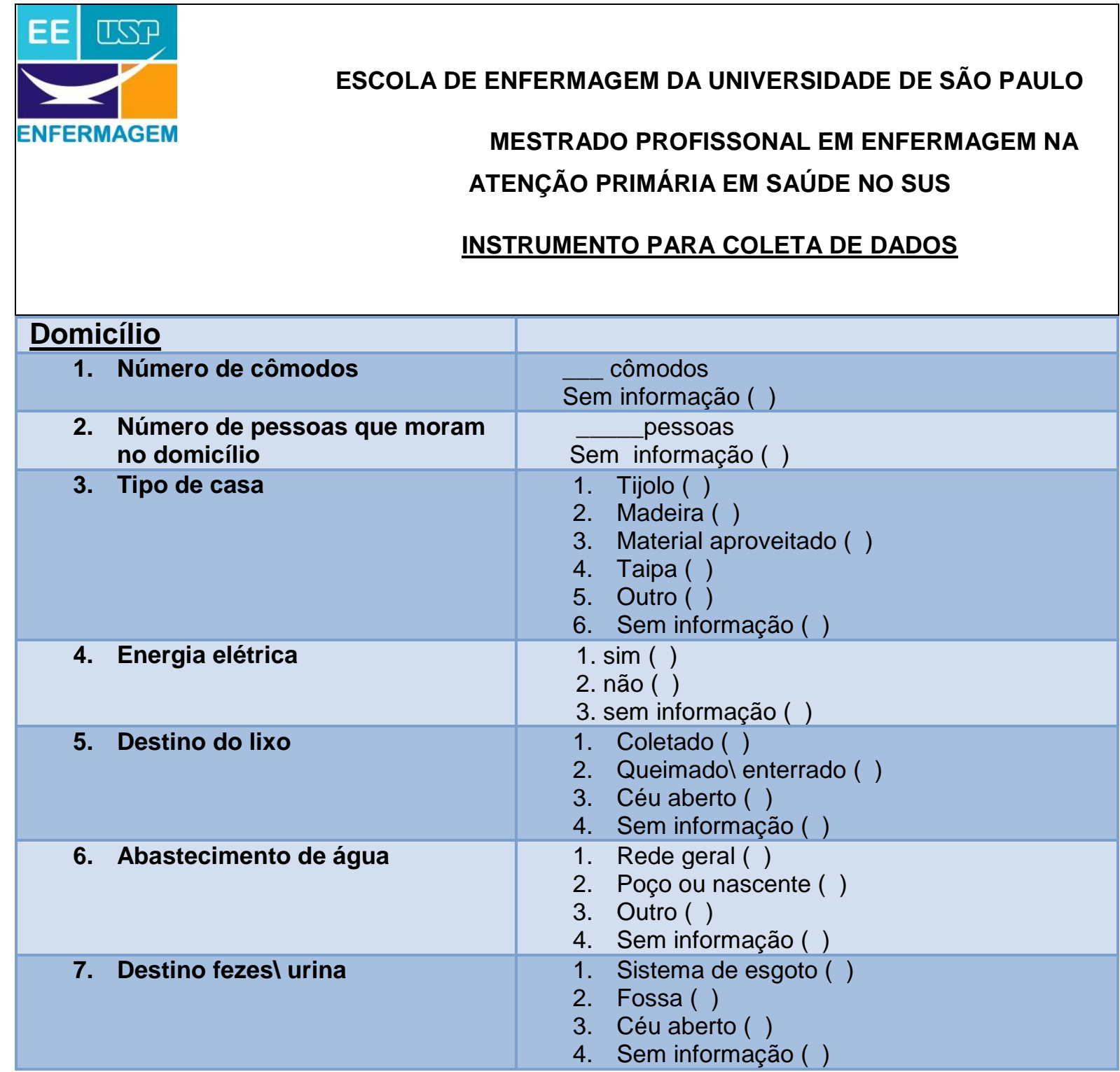

\section{Familiar e individual}

1. Renda familiar

1. Até 1 salário mínimo ( )

2. De 1 a 3 salários mínimos ( )

3. Acima de 3 salários mínimos ( )

4. Sem informação ( )

2. Situação familiar

1. convive com companheiro e filhos ( )

2. convive com companheiro com laços conjugais sem filhos ( )

3. convive com companheiros com filhos el ou outros familiares( )

4. convive com familiares sem companheiro ( ) 


\begin{tabular}{|c|c|}
\hline & $\begin{array}{l}\text { 5. convive com outra (s) pessoa (s), sem laços } \\
\text { consanguíneos el ou laços conjugais ( ) } \\
\text { 6. vive só ( ) } \\
\text { 7. sem informação ( ) }\end{array}$ \\
\hline 3. Estado civil & $\begin{array}{l}\text { 1. Sasada ( ) } \\
\text { 2. Solteira ( ) } \\
\text { 3. Solteira (com união estável) ( ) } \\
\text { 4. Separadal divorciada ( ) } \\
\text { 5. Viúva ( ) } \\
\text { 6. Sem informação ( ) }\end{array}$ \\
\hline 4. Trabalha & $\begin{array}{l}\text { 1. } \operatorname{Sim}() \\
\text { 2. Não }()\end{array}$ \\
\hline 5. Em caso afirmativo, ocupação: & \\
\hline $\begin{array}{l}\text { 6. Escolaridade (em anos de } \\
\text { estudos completos) }\end{array}$ & $\begin{array}{l}\text { 1. Nenhuma ( ) } \\
\text { 2. De } 1 \text { a } 3 \text { anos ( ) } \\
\text { 3. De } 4 \text { a } 7 \text { anos ( ) } \\
\text { 4. De } 8 \text { a } 11 \text { anos ( ) } \\
\text { 5. } 12 \text { anos ou mais ( ) } \\
\text { 6. Sem informação ( ) }\end{array}$ \\
\hline 7. Raça $\backslash$ cor informada & $\begin{array}{l}\text { 1. } \text { Branca ( ) } \\
\text { 2. Negra ( ) } \\
\text { 3. Parda ( ) } \\
\text { 4. Amarela ( ) } \\
\text { 5. Indígena ( ) } \\
\text { 6. Sem informação ( ) }\end{array}$ \\
\hline $\begin{array}{l}\text { 8. Data de nascimento (dia } \backslash \text { mês } \backslash \\
\text { ano com } 4 \text { dígitos) }\end{array}$ & $-1-1$ \\
\hline 9. Local de nascimento ( Estado) & \\
\hline $\begin{array}{l}\text { 10. Pertence a equipe de saúde da } \\
\text { família }\end{array}$ & $\begin{array}{l}\text { 1. } \operatorname{Sim}() \\
\text { 2. } \operatorname{Não(~})\end{array}$ \\
\hline
\end{tabular}

\begin{tabular}{|c|c|}
\hline Antecedentes Pessoais & \\
\hline 1. Peso & $\mathrm{kg}$ \\
\hline 2. Estatura & $\mathrm{cm}$ \\
\hline 3. IMC & \\
\hline 4. Hipertensão arterial & $\begin{array}{l}\text { 1. } \operatorname{Sim}(\text { ( ) } \\
\text { 2. Não ( ) }\end{array}$ \\
\hline 5. Diabetes melitus & $\begin{array}{l}\text { 1. } \operatorname{Sim}(\text { ) } \\
\text { 2. Não ( ) }\end{array}$ \\
\hline 6. Tabagista & $\begin{array}{l}\text { 1. } \operatorname{Sim}(\text { ( ) } \\
\text { 2. Não ( ) }\end{array}$ \\
\hline 7. Alcoolista & $\begin{array}{l}\text { 1. } \operatorname{Sim}() \\
\text { 2. Não( ) }\end{array}$ \\
\hline 8. Drogas & $\begin{array}{l}\text { 1. } \operatorname{Sim}() \\
\text { 2. Não ( ) }\end{array}$ \\
\hline
\end{tabular}

\begin{tabular}{|c|c|}
\hline Última gestação & \\
\hline $\begin{array}{l}\text { 1. Idade gestacional de inicio do pré } \\
\text { natal }\end{array}$ & $\begin{array}{l}\text { semanas } \\
\text { Sem informação ( ) }\end{array}$ \\
\hline 2. Data provável do parto & $\frac{1}{\text { Sem informação ( ) }}$ \\
\hline 3. Intervalo gestação $\backslash$ parto (anos) & $\begin{array}{l}\text { 1. Menos que } 1 \text { ano ( ) } \\
\text { 2. } 1 \text { a } 2 \text { anos ( ) } \\
\text { 3. } 3 \text { a } 4 \text { anos ( ) } \\
\text { 4. Maior que } 4 \text { anos ( ) }\end{array}$ \\
\hline
\end{tabular}




\begin{tabular}{|c|c|}
\hline & 5. Sem informação ( ) \\
\hline 4. Número de consultas de pré natal & $\begin{array}{l}\text { 1. Até } 3 \text { consultas ( ) } \\
\text { 2. De } 3 \text { A } 5 \text { consultas ( ) } \\
\text { 3. } 6 \text { ou mais consultas ( ) }\end{array}$ \\
\hline 5. Infecção comunitária & $\begin{array}{l}\text { Sífilis: } \\
\text { 1. Sim ( ) } \\
\text { 2. Não ( ) } \\
\text { 3. Sem informação ( ) } \\
\text { HIV } \\
\text { 1. Sim ( ) } \\
\text { 2. Não ( ) } \\
\text { 3. Sem informação } \\
\text { Hepatite B } \\
\text { 1. Sim ( ) } \\
\text { 2. Não ( ) } \\
\text { 3. Sem informação } \\
\text { Hepatite C } \\
\text { 1. Sim ( ) } \\
\text { 2. Não ( ) } \\
\text { 3. Sem informação } \\
\text { Infecção Urinária } \\
\text { 1. Sim ( ) } \\
\text { 2. Não ( ) } \\
\text { 3. Sem informação }\end{array}$ \\
\hline
\end{tabular}

\begin{tabular}{|c|c|}
\hline SituaçãoVacinal & \\
\hline 1. Tétano \difiteria & $\begin{array}{ll}\text { 1. } & 1^{\mathrm{a}} \text { dose ( ) } \\
\text { 2. } & 2^{\mathrm{a}} \text { dose }(\mathrm{)} \\
\text { 3. } & \text { Reforço ( ) } \\
\text { 4. } & \text { Imune ( ) } \\
\text { 5. } & \text { Sem informação ( ) }\end{array}$ \\
\hline 2. Hepatite B & $\begin{array}{ll}\text { 1. } & 1^{\mathrm{a}} \text { dose }(\mathrm{)} \\
2 . & 2^{\mathrm{a}} \text { dose }(\mathrm{)} \\
3 . & 3^{\mathrm{a}} \text { dose }(\mathrm{)} \\
\text { 4. } & \text { Sem informação }(\mathrm{)}\end{array}$ \\
\hline 3. Influenza & $\begin{array}{ll}\text { 1. } & \operatorname{Sim}(\mathrm{)} \\
\text { 2. Não ( ) } \\
\text { 3. Sem informação ( ) }\end{array}$ \\
\hline
\end{tabular}

\begin{tabular}{|c|c|}
\hline Parto & \\
\hline 4. Data do parto & $\overline{\text { Sem informação ( ) }}$ \\
\hline 5. $1^{\text {a }}$ consulta $\backslash$ visita puerpério & $\begin{array}{l}\text { 5. Até } 7 \text { dias ( ) } \\
\text { 6. De } 8 \text { a } 30 \text { dias ( ) } \\
\text { 7. De } 31 \text { a } 42 \text { dias ( ) } \\
\text { 8. Sem informação ( ) }\end{array}$ \\
\hline 6. Tempo de internação & $\frac{\text { dias }}{\text { Sem informação ( ) }}$ \\
\hline 7. Tempo de ruptura de membranas & $\overline{\text { Sem informação ( ) }}$ \\
\hline 8. Cesárea de urgência & $\begin{array}{l}\text { 1. Sim ( ) } \\
\text { 2. Não ( ) } \\
\text { 3. Sem informação ( ) }\end{array}$ \\
\hline 9. Cesárea de gemelares & $\begin{array}{ll}\text { 1. } & \text { Sim ( ) } \\
\text { 2. Não ( ) } \\
\text { 3. Sem informação ( ) }\end{array}$ \\
\hline
\end{tabular}




\begin{tabular}{|c|c|}
\hline \multicolumn{2}{|c|}{ Queixas e achados (início dos sintomas após o parto e em até 30 dias) } \\
\hline 1. Dor em baixo ventre & $\begin{array}{ll}\text { 1. } & \text { Sim ( ) } \\
\text { 2. } & \text { Não ( ) }\end{array}$ \\
\hline 2. Alterações urinárias & $\begin{array}{l}\text { 1. } \operatorname{Sim}(\text { ) } \\
\text { 2. Não( ) }\end{array}$ \\
\hline 3. Sangramento & $\begin{array}{l}\text { 1. } \operatorname{Sim}() \\
\text { 2. Não ( ) }\end{array}$ \\
\hline 4. Leucorréia & $\begin{array}{l}\text { 1. } \operatorname{Sim}() \\
\text { 2. Não( })\end{array}$ \\
\hline 5. Febre (acima $\left.37,8^{\circ} \mathrm{C}\right)$ & $\begin{array}{l}\text { 1. Sim ( ) } \\
\text { 2. Não ( ) } \\
\text { 3. Sem informação ( ) }\end{array}$ \\
\hline 6. Dor (incisão cirúrgica) & $\begin{array}{l}\text { 1. Sim ( ) } \\
\text { 2. Não ( ) } \\
\text { 3. Sem informação }\end{array}$ \\
\hline 7. Dor abdominal & $\begin{array}{ll}\text { 1. } & \text { Sim ( ) } \\
\text { 2. Não ( ) } \\
\text { 3. Sem informação ( ) }\end{array}$ \\
\hline
\end{tabular}

\begin{tabular}{|c|c|}
\hline Sítio cirúrgico & \\
\hline 1. Presença de secreção & $\begin{array}{ll}\text { 1. } & \text { Sim ( ) } \\
\text { 2. Não ( ) } \\
\text { 3. Sem informação ( ) }\end{array}$ \\
\hline 2. Aspecto secreção & $\begin{array}{l}\text { 1. Clara ( ) } \\
\text { 2. Amarelal purulenta ( ) } \\
\text { 3. Sanguinolenta ( ) } \\
\text { 4. Sem informação ( ) } \\
\text { 5. Não se aplica ( ) }\end{array}$ \\
\hline 3. Hiperemia & $\begin{array}{l}\text { 1. Sim ( ) } \\
\text { 2. Não ( ) } \\
\text { 3. Sem informação ( ) }\end{array}$ \\
\hline 4. Calor & $\begin{array}{ll}\text { 1. } & \text { Sim ( ) } \\
\text { 2. Não ( ) } \\
\text { 3. Sem informação ( ) }\end{array}$ \\
\hline 5. Edema & $\begin{array}{l}\text { 1. Sim ( ) } \\
\text { 2. Não ( ) } \\
\text { 3. Sem informação ( ) }\end{array}$ \\
\hline 6. Deiscência & $\begin{array}{ll}\text { 1. } & \text { Sim ( ) } \\
\text { 2. Não ( ) } \\
\text { 3. Sem informação ( ) }\end{array}$ \\
\hline 7. Abcesso & $\begin{array}{l}\text { 1. Sim ( ) } \\
\text { 2. Não ( ) } \\
\text { 3. Sem informação ( ) }\end{array}$ \\
\hline $\begin{array}{l}\text { 8. Data inícios dos sinais e } \\
\text { sintomas }\end{array}$ & $\begin{array}{l}\text { Sem informação ( ) } \\
\text { Não se aplica ( ) }\end{array}$ \\
\hline 9. Data da retirada dos pontos & Sem informação ( ) \\
\hline $\begin{array}{l}\text { 10. Aspecto no momento da retirada } \\
\text { dos pontos }\end{array}$ & Sem informação ( ) \\
\hline $\begin{array}{l}\text { 11. Profissional que observou o } \\
\text { evento }\end{array}$ & $\begin{array}{l}\text { 1. Médico ( ) } \\
\text { 2. Enfermeiro ( ) } \\
\text { 3. Técnicol auxiliar de enfermagem ( ) } \\
\text { 4. Hospital ( ) }\end{array}$ \\
\hline
\end{tabular}




\begin{tabular}{|c|c|}
\hline & $\begin{array}{l}\text { 5. Sem informação ( ) } \\
\text { 6. Não se aplica ( ) }\end{array}$ \\
\hline $\begin{array}{l}\text { 12. Encaminhado para avaliaçãol } \\
\text { diagnóstico médico }\end{array}$ & $\begin{array}{l}\text { 1. Sim ( ) } \\
\text { 2. Não ( ) } \\
\text { 3. Sem informação ( ) } \\
\text { 4. Não se aplica ( ) }\end{array}$ \\
\hline $\begin{array}{l}\text { 13. Diagnóstico de infecção } \\
\text { realizado pelo médico }\end{array}$ & $\begin{array}{l}\text { 1. Sim ( ) } \\
\text { 2. Não ( ) } \\
\text { 3. Sem informação ( ) } \\
\text { 4. Não se aplica ( ) }\end{array}$ \\
\hline 14. Encaminhado para outro serviço & $\begin{array}{l}\text { 1. Sim ( ) } \\
\text { 2. Não ( ) } \\
\text { 3. Sem informação ( ) } \\
\text { 4. Não se aplica ( ) }\end{array}$ \\
\hline 15. Tratamento realizado & $\begin{array}{l}\text { 1. Sim ( ) } \\
\text { 2. Não ( ) } \\
\text { 3. Sem informação ( ) } \\
\text { 4. Não se aplica( ) }\end{array}$ \\
\hline 16. Tipo de tratamento & $\begin{array}{l}\text { Sem informação ( ) } \\
\text { Não se aplica ( ) }\end{array}$ \\
\hline 17. Notificação do evento & $\begin{array}{l}\text { 1. Sim ( ) } \\
\text { 2. Não ( ) } \\
\text { 3. Sem informação ( ) } \\
\text { 4. Não se aplica ( ) }\end{array}$ \\
\hline
\end{tabular}




\section{APÊNDICE 2 - TERMO DE CONSENTIMENTO LIVRE E ESCLARECIDO}

Você está sendo convidada a participar da pesquisa "Vulnerabilidades das mulheres às infecções de sítio cirúrgico pós-parto cesárea: subsídios de um roteiro às consultas de enfermeiros da Atenção Básica".

O objetivo desta pesquisa é auxiliar o enfermeiro da UBS a identificar na consulta de puerpério das mulheres que tiveram parto cesárea, a infecção na cirurgia após o parto.

Sua participação será através da análise de seu prontuário geral e prontuário Mãe Paulistana relativa à sua última gestação. As informações coletadas serão tratadas com absoluto sigilo, e não será publicado seu nome ou qualquer dado que possa lhe identificar.

Você não terá nenhum gasto com a participação nesta pesquisa, e poderá retirar-se do estudo a qualquer tempo, sem nenhum problema, incluindo o atendimento na unidade, que continuará normal.

Será fornecida a você uma cópia deste Termo de Consentimento Livre e Esclarecido, devidamente assinado por esta pesquisadora.

Se você tiver dúvidas ou denúncias quanto às questões éticas deste estudo, poderá entrar em contato com o Comitê de Ética em Pesquisa do Município de São Paulo através do e-mail: smscep@gmail.com ou do telefone (11) 3397-2464.

Para dúvidas e esclarecimentos sobre o projeto, entre em contato com a pesquisadora pelo e mail: marciareginacunha18@hotmail.com ou telefone (11) 99369-5616.

Agradeço deste já sua valiosa participação

\section{Pesquisadora Marcia Regina Cunha}

Av. Dr. Enéas de Carvalho Aguiar, 419 São Paulo- SP

$\mathrm{Eu}$ após ter sido devidamente esclarecido, aceito participar voluntariamente do estudo.

São Paulo, de de 2015. 
APÊNDICE 3 - INSTRUTIVO PARA PREENCHIMENTO DO ROTEIRO PARA CONSULTA DO ENFERMEIRO NO PUERPÉRIO PÓS-PARTO CESÁREO

Instrutivo para Preenchimento do Roteiro para Consulta do enfermeiro no puerpério pós-parto cesáreo

\author{
MARCIA REGINA CUNHA \\ SÃO PAULO \\ 2015
}




\section{Instrutivo para Preenchimento do Roteiro para Consulta do enfermeiro no puerpério pós-parto cesáreo}

Este instrutivo é parte integrante da Dissertação apresentada ao programa de pós-graduação Mestrado profissional em Atenção Primária à Saúde no Sistema Único de Saúde da Escola de Enfermagem da Universidade de São Paulo, para obtenção do título de mestre em Ciências.

Marcia Regina Cunha

São Paulo, 2015 


\section{Instrutivo para Preenchimento do Roteiro para Consulta do enfermeiro no puerpério pós-parto cesáreo}

ESTE INSTRUTIVO IRÁ AUXILIÁ-LO NO PREENCHIMENTO DO ROTEIRO PARA CONSULTA DO ENFERMEIRO NO PUERPÉRIO PÓS-PARTO CESÁREO, SUBSIDIANDO ASSIM O PROCESSO DE ENFERMAGEM NO ATENDIMENTO À PUÉRPERA NA ATENÇÃO BÁSICA. 
Instrutivo para Preenchimento do Roteiro para Consulta do enfermeiro no puerpério pós-parto cesáreo

Parte 1. Identificação da puérpera: dados completos, afim de evitar duplicidade de usuárias, promovendo a segurança do paciente.

\begin{tabular}{lc} 
Nome completo: & DN: \\
\hline Cartão SUS/ CNS & Prontuário: \\
\hline Data: & Horário do atendimento:
\end{tabular}

$\checkmark$ Nome: completo, sem abreviaturas.

$\checkmark$ Data de Nascimento (DN): dia e mês do nascimento preenchido com dois dígitos, ano com quatro dígitos.

$\checkmark$ Cartão Nacional de Saúde/ cartão SUS: número com 15 dígitos.

$\checkmark$ Prontuário: número completo do prontuário família e/ ou individual.

$\checkmark$ Data: data do atendimento na consulta de puerpério, preenchidos com dois dígitos no dia e mês de atendimento e quatro dígitos o ano.

$\checkmark$ Horário atendimento: preencher o horário de início da consulta, mensurado em horas e minutos.

Parte 2. Histórico de enfermagem

$\checkmark$ O Histórico de Enfermagem no roteiro compreende a coleta de dados contidos no resumo de alta da puérpera, na consulta de puerpério com relatos da mulher e observação do profissional enfermeiro e o exame físico específico para o tipo de atendimento.

$\checkmark$ O histórico de enfermagem deve conter informações claras, concisas e completas e tem como objetivo identificar os fatores de risco que contribuem para o desenvolvimento de complicações no puerpério, com destaque para as infecções de sítio cirúrgico (ISC) pós-parto cesáreo, bem como sinais e sintomas sugestivos das ISC 


\section{Instrutivo para Preenchimento do Roteiro para Consulta do enfermeiro no}

\section{puerpério pós-parto cesáreo}

2.1 Resumo de alta: deve acompanhar a puérpera no momento da alta hospitalar e a mulher deve ser orientada ainda no pré-natal da necessidade de leva-lo na consulta de puerpério.

\section{RESUMO DE ALTA}

\begin{tabular}{|c|c|c|c|}
\hline Data do parto: & & & \\
\hline \multicolumn{4}{|l|}{ Estabelecimento do parto:_ } \\
\hline \multicolumn{2}{|l|}{ Tempo de trabalho de parto: } & _horas & \\
\hline $\begin{array}{l}\text { Ruptura prematura de } \\
\text { membranas }\end{array}$ & ( ) sim & ( ) não & \\
\hline Quanto tempo: & horas & ( ) sem informação & \\
\hline Aspecto líquido amniótico: & $\begin{array}{l}\text { ( ) } \\
\text { normal }\end{array}$ & $\begin{array}{l}\text { ( ) presença de } \\
\text { mecônio }\end{array}$ & $\begin{array}{l}\text { ( ) sem } \\
\text { informação }\end{array}$ \\
\hline \multicolumn{2}{|l|}{ Tempo de internação: } & _ dias & \\
\hline $\begin{array}{l}\text { Cesárea realizada de } \\
\text { urgência: }\end{array}$ & ( ) sim & ( ) não & $\begin{array}{l}\text { ( ) sem } \\
\text { informação }\end{array}$ \\
\hline \multicolumn{2}{|c|}{ Motivo realização cesárea de urgência: } & informação & ___ ( ) sem \\
\hline RN & ( ) único & ( ) gemelar & \\
\hline $\begin{array}{l}\text { Idade gestacional no } \\
\text { nascimento: }\end{array}$ & $\varlimsup_{\text {as }}$ seman & & \\
\hline Intercorrências: & ( ) $\operatorname{sim}$ & ( ) não & \\
\hline Quais: & & & \\
\hline
\end{tabular}

$\checkmark$ Data do parto: preencher dia e mês do parto com dois dígitos e ano com quatro dígitos.

$\checkmark$ Estabelecimento do parto: local da ocorrência do parto (hospital, maternidade), com nome da instituição.

$\checkmark$ Tempo de trabalho de parto; mensurado em horas do início do trabalho de parto e o procedimento cirúrgico (parto cesáreo).

$\checkmark$ Ruptura de membranas: sim, não ou sem informação, caso não conste no resumo de alta.

$\checkmark$ Caso tenha ocorrido a ruptura de membranas, anotar em horas quanto tempo decorreu entre a ruptura e o parto cesáreo. Caso não haja esta informação no resumo de alta, colocar no item sem informação. 


\section{Instrutivo para Preenchimento do Roteiro para Consulta do enfermeiro no}

puerpério pós-parto cesáreo

2.1 Resumo de alta: deve acompanhar a puérpera no momento da alta hospitalar e a mulher deve ser orientada ainda no pré-natal da necessidade de leva-lo na consulta de puerpério.

$\checkmark$ Aspecto do Líquido Amniótico: assinalar conforme resumo de alta, se normal, presença de mecônio. Caso não exista relato, anotar como sem informação.

$\checkmark$ Tempo de internação: mensurado em dias (inclui internação pré e pós-parto).

$\checkmark$ Cesárea realizada de urgência: sim, não ou sem informação caso não haja relato no resumo de alta.

$\checkmark$ Em caso afirmativo da realização da cesárea de urgência, anotar o motivo/ diagnóstico, ou sem informação caso não tenha esta informação no resumo de alta.

$\checkmark$ Em RN (recém-nascido), assinalar se feto único ou gemelar.

$\checkmark$ Idade gestacional (IG) no nascimento: anotar IG em semanas na data do parto.

Instrutivo para Preenchimento do Roteiro para Consulta do enfermeiro no puerpério pós-parto cesáreo

$\checkmark$ Intercorrências: houve ou não intercorrências. Em caso afirmativo anotar quais intercorrências houveram.

2.2 Puerpério: se inicia imediatamente após o parto e dura, em média seis semanas. É classificado em puerpério imediato (do $1^{\circ}$ ao $10^{\circ}$ após o parto), tardio (do $11^{\circ}$ ao $45^{\circ}$ dia) e remoto (após o 45ํia) (Brasil, 2015).

\begin{tabular}{|lllll|} 
Consulta puerpério & $\begin{array}{l}\text { ( ) até } 7 \\
\text { dias }\end{array}$ & $\begin{array}{l}\text { ( ) } 8 \text { a } 30 \\
\text { dias }\end{array}$ & $\begin{array}{l}\text { ( ) 31 a } 42 \\
\text { dias }\end{array}$ & $\begin{array}{l}\text { ( ) acima de } 42 \\
\text { dias }\end{array}$ \\
\hline Alimentação & $\begin{array}{l}\text { ( ) } \\
\text { adequada }\end{array}$ & $\begin{array}{l}\text { ( ) } \\
\text { inadequada }\end{array}$ & \\
\hline $\begin{array}{l}\text { Suplementação Sulfato } \\
\text { Ferroso }\end{array}$ & $\begin{array}{l}\text { ( ) sim } \\
\text { ( ) não }\end{array}$ & \\
\hline Estado emocional & ( ) normal & $\begin{array}{l}\text { ( ) } \\
\text { deprimido }\end{array}$ & \\
\hline Higiene & $\begin{array}{l}\text { ( ) } \\
\text { adequada }\end{array}$ & $\begin{array}{l}\text { inadequada } \\
\text { inade }\end{array}$ &
\end{tabular}




\section{Instrutivo para Preenchimento do Roteiro para Consulta do enfermeiro no}

\section{puerpério pós-parto cesáreo}

\subsection{Puerpério.}

Consulta de puerpério: anotar em dias, da data do parto à consulta de puerpério.

$\checkmark$ Alimentação: levar em consideração rotina alimentar preconizada pelos 10 passos de uma alimentação Saudável, com 3 refeições diárias (café da manhã, almoço e jantar), mais dois lanches saudáveis por dia, seguindo as recomendações por grupos.

\begin{tabular}{|ll|}
\hline Grupo & Porção/ dia \\
\hline Cereais e tubérculos & 6 \\
\hline Legumes e verduras & 3 \\
\hline Leite e derivado & 1 \\
Carnes, peixes e ovos & 1 \\
Óleos vegetais, azeita, manteiga, margarina & 1 \\
\hline
\end{tabular}

\section{Recomendar:}

Comer arroz e feijão todos os dias da semana (pelo menos cinco vezes na semana).

$\checkmark$ Beber pelo menos dois litros de água por dia (6 a 8 copos).

$\checkmark$ Evitar produtos industrializados, sal.

$\checkmark$ Suplementação de Sulfato ferroso: O Ministério da Saúde recomenda a prescrição de sulfato ferroso $40 \mathrm{mg}$ de ferro elementar (comprimido de $200 \mathrm{mg}$ ), 30 minutos antes almoço, de preferência com suco de frutas cítricas, até três meses após o parto (Brasil, 2013; 2015).

$\checkmark$ Estado emocional: acolher a mulher e observar, humor, preocupações, desânimos, fadiga, tristeza, depressão e transtorno psicótico puerperais

$\checkmark$ Anotar se normal ou humor deprimido.

$\checkmark$ Higiene: avaliar higiene corporal, sítio cirúrgico (atentar para cultura popular no sítio cirúrgico como o uso do pó de café no sítio cirúrgico, não lavagem de cabelos ou do local do procedimento). 


\section{Instrutivo para Preenchimento do Roteiro para Consulta do enfermeiro no}

\section{puerpério pós-parto cesáreo}

2.3 Queixas e achados: Perguntar à puérpera queixas, estar atento as suas respostas, observando sinais indicativos que possam auxiliar nesta etapa.

Anotar nos locais indicados se resposta afirmativa, sim ou não em caso negativo.

\begin{tabular}{|ll|l|}
\hline Febre: & ( ) sim & ( ) não \\
\hline Dor em baixo ventre & ( ) sim & ( ) não \\
\hline Dor sítio cirúrgico & ( ) sim & ( ) não \\
\hline Alterações urinárias (disúria, polaciúria...) & ( ) sim & ( ) não \\
\hline Leucorréia & ( ) sim & ( ) não \\
\hline Sangramento vaginal & ( ) sim & ( ) não \\
\hline Outras queixas/ achados & & \\
\hline
\end{tabular}

$\checkmark$ Febre: Temperatura aferida em termômetro acima de $37,8^{\circ} \mathrm{C}$.

$\checkmark$ Dor em baixo ventre;

$\checkmark$ Dor em sítio cirúrgico.

$\checkmark$ Alterações urinárias: dor, dificuldade ao urinar, polaciúria.

$\checkmark$ Leucorréia: presença e aspecto da secreção vaginal.

$\checkmark$ Sangramento vaginal: presença, quantidade e aspecto do sangramento.

$\checkmark$ Anotar no espaço outra, se queixa ou achado não listado acima.

\subsection{Exame físico: geral e específico}

\begin{tabular}{|c|c|c|c|c|}
\hline Mamas & ( ) normais & ( ) ingurgitadas & ( ) fissuras & ( ) mastite \\
\hline Abdômen & ( ) flácido & ( ) distendido & & \\
\hline Sítio cirúrgico & $\begin{array}{l}\text { ( ) sem sinais } \\
\text { flogísticos }\end{array}$ & $\begin{array}{l}\text { ( ) calor local } \\
\text { ( ) hiperemia }\end{array}$ & ( ) edema & $\begin{array}{l}\text { ( ) } \\
\text { deiscência }\end{array}$ \\
\hline $\begin{array}{l}\text { Secreção em } \\
\text { sítio cirúrgico }\end{array}$ & ( ) $\operatorname{sim}$ & ( ) não & & \\
\hline $\begin{array}{l}\text { Aspecto da } \\
\text { secreção }\end{array}$ & ( ) serosa & $\begin{array}{l}\text { ( ) amarela/ } \\
\text { purulenta }\end{array}$ & ( ) sanguinolenta & \\
\hline $\begin{array}{l}\text { Exame } \\
\text { ginecológico } \\
\text { (se necessário) }\end{array}$ & $\begin{array}{l}\text { ( ) normal ( } \\
\text { colo integro) }\end{array}$ & $\begin{array}{l}\text { ( ) alterado } \\
\text { (presença de } \\
\text { lesão, verrugas) }\end{array}$ & ( ) não realizado & $\begin{array}{l}\text { ( ) não se } \\
\text { aplica }\end{array}$ \\
\hline $\begin{array}{l}\text { Aspecto } \\
\text { Lóquios }\end{array}$ & $\begin{array}{l}\text { () vermelho } \\
\text { (escuro, após } 2 \\
\text { dias) }\end{array}$ & $\begin{array}{l}\text { ( ) amarelado } \\
\text { (após } 10 \text { dias do } \\
\text { parto) }\end{array}$ & $\begin{array}{l}\text { ( )branco ou seroso } \\
\text { (após } 160 \text { dia pós } \\
\text { parto) }\end{array}$ & $\begin{array}{l}\text { ( ) } \\
\text { purulento ( } \\
\text { patológico) }\end{array}$ \\
\hline $\begin{array}{l}\text { Outros } \\
\text { achados: }\end{array}$ & & & & \\
\hline
\end{tabular}




\section{Instrutivo para Preenchimento do Roteiro para Consulta do enfermeiro no} puerpério pós-parto cesáreo

2.4 Exame físico: geral e específico

$\checkmark$ Mamas: avaliar mamas e mamilos, observando sinais de alerta.

$\checkmark$ Anotar alterações no campo indicado ou normais, em caso de não alteração

$\checkmark$ Abdome: realizar palpação abdominal e anotar se normal, distendido.

$\checkmark$ Sítio cirúrgico: avaliar sítio cirúrgico e anotar alterações ou normal.

$\checkmark$ Verificar presença de secreção em sítio cirúrgico e anotar em caso afirmativo em sim, caso não haja em não.

$\checkmark$ Em caso de presença de secreção em sítio cirúrgico, verificar e anotar aspecto no local indicado.

$\checkmark$ Exame ginecológico: realizar exame especular se necessário. Em caso necessário observar aspecto do colo, presença de secreção anormal ou lesões, verrugas anotar em local indicado.

$\checkmark$ Nos casos de não necessidade de realização do exame especular, anotar como não se aplica. E em não realizado se necessário, porém sem condições de realizar o exame como por exemplo consulta domiciliar.

$\checkmark$ Aspecto dos lóquios: verificar aspecto conforme classificação e anotar no local apropriado.

$\checkmark$ Anotar em outros achados, caso demais queixas ou achados não listados acima. 
Instrutivo para Preenchimento do Roteiro para Consulta do enfermeiro no puerpério pós-parto cesáreo

Parte 3. Diagnóstico CIPESC ${ }^{\circledast}$

$\checkmark$ Realizar os diagnósticos das necessidades da mulher no ciclo puerperal e o planejamento das intervenções.

$\checkmark$ Anotar o/ os diagnósticos levantados na consulta de puerpério em local apropriado, em caso de outros diagnósticos, anotar no campo outros diagnósticos.

\section{DIAGNÓSTICO DE ENFERMAGEM- CIPESC}

\begin{tabular}{|c|c|c|}
\hline Corrimento vaginal & ( )presente & \\
\hline Dor em baixo ventre & ( ) presente & \\
\hline Eliminação urinária & ( ) adequada & ( ) comprometida \\
\hline Higiene corporal & ( ) adequada & ( ) alterada \\
\hline Ingestão alimentar & ( ) adequada & ( ) alterada \\
\hline Ingurgitamento Mamário & ( ) presente & \\
\hline Mastite & ( ) presente & \\
\hline Repouso & ( ) alterado & \\
\hline Trauma na pele & ( ) presente & \\
\hline Vínculo mãe-filho & ( ) preservado & ( ) comprometido \\
\hline Outros Diagnósticos: & & \\
\hline
\end{tabular}




\section{Instrutivo para Preenchimento do Roteiro para Consulta do enfermeiro no puerpério pós-parto cesáreo}

Parte 4. Classificação Internacional da Atenção Básica- CIAP2

Componente obrigatório par digitação da produção no eSUS AB, deverá ser realizada a classificação a partir da consulta de puerpério, anotando nos campos correspondentes. Caso existam outras classificações, anotar no campo outras classificações.

CLASSIFICAÇÃO INTERNACIONAL ATENÇÃO PRIMÁRIA- CIAP 2

\begin{tabular}{l} 
( ) Exame médico/avaliação de saúde / completa \\
( ) W17 HEMORRAGIA PÓS-PARTO (sangramento pós-parto critérios: hemorragia franca \\
no, durante ou até 6 semanas após o parto) \\
( ) W19 SINAIS/SINTOMAS DA MAMA/LACTAÇÃO (galactorreia, ablactação, desmame) \\
\hline ( ) W70 SÉPSIS/INFECÇÃO PUERPERA (critérios: infecção do canal de nascimento ou dos \\
órgãos reprodutores até 6 semanas pós-parto) \\
( IW71 INFECÇÕES QUE COMPLICAM A GRAVIDEZ infecções maternas que complicam a \\
gravidez ou o puerpério) \\
( ) W92 PARTO DE NASCIDO VIVO (parto assistido; parto pélvico; cesariana; distocia; \\
parto induzido; lesões causadas pelo parto; placenta prévia durante o parto) \\
W94 MASTITE PUERPERAL (abcesso na mama; critérios: dor, inflamação da mama nas 6 \\
semanas após o parto ou durante o aleitamento). \\
\hline W95 OUTROS PROBLEMAS DA MAMA DURANTE A GRAVIDEZ/PUERPÉRIO (problemas da \\
mama durante o puerpério, mamilo rachado) \\
Outras Classificações:
\end{tabular}

Parte 5. Prescrição de Enfermagem

Realizar a prescrição de enfermagem com base nos diagnósticos CIPESC ${ }^{\circledR}$ levantados e outros se necessário

PRESCRIÇÃO DE ENFERMAGEM 


\section{Instrutivo para Preenchimento do Roteiro para Consulta do enfermeiro no}

$$
\text { puerpério pós-parto cesáreo }
$$

\section{Parte 6. Encaminhamentos}

$\checkmark$ Anotar encaminhamentos necessários (outros profissionais, grupos, retorno consulta, hospital onde ocorreu o parto...).

$\checkmark$ Em caso de presença de infecção de sítio cirúrgico pós-parto cesáreo, realizar contato com o hospital onde ocorreu o parto, comunicando os dados da mulher com o histórico do diagnóstico da infecção de sítio cirúrgico pós-parto cesáreo. Anotar como encaminhamento esta ação.

\section{ENCAMINHAMENTOS}

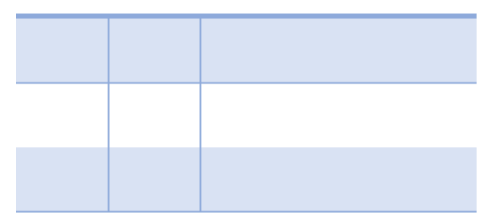

Ao final do atendimento assinar e carimbar a ficha

\section{Assinatura e carimbo do profissional:}

Parte 7. Retirada de pontos

$\checkmark$ Este espaço destina-se ao momento da retira de pontos, não está ligado necessariamente a consulta de puerpério, podendo inclusive anteceder este atendimento.

$\checkmark$ O profissional da enfermagem que irá fazer a retirada de pontos deverá anotar a data da retirada de pontos, constando no dia e mês, dois dígitos e ano, com quatro dígitos.

$\checkmark$ Observar e anotar o aspecto do sítio cirúrgico e encaminhamentos necessários, como por exemplo avaliação do enfermeiro, médico.

$\checkmark$ Em caso de encaminhamento, o profissional que irá realizar a avaliação deverá anotar no espaço de Avaliação para retirada de pontos sua avaliação e conduta.

$\checkmark$ Ao final do atendimento assinar e carimbar a ficha 
Instrutivo para Preenchimento do Roteiro para Consulta do enfermeiro no puerpério pós-parto cesáreo

Data retirada de pontos:

Aspecto sítio cirúrgico:

Encaminhamentos:

Avaliação retirada para retirada de pontos:

Assinatura e carimbo do profissional

Roteiro

\begin{tabular}{|c|c|c|c|}
\hline \multicolumn{4}{|c|}{ CESAREO } \\
\hline Cartão SU S/ CN S & & \multicolumn{2}{|r|}{ Prontuário: } \\
\hline Data: & & \multicolumn{2}{|c|}{ Horário do atendimento: } \\
\hline \multicolumn{4}{|c|}{ HIST ÓRICO DE ENFERMAGEM } \\
\hline \multicolumn{4}{|l|}{ RESUMO DE ALTA } \\
\hline \multicolumn{4}{|l|}{ Data do parto: } \\
\hline \multicolumn{4}{|c|}{ Estabelecimento do parto:_ } \\
\hline \multicolumn{2}{|c|}{ Tempo de trabalho de parto: } & __horas & \\
\hline $\begin{array}{l}\text { Ruptura } \\
\text { prematura de } \\
\text { membranas }\end{array}$ & ( ) $\sin$ & ( ) não & \\
\hline Quanto tempo: & _horas & \multicolumn{2}{|c|}{ () sem informação } \\
\hline $\begin{array}{l}\text { Aspecto liquido } \\
\text { amniótico: }\end{array}$ & ( ) normal & $\begin{array}{l}\text { ( ) presença de } \\
\text { mecônio }\end{array}$ & ( ) sem informação \\
\hline \multicolumn{2}{|c|}{ Tempo de internação: } & _dias & \multirow[b]{2}{*}{ ( ) sem informação } \\
\hline $\begin{array}{l}\text { Cesár ea realizada } \\
\text { de urgência: }\end{array}$ & ( ) $\sin$ & ( ) não & \\
\hline \multicolumn{4}{|c|}{$\begin{array}{l}\text { Motivo re alização cesárea de } \\
\text { urgência: }\end{array}$} \\
\hline RN & ( ) único & () gemelar & \\
\hline \multicolumn{4}{|c|}{$\begin{array}{l}\text { Idade gestacional __semanas } \\
\text { no nascimento: }\end{array}$} \\
\hline Intercorrências: & (1) $\sin$ & ( ) não & \\
\hline \multicolumn{4}{|l|}{ Quais: } \\
\hline \multicolumn{4}{|c|}{ PUERPÉRIO } \\
\hline $\begin{array}{l}\text { Consulta } \\
\text { puerpério }\end{array}$ & () até7 dias & ( ) 8 a 30 dias & ( ) 31 a 42 dias \\
\hline Alimentação & ( ) adequada & ( ) inadequada & \\
\hline $\begin{array}{l}\text { Suplementação } \\
\text { Sulfato Ferroso }\end{array}$ & ( ) sim & ( ) não & \\
\hline Estado emocional & ( ) normal & ( ) depr imido & \\
\hline Higiene & () adequada & ( ) inadequada & \\
\hline \multicolumn{4}{|c|}{ QUEIXAS EACHADOS } \\
\hline Febre: & ( ) $\operatorname{sim}$ & ( ) não & \\
\hline $\begin{array}{l}\text { Dor em baixo } \\
\text { ventre }\end{array}$ & (1) $\operatorname{sim}$ & ( ) não & \\
\hline Dor sítio cirúrgico & ( ) $\sin$ & ( ) não & \\
\hline $\begin{array}{l}\text { Alterações } \\
\text { urinárias (disúria, } \\
\text { polaciúria...) }\end{array}$ & (1) $\sin$ & ( ) não & \\
\hline Leucorréia & ( ) $\operatorname{sim}$ & ( ) não & \\
\hline $\begin{array}{l}\text { Sangramento } \\
\text { vaginal }\end{array}$ & () $\sin$ & ( ) não & \\
\hline
\end{tabular}


Referências

Albuquerque LM, Cubas MR. Cipescando em Curitiba: Construção e implementação da nomenclatura de diagnósticos e intervenções de enfermagem na Rede básica de Saúde. Curitiba: ABEn; 2005.

BRASIL. Ministério da Saúde. Atenção ao pré-natal de baixo risco. Brasília: Ministério da Saúde, 2012. (Cadernos de Atenção Básica, 32).

Comitê Internacional de Classificação da Organização Mundial de Associações Nacionais, Academias e Associações Acadêmicas de Clínicos Gerais/Médicos de Família (WONCA). Classificação Internacional da Atenção Primária. Florianópolis: SBMFC; 2009.

Cubas MR. Instrumentos de Inovação tecnológica e política no trabalho em saúde e em enfermagem- a experiência da CIPE ${ }^{\circledR}$ CIPESC $^{\circledR}$. Rev. Bras. Enferm [Internet]. 2009 [citado 2016 jan 03]; 62 (5): 745-7. Disponível em:

http://www.scielo.br/scielo.php?pid=So034-71672009000500016\&script=sci arttext. 
ANEXOS 



\section{ANEXOS}

ANEXO 1 - PARECER CONSUBSTANCIADO DO CEP ESCOLA DE ENFERMAGEM DA UNIVERSIDADE DE SÃO PAULO

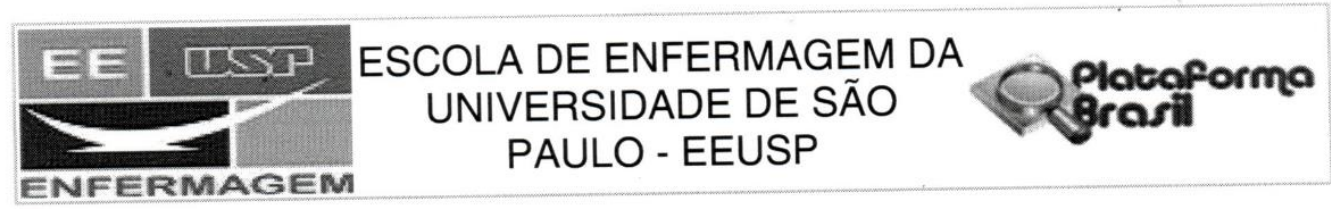

PARECER CONSUBSTANCIADO DO CEP

\section{DADOS DO PROJETO DE PESQUISA}

Título da Pesquisa: Vulnerabilidades das mulheres às infecções de sítio cirúrgico pós parto cesárea: subsídios de um roteiro às consultas de enfermeiros da Atenção Básica

Pesquisador: Marcia Regina Cunha

Área Temática:

Versão: 1

CAAE: 39140214.8 .0000 .5392

Instituição Proponente: Escola de Enfermagem da USP

Patrocinador Principal: Financiamento Próprio

\section{DADOS DO PARECER}

Número do Parecer: 912.494

Data da Relatoria: 08/12/2014

Apresentação do Projeto:

Trata-se de projeto de pesquisa que toma como objeto de estudo a vulnerabilidade à infecção de sítio cirúrgico pós-cesárea de mulheres, acompanhadas no puerpério pela Atenção Básica. Os pesquisadores abordam a magnitude da infecção de sítio cirúrgico pós-cesárea e as principais diretrizes que norteiam seu controle.

O presente estudo tem como finalidade contribuir para a melhoria da atenção à mulher, no período do puerpério. Os dados a serem obtidos poderão qualificar as práticas do enfermeiro oferecendo subsídios para propor instrumentos de notificação de infecção de sítio cirúrgico pós-cesárea.

Trata-se de pesquisa exploratória, descritivo, longitudinal, retrospectiva, por meio de revisão de prontuários do programa Mãe Paulistana de puérperas moradoras na área de abrangência das Unidades Básicas de Saúde pertencentes à Supervisão Técnica de Saúde Butantã e que tiveram parto cesárea, realizado no período de 01 de janeiro a 31 de dezembro de 2014.0 tamanho da amostra é de 67 casos.

Serão acessados dados secundários a partir do prontuário geral e prontuário Mãe Paulistana das puérperas. Serão investigados dados do perfil sócio demográfico, histórico da gestação atual e anterior, peso, altura, IMC e pressão arterial, avaliação de riscos, antecedentes, queixas, exame

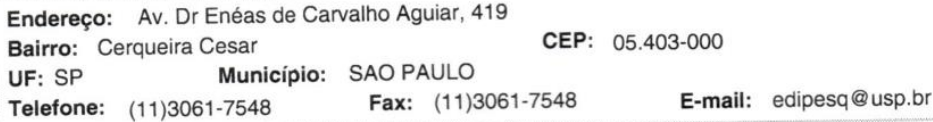




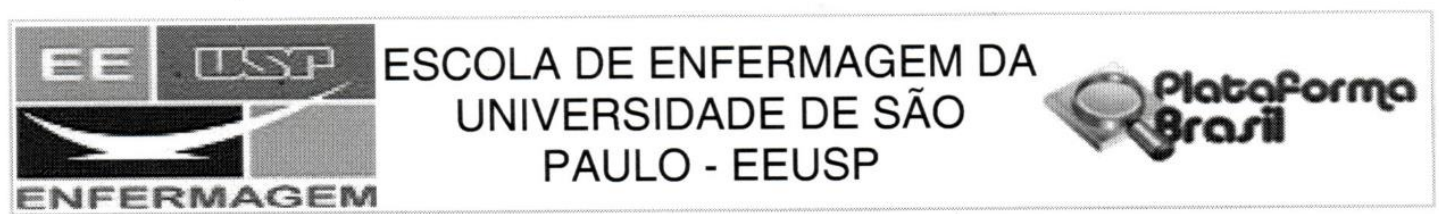

Continuação do Parecer: 912.494

físico, acompanhamento da gestação, exames, gráfico de altura uterina e idade gestacional, situação vacinal, encaminhamentos, deslocamentos, consulta de puerpério com dados do parto, do recém-nascido e da puérpera, além de dados que se façam necessários no prontuário. Os critérios de inclusão são: puérperas que tiveram parto cesárea no período proposto, que passaram por atendimento na unidade básica de saúde em até 30 dias após o parto. Critérios de exclusão: puérperas que tiveram parto normal, ou puérperas que não tiveram atendimento após o parto em até 30 dias.

\section{Objetivo da Pesquisa:}

Objetivo Primário:

Propor um roteiro que auxilie o Enfermeiro da Atenção Básica a identificar, nas mulheres submetidas ao parto cesárea, infecção de sítio cirúrgico pós-cesárea, tipo superficial, profundo e infecção de órgãos ou espaço, na consulta à puérpera.

Objetivo Secundário:

1. Descrever o perfil das mulheres em relação às suas condições de vida, perfil sócio demográfico e de saúde durante a gestação, parto e puerpério;2. Caracterizar a vulnerabilidade à infecção de sítio cirúrgico de mulheres submetidas ao parto cesárea.

\section{Avaliação dos Riscos e Benefícios:}

Riscos:

Os riscos referem-se aos aspectos da confidencialidade na consulta dos dados das participantes.

Benefícios:

Identificação das infecções de sítio cirúrgico em mulheres que realizaram parto cesárea de maneira precoce, contribuindo para a diminuição da morbidade e mortalidade materna.Melhoria da qualidade na assistência ao puerpério.

\section{Comentários e Considerações sobre a Pesquisa:}

Pesquisa bem apresentada, com referencial teórico suficiente e pertinente para justificar o desenvolvimento da pesquisa. O estudo trará contribuições para o conhecimento científico da área.

\section{Considerações sobre os Termos de apresentação obrigatória:}

O termo de responsabilidade com os dados da pesquisa foi apresentado e não apresenta pendências éticas. Os pesquisadores solicitam a dispensa da aplicação do termo de consentimento livre e esclarecido e apresentam justificativa pertinente.

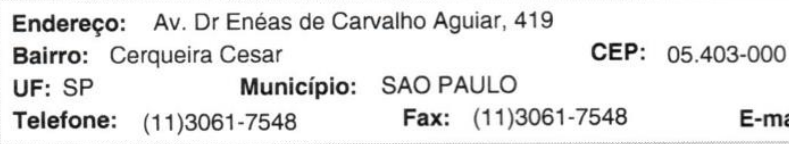




\section{EE USP ESCOLA DE ENFERMAGEM DA ENFERMAGEM UNIVERSIDADE DE SÃO Q Pratofil}

Continuação do Parecer: 912.494

\section{Recomendações:}

Não há.

\section{Conclusões ou Pendências e Lista de Inadequações:}

Pela aprovação do protocolo. Lembrando que: no termo de responsabilidade é preciso constar que o pesquisador se empenhará em localizar os participantes para pedir autorização para ver o prontuário. Este pode ser um motivo de recusa da instituição co-participante.

\section{Situação do Parecer:}

Aprovado

\section{Necessita Apreciação da CONEP:}

Não

Considerações Finais a critério do CEP:

A aprovação do Comitê de Ética em Pesquisa da EEUSP não substitui a autorização da instituição coparticipante para o início da pesquisa.

O CEP EEUSP informa que há necessidade de registro dos relatórios: parcial e final da pesquisa, na Plataforma Brasil.

SAO PAULO, 12 de Dezembro de 2014

\section{Assinado por:}

Ruth Natalia Teresa Turrini

(Coordenador)

Endereço: Av. Dr Enéas de Carvalho Aguiar, 419

Bairro: Cerqueira Cesar

CEP: $\quad 05.403-000$

UF: SP Município: SAO PAULO

Telefone: (11)3061-7548 


\section{ANEXO 2- PARECER CONSUBSTANCIADO DO CEP COMITÊ DE ÉTICA EM PESQUISA SMS- SÃO PAULO}

EM PESQUISA-SMS
SAÚDE DE SÃO PAULO -
SMS/SP

\section{PARECER CONSUBSTANCIADO DO CEP}

Elaborado pela Instituição Coparticipante

\section{DADOS DO PROJETO DE PESQUISA}

Título da Pesquisa: Vulnerabilidades das mulheres às infecções de sítio cirúrgico pós parto cesárea: subsídios de um roteiro às consultas de enfermeiros da Atenção Básica

Pesquisador: Marcia Regina Cunha

Área Temática:

Versão: 1

CAAE: 39140214.8 .3001 .0086

Instituição Proponente: Escola de Enfermagem da USP

Patrocinador Principal: Financiamento Próprio

\section{DADOS DO PARECER}

Número do Parecer: 937.056

Data da Relatoria: 04/02/2015

\section{Apresentação do Projeto:}

Trata-se de pesquisa exploratória, descritivo, longitudinal retrospectivo de casos

por meio de revisão de prontuário e prontuário Mãe Paulistana de puérperas moradoras na área de abrangência das Unidades Básicas de Saúde pertencentes à Supervisão Técnica de Saúde Butantã e que tiveram parto cesárea, realizado no período de 01 de janeiro a 31 de dezembro de 2014.

Serão acessados dados secundários a partir do prontuário geral e prontuário Mãe Paulistana das puérperas que contam com os dados da UBS de referência da usuária, número do SISPRENATAL, perfil sócio demográfico, histórico da gestação atual e anterior, peso,altura, IMC e pressão arterial, avaliação de riscos gravídicos potenciais, antecedentes familiares e pessoais, queixas, exame físico, prontuário de acompanhamento da gestação (consultas), exames solicitados e resultados, gráfico de altura uterina e idade gestacional, quadro de risco gestacional, gráfico de acompanhamento nutricional da gestante, situação vacinal,encaminhamentos, deslocamentos (Sptrans), consulta de puerpério com dados do parto, do recémnascido e da puérpera, além de dados que se façam necessários no prontuário. Os dados referentes a condições de moradia e cobertura por plano de saúde serão levantados através da ficha $\mathrm{A}$ do prontuário familiar das puérperas. A análise de cada prontuário será realizada utilizando-se um instrumento na forma de formulário para coleta dos dados e posterior tabulação. Será realizado um teste piloto para

Endereço: Rua General Jardim, $36-1^{\circ}$ andar Bairro: CENTRO

UF: SP Município: SAO PAULO

Telefone: (11)3397-2464

CEP: $01.223-010$

E-mail: smscep@gmail.com 


\section{*- OComité de SECRETARIA MUNICIPAL DA \\ SAÚDE DE SÃO PAULO - SMS/SP

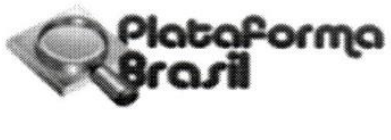

Continuação do Parecer: 937.056

verificação da viabilidade do instrumento e posterior reformulação.

Critérios de inclusão na amostra: puérperas que tiveram parto cesárea no período de 01 de janeiro a 31 de dezembro de 2014 , de qualquer idade, que passaram por atendimento na unidade básica de saúde em até 30 dias após o parto.

Critérios de exclusão: puérperas que tiveram parto normal, ou puérperas que não tiveram atendimento após o parto em até 30 dias. Os dados serão analisados a partir da realização de uma estatística descritiva coma a utilização de médias, medianas, desvio padrão,com intervalo de confiança de 90\%.

Os resultados têm como finalidade qualificar as práticas do enfermeiro ao mesmo tempo em visa oferecer subsídios à futuramente elaborar uma notificação de contra referência de infecção de sítio cirúrgico póscesárea para o hospital aonde ocorreu o parto da puérpera com infecção de sítio cirúrgico pós-parto cesárea diagnosticado na Atenção básica.

\section{Objetivo da Pesquisa:}

Objetivo geral

Propor um roteiro que auxilie o Enfermeiro da Atenção Básica a identificar, nas mulheres submetidas ao parto cesárea, infecção de sítio cirúrgico pós-cesárea, tipo superficial, profundo e infecção de órgãos ou espaço, na consulta à puérpera.

Objetivos específicos

1. Descrever o perfil das mulheres em relação às suas condições de vida, perfil sócio demográfico e de saúde durante a gestação, parto e puerpério;

2. Caracterizar a vulnerabilidade à infecção de sítio cirúrgico de mulheres submetidas ao parto cesárea.

\section{Avaliação dos Riscos e Benefícios:}

Riscos: por se tratar de pesquisa em fonte secundária, os riscos estão relacionados ao cuidado e manutenção do anonimato ao manusear os prontuários. Foi esclarecido pela pesquisadora a respeito do cuidado em se manusear os prontuários.

Benefícios: Identificação das infecções de sítio cirúrgico em mulheres que realizaram parto cesárea de maneira precoce, contribuindo para a diminuição da morbidade e mortalidade materna. Melhoria da qualidade na assistência ao puerpério.

\section{Comentários e Considerações sobre a Pesquisa:}

A pesquisa tem valor relevante para a área de Saúde Coletiva, a metodologia está bem descrita e

Endereço: Rua General Jardim, $36-1^{\circ}$ andar
Bairro: CENTRO
$\begin{aligned} & \text { UF: SP } \\ & \text { Telefone: } \quad \text { (11)3397-2464ípio: SAO PAULO }\end{aligned}$
CEP: $01.223-010$

E-mail: smscep@gmail.com 


\begin{tabular}{|c|c|}
\hline$\sum_{\text {SMS }}$ & $\begin{array}{c}\text { SECRETARIA MUNICIPAL DA } \\
\text { SAÚDE DE SÃO PAULO - } \\
\text { SMS/SP }\end{array}$ \\
\hline
\end{tabular}

Continuação do Parecer: 937.056

deverá atingir os objetivos propostos, fornecendo resultados para ações futuras na área prática.

Considerações sobre os Termos de apresentação obrigatória:

Folha de rosto corretamente preenchida e assinada, a autorização do gestor da Coordenadoria Centro Oeste foi apresentada, o currículo da pesquisadora está cadastrado na Plataforma Lattes e é condizente com a área da pesquisa.Foi apresentado TCLE

Cronograma está adequado e o orçamento é de responsabilidade do pesquisador.

\section{Conclusões ou Pendências e Lista de Inadequações:}

Sem pendências ou inadequações.

\section{Situação do Parecer:}

Aprovado

\section{Necessita Apreciação da CONEP:}

Não

\section{Considerações Finais a critério do CEP:}

Para início da coleta dos dados, o pesquisador deverá se apresentar na mesma instância que autorizou a realização do estudo (Coordenadoria, Supervisão, SMS/Gab, etc).

Se o projeto prever aplicação de TCLE, todas as páginas do documento deverão ser rubricadas pelo pesquisador e pelo voluntário e a última página assinada por ambos, conforme Carta Circular no 003/2011 da CONEP/CNS.

Salientamos que o pesquisador deve desenvolver a pesquisa conforme delineada no protocolo aprovado. Eventuais modificações ou emendas ao protocolo devem ser apresentadas ao CEP de forma clara e sucinta, identificando a parte do protocolo a ser modificada e suas justificativas. Lembramos que esta modificação necessitará de aprovação ética do CEP antes de ser implementada.

De acordo com a Res. CNS 466/12, o pesquisador deve apresentar a este CEP/SMS os relatórios semestrais. O relatório final deverá ser enviado através da Plataforma Brasil, ícone Notificação. Uma cópia digital (CD/DVD) do projeto finalizado deverá ser enviada à instância que autorizou a realização do estudo, via correio ou entregue pessoalmente, logo que o mesmo estiver concluído.

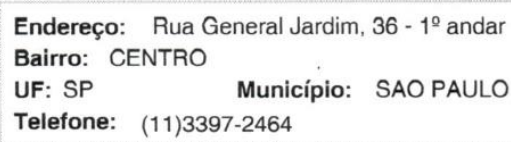




\begin{tabular}{|c|c|}
\hline Q & $\begin{array}{c}\text { SECRETARIA MUNICIPAL DA } \\
\text { SAÚDE DE SÃO PAULO - } \\
\text { SMS/SP }\end{array}$ \\
\hline
\end{tabular}

Continuação do Parecer: 937.056

SAO PAULO, 11 de Fevereiro de 2015

Assinado por:

SIMONE MONGELLI DE FANTINI

(Coordenador) 